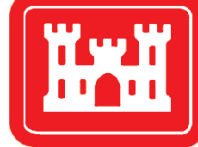

US Army Corps of Engineers ${ }_{\circledast}$ Engineer Research and Development Center

\title{
Joint Rapid Airfield Construction (JRAC) Program 2004 Demonstration Project-- Fort Bragg, North Carolina
}

Gary L. Anderton, Ernest S. Berney IV, John K. Newman,

Travis A. Mann, Chad Gartrell, and Daniel K. Miller
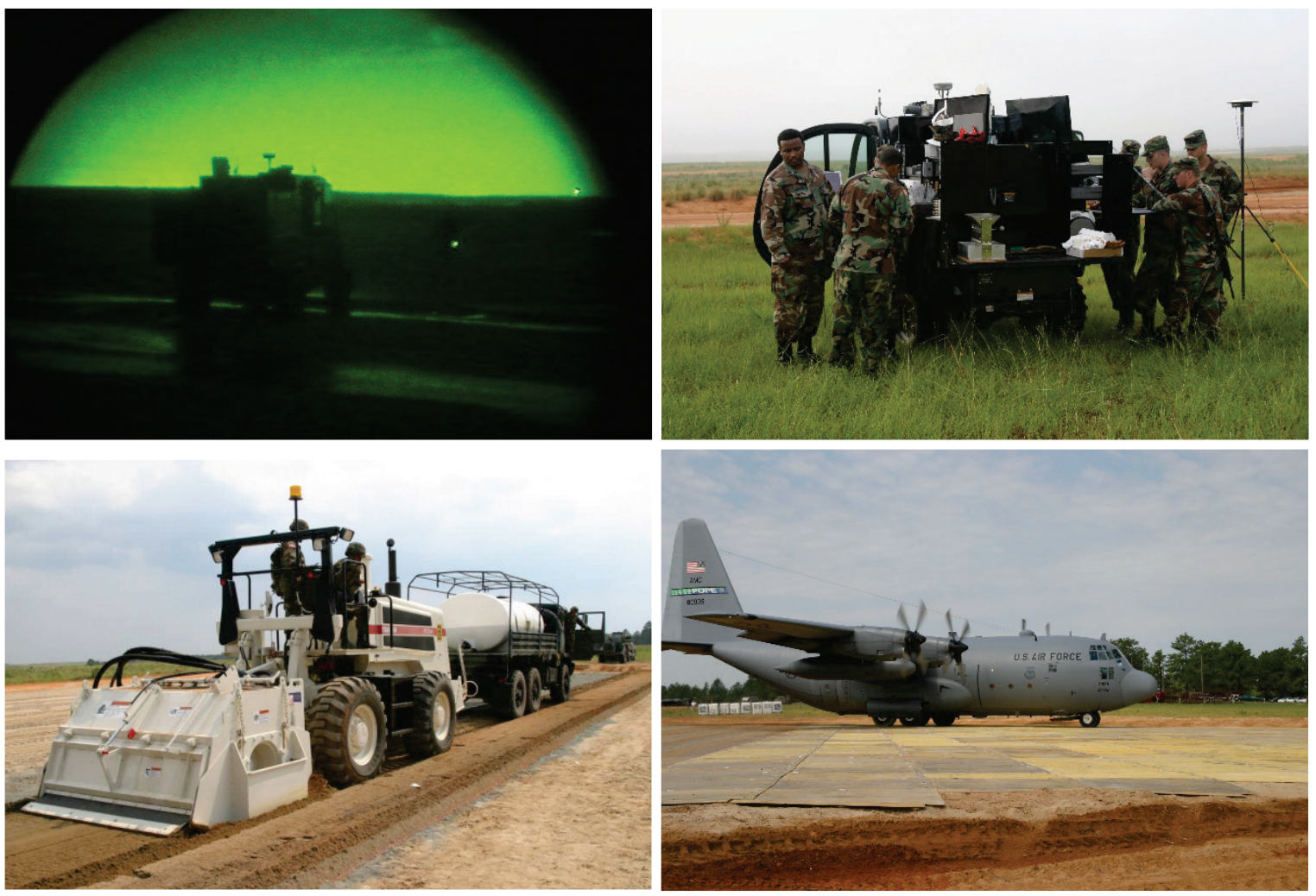
The U.S. Army Engineer Research and Development Center (ERDC) solves the nation's toughest engineering and environmental challenges. ERDC develops innovative solutions in civil and military engineering, geospatial sciences, water resources, and environmental sciences for the Army, the Department of Defense, civilian agencies, and our nation's public good. Find out more at www.erdc.usace.army.mil.

To search for other technical reports published by ERDC, visit the ERDC online library at https://erdclibrary.on.worldcat.org/discovery. 


\section{Joint Rapid Airfield Construction (JRAC) Program 2004 Demonstration Project-- Fort Bragg, North Carolina}

Gary L. Anderton, Ernest S. Berney IV, John K. Newman, Travis A. Mann, Chad Gartrell, and Daniel K. Miller

Geotechnical and Structures Laboratory

U.S. Army Engineer Research and Development Center

3909 Halls Ferry Road

Vicksburg, MS 39180

Final report

Approved for public release; distribution is unlimited.

Prepared for U.S. Army Corps of Engineers

Washington, DC 20314-1000

Under Project \#117101, “Joint Rapid Airfield Construction” 


\section{Abstract}

This report describes the demonstration of technologies and procedures developed during April 2002 and May 2004 under the Joint Rapid Airfield Construction (JRAC) Program. The demonstration took place at Sicily Landing Zone (LZ) at Fort Bragg, NC, in July of 2004. The objective of the exercise was to demonstrate the procedures and technologies developed under the JRAC Program by rapidly building two parking aprons capable of supporting $\mathrm{C}-130$ transport aircraft taxiing and parking operations. The exercise was conducted under continuous 24 -hr operations to simulate a real-world rapid construction environment. Apron 1 (north apron) was constructed using two technologies, one-half being $\mathrm{ACE}^{\mathrm{TM}}$ Matting and the other half being a cement-polymer stabilized soil surface. Apron 2 (south apron) was constructed solely of a fiber-cement-stabilized soil system. Both aprons were treated with a polymer emulsion surface application to form a sealed surface against abrasion and water infiltration. The entire construction of both aprons required $76 \mathrm{hr}$, with Apron 1 finished in $48 \mathrm{hr}$. The construction of Apron 1 was validated by operation of a C-130 aircraft approximately $31 \mathrm{hr}$ after completion with success and high praises from the aircraft flight crew on the stability and surface of the apron, as well as its dust-abating characteristics.

DISCLAIMER: The contents of this report are not to be used for advertising, publication, or promotional purposes. Citation of trade names does not constitute an official endorsement or approval of the use of such commercial products. All product names and trademarks cited are the property of their respective owners. The findings of this report are not to be construed as an official Department of the Army position unless so designated by other authorized documents. 


\section{Contents}

Abstract..................................................................................................................... ii

Figures and Tables...............................................................................................v

Preface ..................................................................................................................................vifi

Executive Summary ......................................................................................................... ix

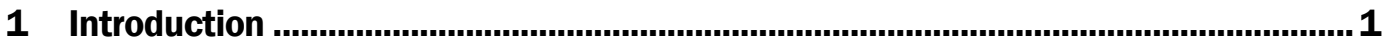

1.1 JRAC background ................................................................................... 1

1.2 Demonstration objective .................................................................. 1

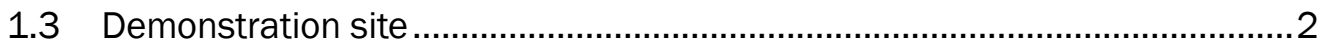

1.4 Personnel .........................................................................................

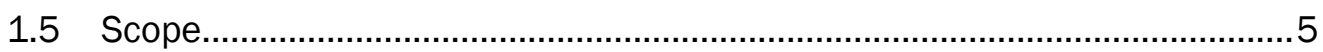

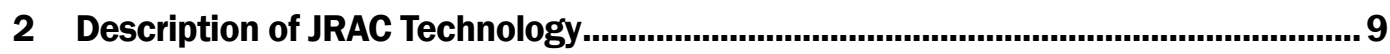

2.1 Site selection and assessment......................................................

2.2 Rapid soils analysis kit ..................................................................... 10

2.3 Enhanced construction technology ....................................................14

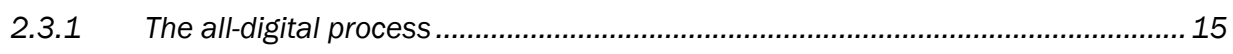

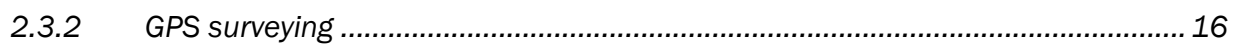

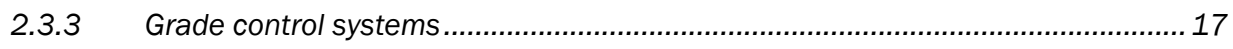

2.3.4 RAVEN (Rapid assessment vehicle-engineer) .................................................. 19

2.4 Soil stabilization technology ......................................................... 22

2.4.1 Methods for rapid soil stabilization .................................................................... 23

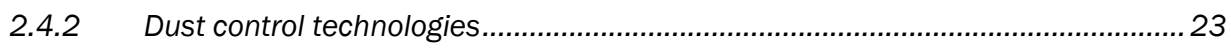

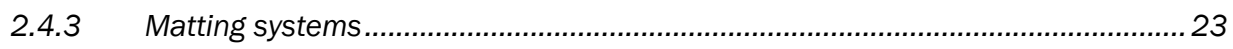

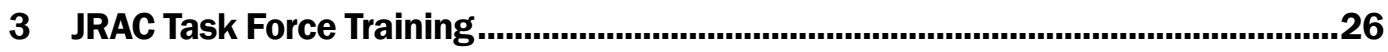

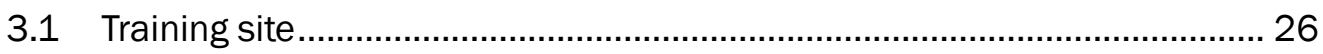

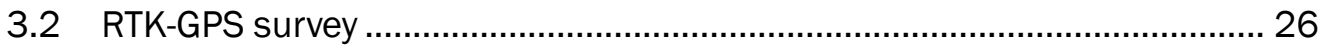

3.3 GPS-instrumented earthmoving system.............................................. 28

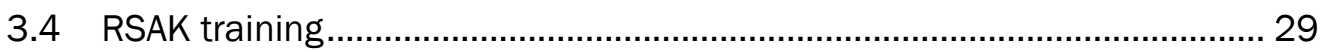

3.5 Rapid design system ....................................................................... 32

3.6 Army Corps of Engineers (ACE) Matting System ..................................... 34

3.7 Soil stabilization............................................................................. 36

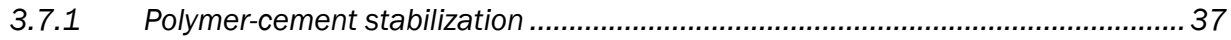

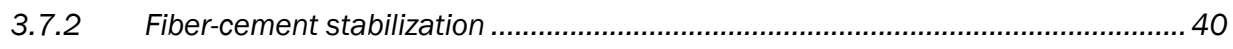

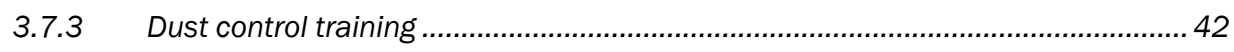

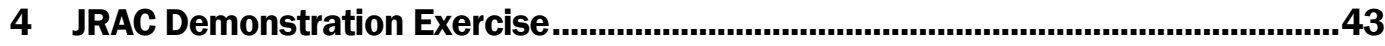

4.1 Overview ........................................................................................ 43

4.2 Demonstration tasks .................................................................. 43

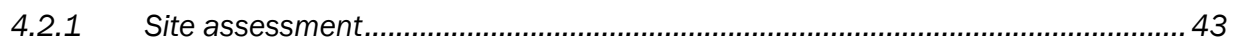


4.2.2 Enhanced construction.................................................................................... 44

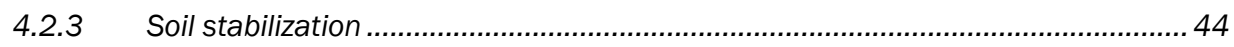

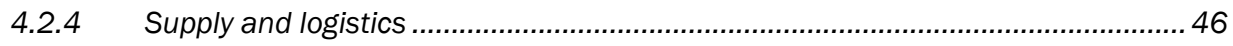

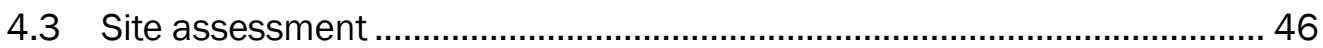

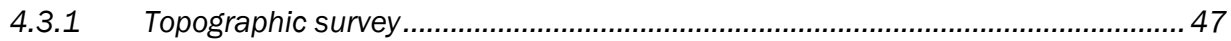

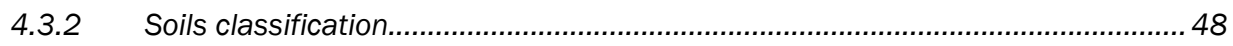

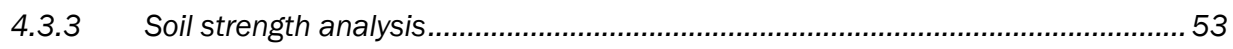

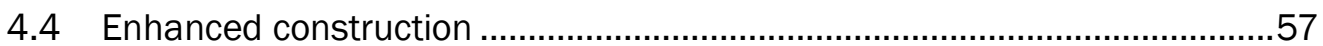

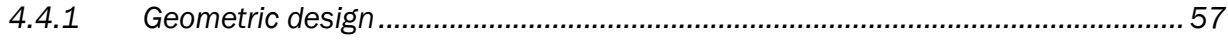

4.4.2 Uploading digital designs and clearing/grubbing .............................................59

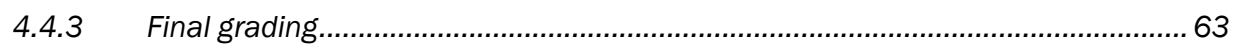

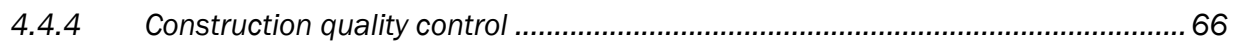

4.5 Rapid stabilization (Apron 1) ...................................................... 69

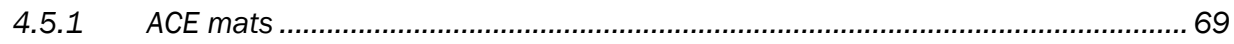

4.5.2 Polymer-cement stabilization ........................................................................ 71

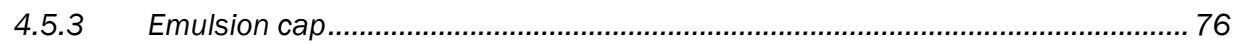

4.6 Rapid stabilization (Apron 2) .......................................................... 78

4.6.1 Fiber-cement stabilization ............................................................................... 78

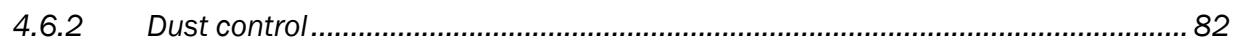

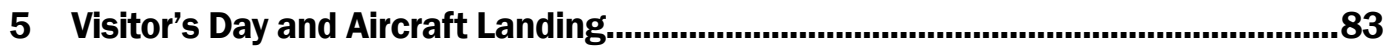

5.1 Visitor's day .................................................................................... 83

5.2 Airfield certification ............................................................................ 84

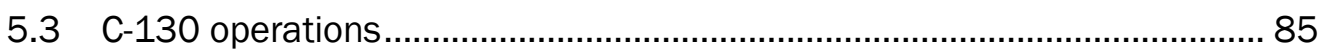

6 Conclusions and Lessons Learned .....................................................................88

6.1 Conclusions ................................................................................... 88

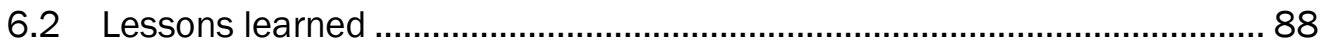

6.2.1 Rapid Assessment Vehicle-Engineer (RAVEN)................................................... 88

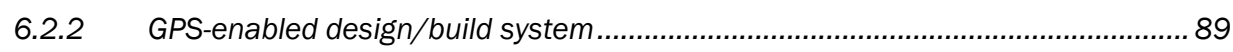

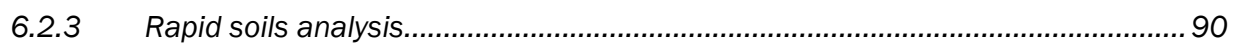

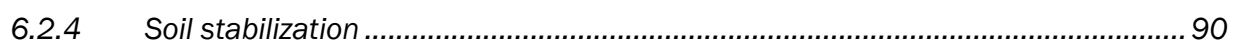

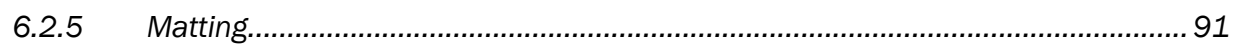

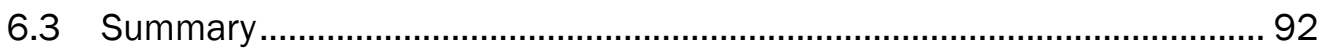

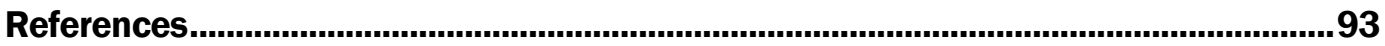

Appendix A: Memorandum of Agreement ............................................................94

Appendix B: Daily Construction Reports.................................................................... 100

Appendix C: Procedure for Performing a Soils Analysis........................................ 117

Appendix D: Equipment Lists .................................................................................. 119

Unit Conversion Factors.............................................................................................. 121

Report Documentation Page 


\section{Figures and Tables}

\section{Figures}

Figure 1. JRAC task force organizational tree.

Figure 2. Aerial photograph of Sicily Assault Landing Zone with JRAC apron

locations.

Figure 3. JRAC trapezoidal parking apron.

Figure 4. JRAC demonstration project geometries and cross sections

Figure 5. Sieve shaker, splitter, balance, plastic limit roller, and laptop for data entry; microwave not pictured

Figure 6. Soil sampling and processing tools included in the toolkit.

Figure 7. RSAK mounted on the JRAC Rapid Assessment Vehicle - Engineer (RAVEN).

Figure 8. Screenshots from the RSAK Classification 1.0 software.

Figure 9. Typical compaction results from the RSAK Classification 1.0 software.

Figure 10. GPS equipment used during the JRAC demonstration.

Figure 11. Trimble ${ }^{\circledR}$ GCS900 System installed on a U.S. Army DEUCE.

Figure 12. Comparison of Bobcat ToolCat commercial version to the RAVEN....................20

Figure 13. RAVEN vehicle with DCP attachment. .................................................................21

Figure 14. All American training site at Fort Bragg............................................................26

Figure 15. Collective troop training on GPS survey equipment at All-American site..........28

Figure 16. Training of soldiers on soils analysis kit at All American site. ............................30

Figure 17. Training results from soils sampled at All-American site...................................30

Figure 18. Training on mat assembly at All-American site. ...............................................35

Figure 19. Screenshot of spreadsheet used to calculate pertinent variables for polymer-cement stabilization training using the Terex 325RS. Input variables are in green, outputs in yellow.

Figure 20. Excel spreadsheet used for fiber-cement soil stabilization calculations for training......

Figure 21. RAVEN deployed at 00:30 to Sicily LZ jobsite. ..................................................44

Figure 22. Digging of soil test pits for sampling using KEM lighting..................................49

Figure 23. Operation of RSAK on samples soils...........................................................50

Figure 24. Standard Proctor moisture-density curve for Apron 1........................................51

Figure 25. Standard Proctor moisture-density curve for Apron 2. .....................................52

Figure 26. Unsoaked CBR design curve for Apron 1.......................................................52

Figure 27. Unsoaked CBR design curve for Apron 2 ......................................................53

Figure 28. DCP tests being conducted on Apron 1 prior to construction..............................55

Figure 29. CBR averages for Apron 1 before construction for top 24 in. .............................56

Figure 30. CBR averages for Apron 2 before construction for top 24 in............................56

Figure 31. CBR averages for Apron $124 \mathrm{hr}$ after stabilization to a depth of $24 \mathrm{in}$..............57 
Figure 32. Analysis of survey data to obtain Terramodel design. .......................................58

Figure 33. Uploading of digital design onto flash memory cards. ...................................59

Figure 34. On board display showing vehicle position and elevation data........................60

Figure 35. Deployment of RTK-GPS-enabled construction equipment to Apron 1.............61

Figure 36. GPS-enabled motorgrader beginning clearing and grubbing operations.

Figure 37. GPS-enabled scraper beginning clearing and grubbing operations.................62

Figure 38. GPS-enabled DEUCE beginning clearing and grubbing operations..................62

Figure 39. Apron 1 before (top) and after (bottom) clearing and grubbing activity. ...........64

Figure 40. Apron 2 before (top) and after (bottom) clearing and grubbing activity...........65

Figure 41. Cut and grading complete on Apron 2 on afternoon of July 13.........................66

Figure 42. Use of manual GPS rover to spot check elevations after RTK grading.............68

Figure 43. Placement of the ACE ${ }^{\mathrm{TM}}$ mats at 0300 on 13 July 2004 .................................70

Figure 44. Completion of matting on Apron 1 on afternoon of July 13...............................70

Figure 45. Screenshot of spreadsheet used to calculate pertinent variables for polymer-cement stabilization using the Terex 325RS. Input variables are in green, outputs in yellow. 72

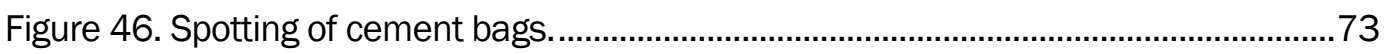

Figure 47. Spreading of cement. 74

Figure 48. Stabilization 'train' showing MTVR with nurse tank attached to the Terex. 75

Figure 49. Military Caterpillar 433 compactors closely following the stabilization train.

Figure 50. Polymer cap placement using HMMWV sprayer................................................77

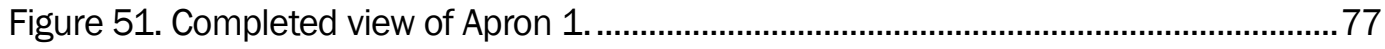

Figure 52. Excel spreadsheet used for Apron 2 soil stabilization calculations. ...................79

Figure 53. Fibers being spread over the surface of the cement.......................................80

Figure 54. Fiber-cement stabilization train. .................................................................. 81

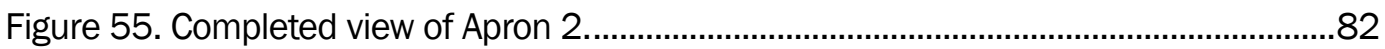

Figure 56. ERDC JRAC team briefings on Sicily LZ site.......................................................83

Figure 57. ACE Mat placement during visitor's day. ...........................................................84

Figure 58. Final check of CBR on Apron 1 using a DCP on the morning of C-130 landing.

Figure 59. C-130 making initial touchdown on Sicily LZ with finished Apron 1 in foreground. 86

Figure 60. C-130 performing a turn on Apron 1 86

Figure 61. ERDC JRAC team and military leads for the construction effort.

\section{Tables}

Table 1. JRAC demonstration construction timeline.

Table 2. Timeline comparison of conventional to JRAC construction technologies. 


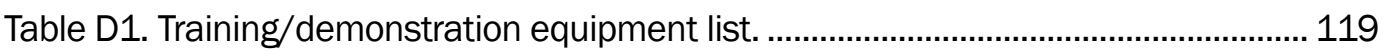

Table D2. Training/demonstration materials list............................................................. 120 


\section{Preface}

This study was conducted for the Office of the Assistant Secretary of the Army for Acquisition, Logistics and Technology under Science and Technology Objective Project \#117101, entitled “Joint Rapid Airfield Construction.” The technical monitor was Dr. David Horner.

The work was performed by the Airfields and Pavements Branch (GMA) of the Engineering Systems and Materials Division (GM), U.S. Army Engineer Research and Development Center, Geotechnical and Structures Laboratory (ERDC-GSL). At the time of publication, Ms. Anna Jordan was Chief, GMA; Mr. Justin S. Strickler was Chief, GM; and Mr. Nicholas Boone, GZT, was the Technical Director for Force Projection. The Deputy Director of ERDC-GSL was Mr. Charles W. Ertle II, and the Director was Mr. Bartley P. Durst.

COL Teresa A. Schlosser was the Commander of ERDC, and Dr. David W. Pittman was the Director. 


\section{Executive Summary}

This report describes the first field demonstration of the Joint Rapid Airfield Construction (JRAC) Program and the technologies used to rapidly construct parking aprons for the $\mathrm{C}-130$ aircraft at austere airfields that lack the necessary ramp/parking space for force projection operations. This demonstration followed $2 \mathrm{yr}$ of research that began in April of 2002, including laboratory tests, field trials, and numerous test sections at the U.S. Army Engineer Research and Development Center (ERDC) in Vicksburg, MS. The demonstration project was built during July 2004, and the lessons learned were used to not only validate the JRAC concept, but to provide direction for the remainder of the research program scheduled to conclude in 2007.

The demonstration was conducted at Sicily Landing Zone (LZ) at Fort Bragg, NC, under continuous 24-hr operations to simulate a real-world environment. The exercise involved employing new JRAC procedures and technologies to construct two parking aprons along the west side of the existing taxiway. The exercise began with the survey of the airfield at night (blackout operations) followed by the design of the aprons and construction the following morning. The construction of the two aprons allowed the demonstration of all JRAC procedures and technologies developed to date and provided the research team with an opportunity to obtain feedback on procedures and technologies used during the demonstration.

Apron 1 (north apron) consisted of two different stabilization technologies. The western half of the apron was constructed with $\mathrm{ACE}^{\mathrm{TM}}$ mats to provide a structurally stable surface for aircraft operations. The eastern half was constructed with a combination of Type III Portland cement and Soil Sement Engineered Formula ${ }^{\circledR}$ polymer emulsion to stabilize the surface to a depth of $152 \mathrm{~mm}$ (6 in.) and was finished with a topical application of Soil Sement Engineered Formula ${ }^{\circledR}$ applied to form a water infiltration barrier. The polymer emulsion provided part of the necessary water for cement hydration, thereby creating a synergy between the two materials. This apron was designed, constructed, and ready for traffic within $48 \mathrm{hr}$ of commencement and received limited C-130 traffic approximately $31 \mathrm{hr}$ after completion without occurrence of damage.

Apron 2 (south apron) was constructed using only one stabilization technology for the entire apron. This system consisted of Type III 
Portland cement and Geofibers $₫$ mixed together with the appropriate amount of water for cement hydration. The surface of Apron 2 was also treated with a topical application of Soil Sement Engineered Formula ${ }^{\circledR}$ polymer emulsion. In this instance, the surface application served two purposes: to provide a water infiltration barrier and to adhere the ends of the Geofibers $\AA$ at the surface of the soil to prevent "pull-out" of the fibers during aircraft taxiing and parking operations. Due to curing time for the surface application and limited availability of aircraft, this apron did not receive any traffic during the demonstration. However, due to popularity of the facility, moderate traffic was expected in the months following the demonstration. At the time of this publication, data regarding the performance of the Apron 2 were not available. 


\section{Introduction}

\subsection{JRAC background}

The U.S. Army Engineer Research and Development Center (ERDC) began a 6-yr comprehensive research, development, and demonstration program in 2002 known as the Joint Rapid Airfield Construction (JRAC) program. The JRAC program was focused on providing engineering tools and systems that dramatically increase the U.S. military's contingency airfield upgrade and construction capabilities. These new capabilities would allow the warfighter to meet Future Force deployment requirements (First Brigade in $96 \mathrm{hr}$, First Division in $120 \mathrm{hr}$, and Five Divisions in 30 days). This would happen through advancements in site selection technologies, enhanced construction methodologies, and new materials and techniques for rapid soil stabilization. All of these technologies, either separately or as part of an integrated system, would focus on reducing the engineering timeline, manpower requirements, and logistical footprint, while increasing system reliability and engineer capabilities.

The JRAC program is focused on providing solutions for the $\mathrm{C}-130$ and $\mathrm{C}-$ 17 aircraft, which are critical for rapid deployment scenarios. JRAC "spinoff" technologies are certain to have a positive impact on other aspects of military engineering including design and assessment, materials analysis, and horizontal construction. Major demonstrations of JRAC technologies were scheduled for fiscal year 2004 and fiscal year 2007. The first demonstration took place at Fort Bragg, NC's Sicily Assault Landing Zone during the summer of 2004 and is described in this report.

\subsection{Demonstration objective}

The objective of the $2004 \mathrm{JRAC}$ demonstration was to validate technologies developed during the first $3 \mathrm{yr}$ of the program's existence and to validate these technologies in a realistic military construction scenario. During these initial years, research and development was conducted at the ERDCVicksburg, MS, campus. Test sections were constructed, tested, and evaluated using simulated $\mathrm{C}-130$ aircraft loads. Testing on $\mathrm{C}-130$ aircraft was selected in the first half of the JRAC program to validate the initial engineering efforts developed due to its lighter loading and simple gear configuration. The JRAC program objectives included developing structural 
pavement solutions for the $\mathrm{C}-13 \mathrm{O}$ first, and then building on those successes to develop solutions for the $\mathrm{C}-17$ by the end of the program. The scheduled demonstration events were developed in parallel with these objectives and included the 2004 demonstration with a focus on the $\mathrm{C}-130$ aircraft and the 2007 demonstration with a focus on the C-17 aircraft.

Another important element of the demonstration was the need to use military construction and engineering troops for the entire site assessment, design, and construction process. The JRAC program is based on the understood need for simple, robust systems and tools that require minimal training for successful use within the military. Conducting full scale demonstrations using military troops and equipment provides critical feedback to the research and development team and was used to further refine technology and operational requirements of the end user.

The most important objective for this demonstration exercise was to achieve the rapid timeline for the entire site assessment, design, and construction process. The JRAC program had a stated goal of expanding the maximum-on-ground (MOG) rating of an existing airfield by one in 48 hr. Expanding by a MOG of one means providing additional parking space for one aircraft clear of the active runway. From an operational standpoint, the single most effective way of increasing the throughput capacity of an existing airfield for rapid military deployments is to increase parking space. Our current capability is measured in weeks, so being able to achieve this very important airfield upgrade in a matter of hours or days would be a revolutionary asset to our military.

\subsection{Demonstration site}

The demonstration objectives pointed to a site that had an active C-130 capable unsurfaced airfield with available military troops that could be trained and observed during a military engineering and construction exercise. One of the best locations for these requirements was at Fort Bragg, which has a number of active, unsurfaced airfields, is home to several engineering and construction battalions within the $18^{\text {th }}$ Airborne Corps, and has access to C-130 aircraft from neighboring Pope Air Force Base for training exercises on their unsurfaced airfields. After several trips to Fort Bragg for airfield site reconnaissance and negotiations with base personnel, JRAC researchers settled on the Sicily Assault Landing Zone (LZ) as the best possible site for the 2004 demonstration. 
Sicily LZ consists of a 1,067 $\mathrm{m}$ (3,500 ft) semi-prepared runway with a parallel taxiway, both surfaced with a compacted sandy-clay material. Although aircraft could park on the taxiway and allow another aircraft to operate on the runway, there was no apron parking space at Sicily LZ. For a rapid deployment scenario, parking aircraft on the parallel taxiway is a limiting means of increasing throughput, as the taxiway is too narrow for passing aircraft or 180-deg turns. There was sufficient lateral clearance to construct one or two single-aircraft parking ramps, and the $18^{\text {th }}$ Airborne Corps agreed that more parking space would only make Sicily LZ a more valuable training asset in the future. A Memorandum of Agreement (MOA) between the $18^{\text {th }}$ Airborne Corps and the ERDC Geotechnical and Structures Laboratory (GSL) was signed in November 2003, designating Sicily LZ as the site for the 2004 JRAC Demonstration. This memorandum is found in Appendix A.

\subsection{Personnel}

Many personnel were involved in the activities and events leading up to and during the demonstration exercise. People contributing to this exercise came from many different groups, including:

1. Engineer Research and Development Center (ERDC),

2. $20^{\text {th }}$ Engineer Brigade (Fort Bragg),

3. $37^{\text {th }}$ Engineer Battalion (Fort Bragg),

4. $618^{\text {th }}$ Engineer Company (Fort Bragg),

5. $412^{\text {th }}$ Engineer Command (Vicksburg), and

6. Local and out-of-state vendors, factory representatives, and technicians including:

Trimble Navigation Limited, Spectra Integrated Systems Inc., Terex Corporation, Bobcat Corporation, Midwest Industrial Supply Inc., GFI Inc., Local and regional cement suppliers, equipment rental companies, and material vendors.

Elements I thru $\mathrm{V}$ above all composed the task force tree that supported the JRAC demonstration as shown in Figure 1. 
Figure 1. JRAC task force organizational tree.

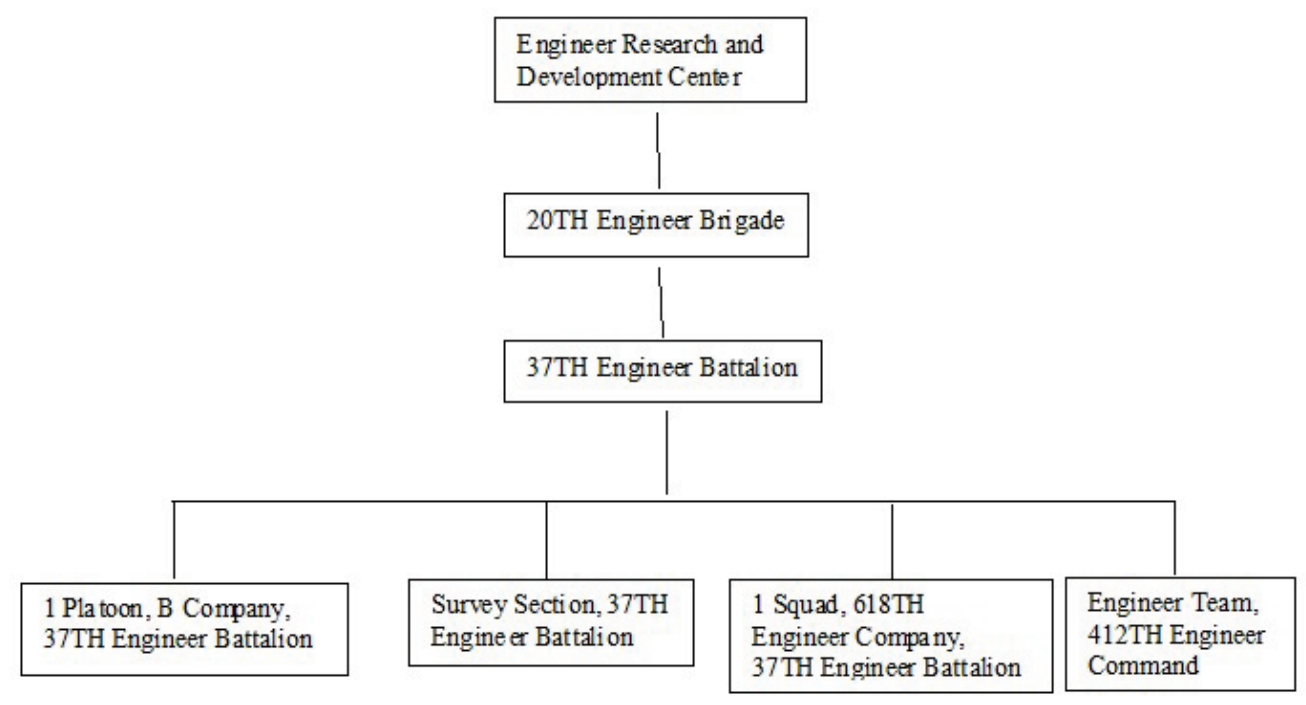

The core planning and execution of the exercise was conducted by the ERDC project managers and pillar leaders, including Dr. Gary Anderton, Dr. Kent Newman, Dr. Ernest Berney, Travis Mann, and Chad Gartrell. In addition, these team members worked very closely with several representatives from the Fort Bragg community. Initially, this included Maj. Daniel Colling and Cpt. Armand Dao of the $2^{\text {th }}$ Engineer Brigade, along with their support staff. When Maj. Colling was transferred, Cpt. Jerrod Melander of the $20^{\text {th }}$ Engineer Brigade was put in charge of the demonstration. A MOA was instituted to enable the military units at Fort Bragg to actively participate in the JRAC demonstration, as documented in Appendix A.

Though multiple tiers of several organizations were present, all provided exceptional communication and coordination in preparation of training and demonstration events. The ERDC team was led by Dr. Gary Anderton, who provided all mission parameters to the $20^{\text {th }}$ Engineer Brigade and had the authority to guide or change the direction of the execution of the demonstration. The $20^{\text {th }}$ Engineer Brigade provided their construction officer as a liaison, which provided coordination at Fort Bragg. The $37^{\text {th }}$ Engineer Battalion provided all battalion-level surveyors and one platoon from one of the line companies to provide the construction equipment and operators. A squad from the $618^{\text {th }}$ Engineer Company helped augment equipment operators. The $412^{\text {th }}$ Engineer Command provided a team that added an engineer and surveyors who were experienced with the GPS surveying equipment and the latest version of TerraModel. The project officer on site was a Major from the $412^{\text {th }}$ Engineer Command, which directed 
the demonstration's troop work effort and maintained coordination with Dr. Anderton and his staff on the progress and any issues encountered.

The $20^{\text {th }}$ Engineer Brigade was very instrumental in making the demonstration exercise a success. Most of the coordination of equipment, soldiers, and locations was implemented by this brigade. Scheduling times to occupy the Sicily LZ, as well as composing and submitting the proper paperwork and stormwater permits, were some of the key jobs accomplished by the brigade.

\subsection{Scope}

The scope of the demonstration project was governed by several factors, i.e., land space available at Sicily LZ, site topography, Fort Bragg's desired end state, and the number of stabilization techniques that needed to be demonstrated. Added to these were the criteria found in Army Field Manual FM 5-430 Vol. 1 and 2 (Department of the Army 1994a, 1994b) with updates from Engineer Technical Letters (ETL) 979, 98-5, and 04-07 (AFCEC 1997, 1998, 2004) providing requirements for apron space, geometry, and clear zones. Taking all of these issues into consideration resulted in the decision to construct two separate parking aprons connected to the existing parallel taxiway. The general location of these parking aprons is shown in Figure 2.

ETL 98-5 provides no specific surface area requirement for C-130 parking aprons, but experience has shown that a minimum $61-\mathrm{m}$ by $61-\mathrm{m}$ apron provides enough space to taxi onto and off, while maintaining the required $15-\mathrm{m}$ wingtip clearance between parked aircraft and taxiing aircraft. Experience has also shown that with minimal geometry, unsurfaced aprons and taxiways, the repeated sharp turns in the same wheel path can lead to early deformation and distresses in the pavement surface. The decision was made to design an alternative surface geometry to help alleviate this problem. A trapezoidal shape with the widest edge connected to the taxiway would provide the aircraft with the opportunity for less-damaging, wide turns onto and off of the parking aprons. The final surface geometry design had the same surface area as the traditional rectangular $61-\mathrm{m}$ by $61-\mathrm{m}$ apron and still provided sufficient space for the $15-\mathrm{m}$ aircraft clearance requirement. The JRAC trapezoidal parking apron surface geometry is shown in Figure 3. 
The JRAC program developed at least three stabilization technologies worthy of full-scale validation in the demonstration project; therefore, the construction of two parking aprons was necessary. Cost and availability of stabilization specific materials were the governing factors in which materials went where, and not their constructability or expected performance. Stabilized soil test sections under simulated C-130 aircraft loads had been previously evaluated at the ERDC-Vicksburg site's Hangar 4 Test Facility. These evaluations led to the selection of three stabilization systems for the JRAC demonstration project, i.e., polymer and Portland cement combination, fiber and Portland cement combination, and fiberglass-reinforced multi-purpose matting, each of which provided sufficient structural support to carry the required C-130 traffic and could be constructed in a compressed timeframe. Each of these stabilization systems will be described in greater detail later in this report. The general design schematics of these stabilization systems are shown in Figure 4.

The final, and perhaps most critical, consideration for the planned scope of the demonstration project was the construction timeline, which would include on-site assessments and designs. As previously mentioned, the JRAC program has a stated goal of expanding the MOG rating at any given site by one within $48 \mathrm{hr}$. After deciding to build two separate aprons, the question became, "How quickly can one military construction platoon construct two aprons at the same site?" A synchronized assessment, design, and construction plan was developed with experiences from ERDC test section work and preliminary troop training exercises at Fort Bragg to help answer this all-important timeline question. From this effort, it was determined that the two aircraft parking aprons could be built in three days with 24-hr operations. To add some realism to this projected timeline, JRAC researchers scheduled a C-130 aircraft to operate on the completed aprons early on the fourth day of the demonstration project. 
Figure 2. Aerial photograph of Sicily Assault Landing Zone with JRAC apron locations.

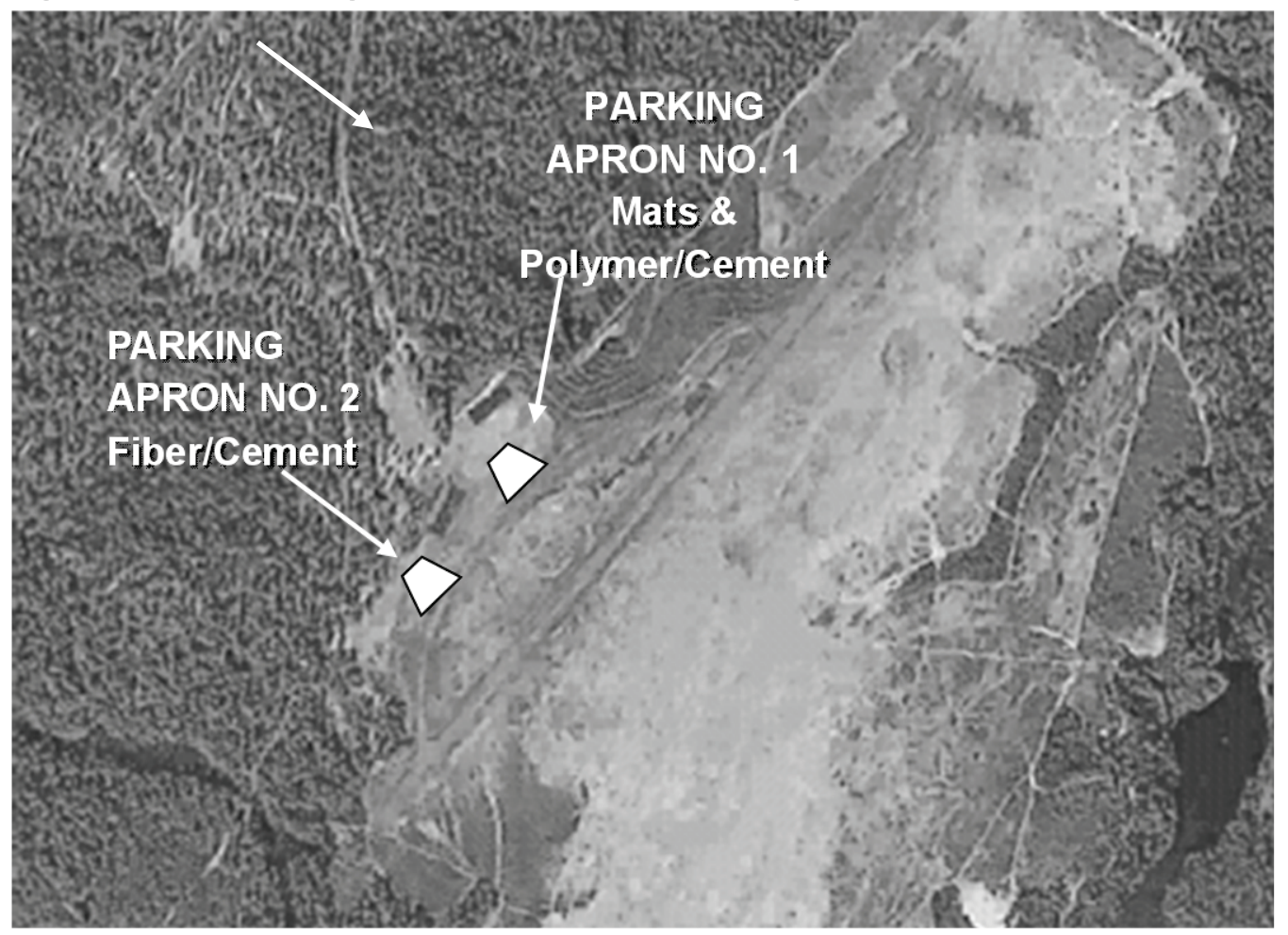

Figure 3. JRAC trapezoidal parking apron.

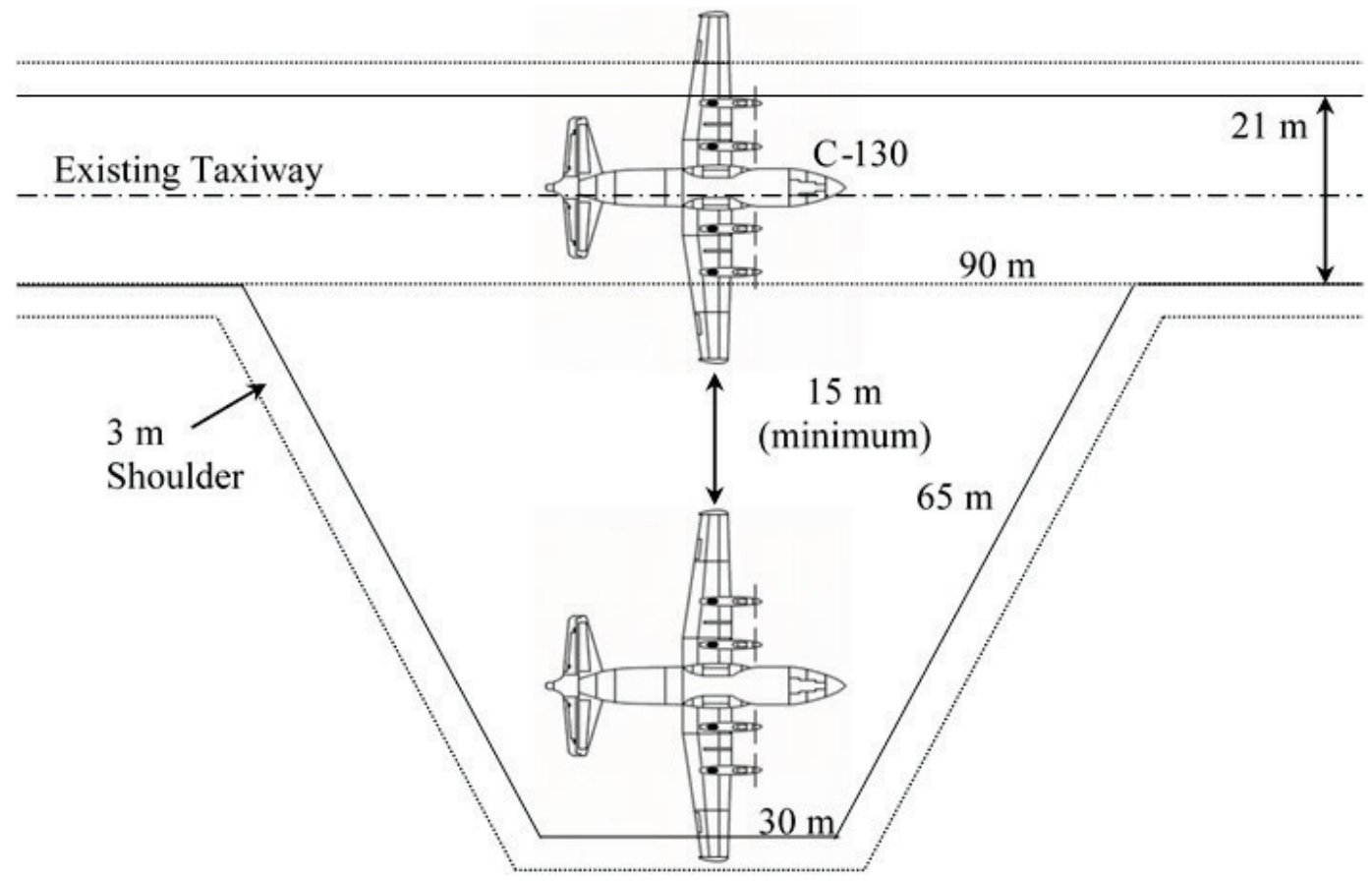


Figure 4. JRAC demonstration project geometries and cross sections.

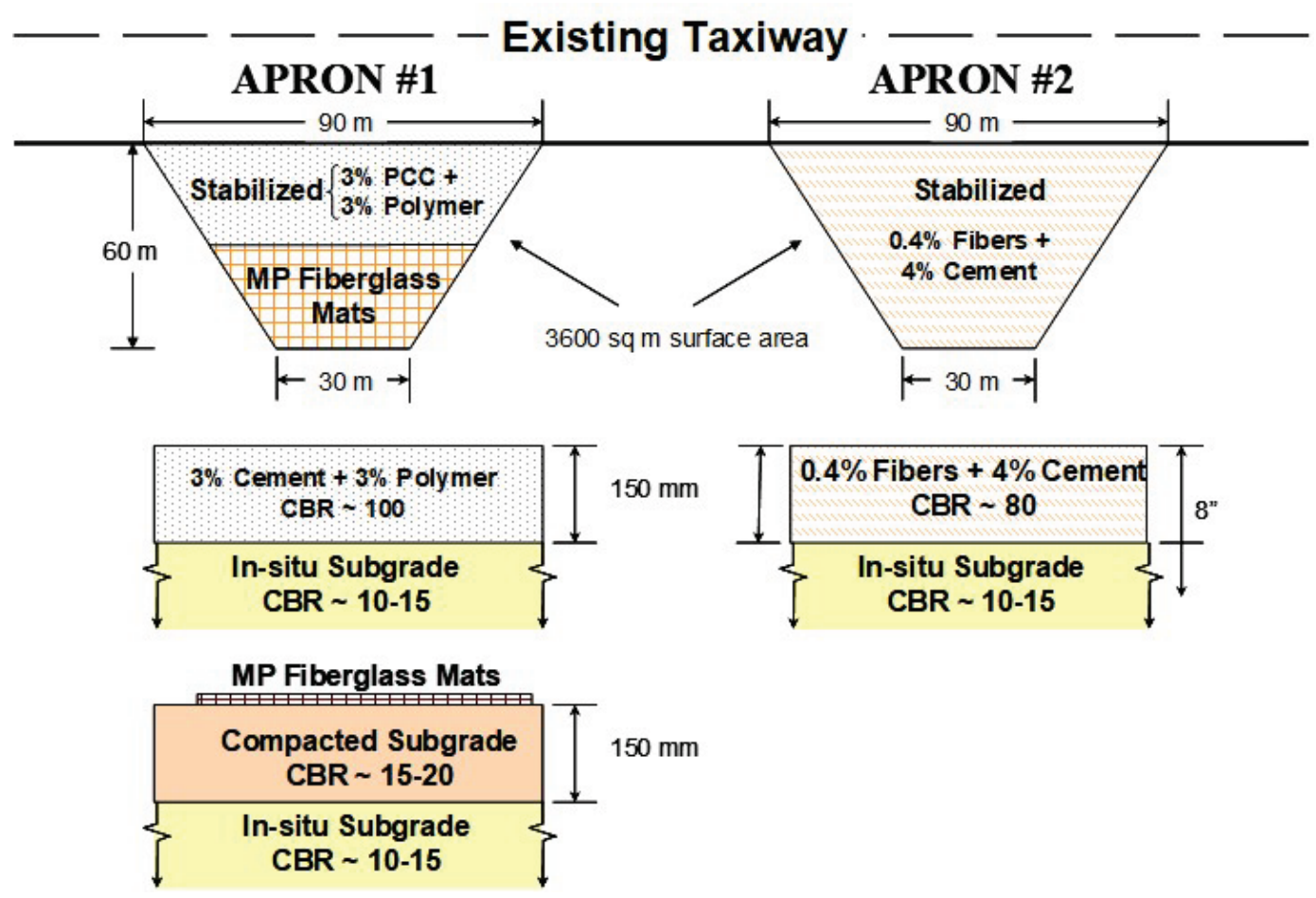




\section{Description of JRAC Technology}

\subsection{Site selection and assessment}

The ability to rapidly deploy military force by air requires comprehensive knowledge of the theater of interest prior to execution of the mission. At the time of the demonstration, the assimilation of data relevant to the battlespace was inefficient and did not meet the timelines established for the JRAC mission scenario. An important part of the JRAC site selection process is labeled the Rapid Airfield Construction-Decision Support System (RAC-DSS). RAC-DSS is a streamlined computer software program used to integrate information from multiple data sources that enables the war-planner to best select the most favorable points of entry into the battlefield. This deployment planning tool was in the process of development and design to collect information relating to geo/topographical, soil type, existing infrastructure and airfields, and suitability of construction materials and terrain. Identification of mission critical data was quickly performed, and a listing of optimal airfield sites was generated for future field reconnaissance validation.

Specific tools that determine construction criteria for local soil materials provide engineering decision support in addition to topographic optimization. Currently, war-planners look solely at existing terrain and soil type to establish desired landing sites. However, knowledge of the engineering effort required for earthmoving and construction with local materials can negate potential landing sites based on available equipment and resources. Two essential tools were developed to advance technology in this area. The first was the RACDSS tool that provided three key capabilities:

1. Quickly down-select potential airfield sites populated with information obtained from geospatial databases including azimuth and length,

2. Rapidly estimate earthmoving volumes for known airfield cross sections based on available imagery, and

3. Compute the construction timeline for variable sets of earthmoving machinery.

The second was a predictive tool for determining the construction requirements for a given soil known as the Rapid Soils Analysis Kit (RSAK). The RSAK was successfully demonstrated in the 2004 JRAC 
Demonstration and then was actively deployed with several engineering units for Operation Enduring Freedom. These tools provide the warplanner with a far greater capability of defining the most feasible points of entry. The RAC-DSS was in the concept stage and not ready for operation during the 2004 demonstration.

\subsection{Rapid soils analysis kit}

An accurate and expedient means to determine the soil classification is essential to establish design criteria for rapid airfield construction using the in-situ soil. Under a contingency design and construction scenario, only a few hours may be available to accumulate necessary ground truth data. Until this demonstration, only subjective field analysis techniques satisfied this requirement, and the results failed to provide tangible numerical data that could be used to establish the necessary construction criteria for an airfield. To address this need, a small-scale field laboratory following a stepwise procedure was developed for the JRAC program.

The field kit consists of laboratory quality testing instruments that include a 700-watt microwave oven electric balance, sieve shaker, sieves, plastic limit (PL) tool (Figure 5), and necessary bowls, spatulas, and scoops to handle the material (Figure 6). These instruments provide a measure of soil moisture, grain size distribution (GSD), and PL (Figure 7). Numerical data generated from these soils tests are input real-time into a software program that calculates a soil classification using linear regression to convert PL into plasticity index, PI (Figure 8). Using the soil classification, PI and GSD, the software program uses linear regression routines based on an extensive database of soil properties to estimate optimum moisture content (OMC) and maximum dry density (MDD) (Figure 9). Built-in higher order regression equations allow the user to visualize complete curves for proctor density, as-built California Bearing Ratio (CBR), and soaked CBR for the constructed condition of the soil of interest. The proctor curve and potential CBR strength data are necessary to establish design criteria for rapid airfield construction.

Moisture contents taken from in-situ soil samples establish baseline moisture requirements. Dynamic Cone Penetrometer (DCP) data points taken at random locations within the area of interest provide baseline CBR strength data. Initial CBR strength data can determine the feasibility of landing on the site of interest, whether conditions need modification or are satisfactory as is. If improvement is necessary at the 
site, knowledge of the in-situ soil condition and conducting the rapid soil classification allows the soldier to estimate the potential CBR increase from soil compaction. The complete proctor curve tells the soldier the water and mechanical effort requirements to bring the in-situ soil to a satisfactory CBR strength condition and the compaction tolerance allowed during construction. The current metric to collect and analyze in-situ soil to obtain this construction information takes days to weeks as per Army Field Manual FM 5-410 (Department of the Army 1992); whereas, within the first few hours of arriving at a site, the ERDC Rapid Soil Analysis Kit (RSAK) provides sufficient construction information to the planners for a Go-No-Go decision regarding asset deployment.

Figure 5. Sieve shaker, splitter, balance, plastic limit roller, and laptop for data entry; microwave not pictured.

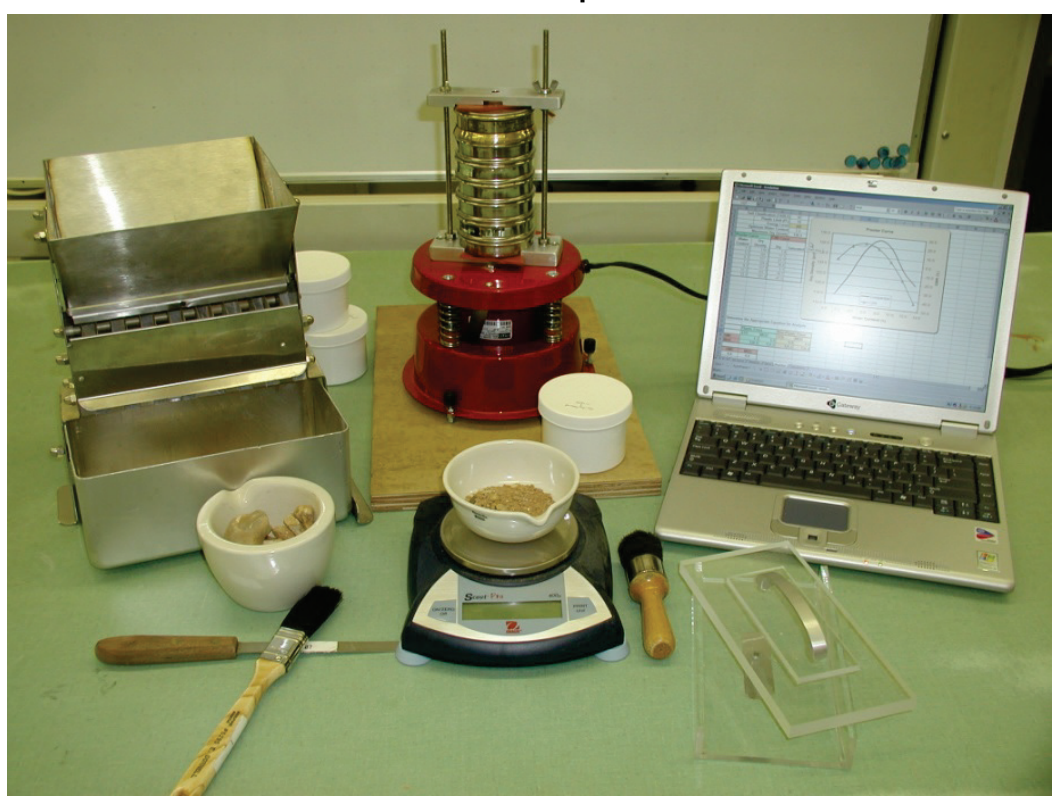


Figure 6. Soil sampling and processing tools included in the toolkit.

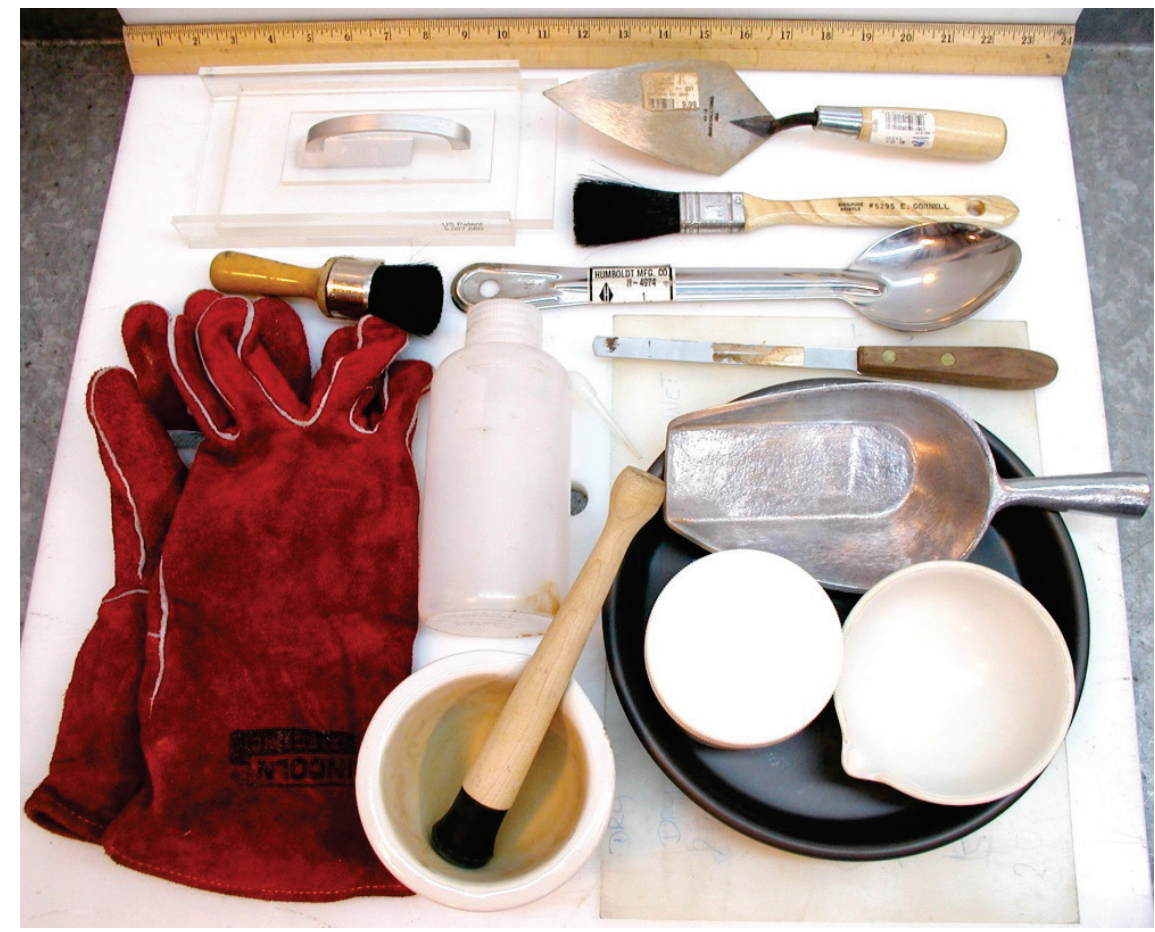

Figure 7. RSAK mounted on the JRAC Rapid Assessment Vehicle - Engineer (RAVEN).

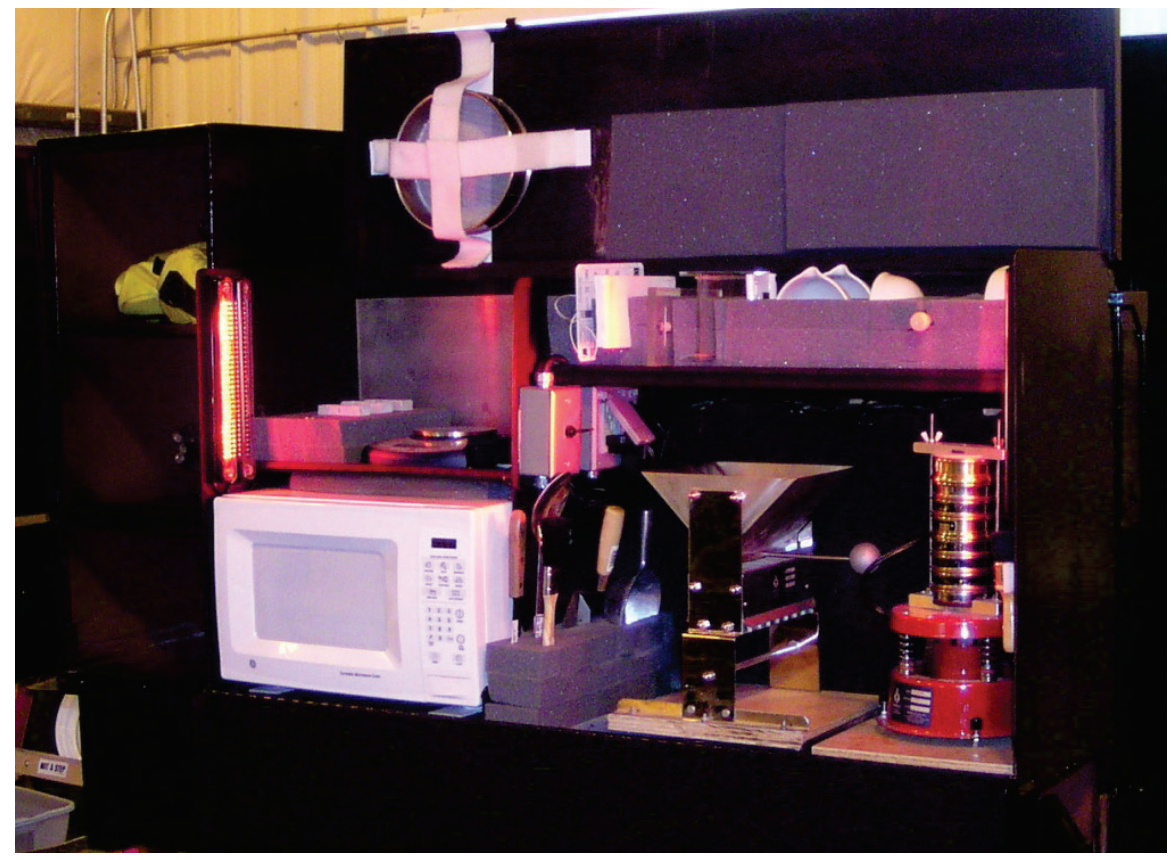


Figure 8. Screenshots from the RSAK Classification 1.0 software.

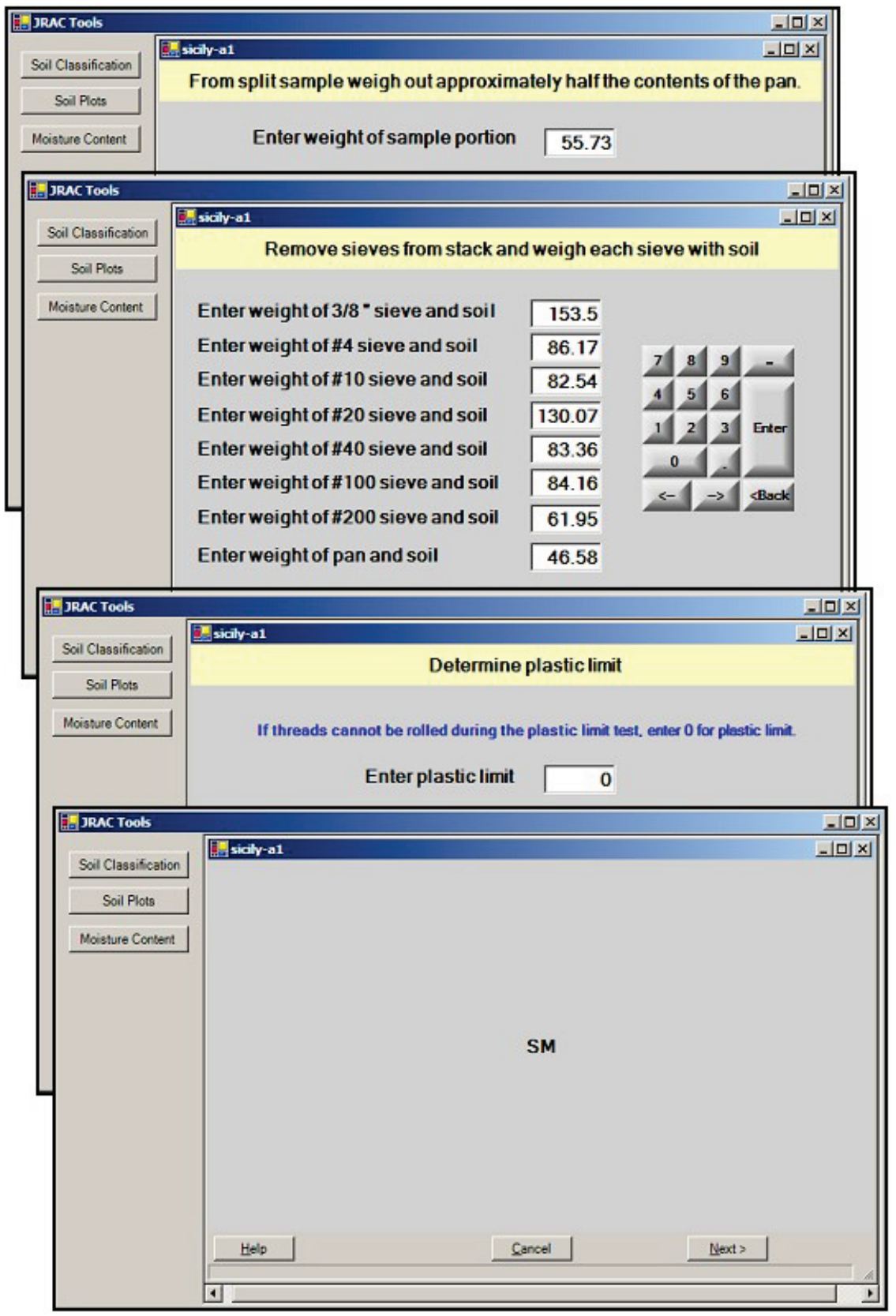


Figure 9. Typical compaction results from the RSAK Classification 1.0 software.

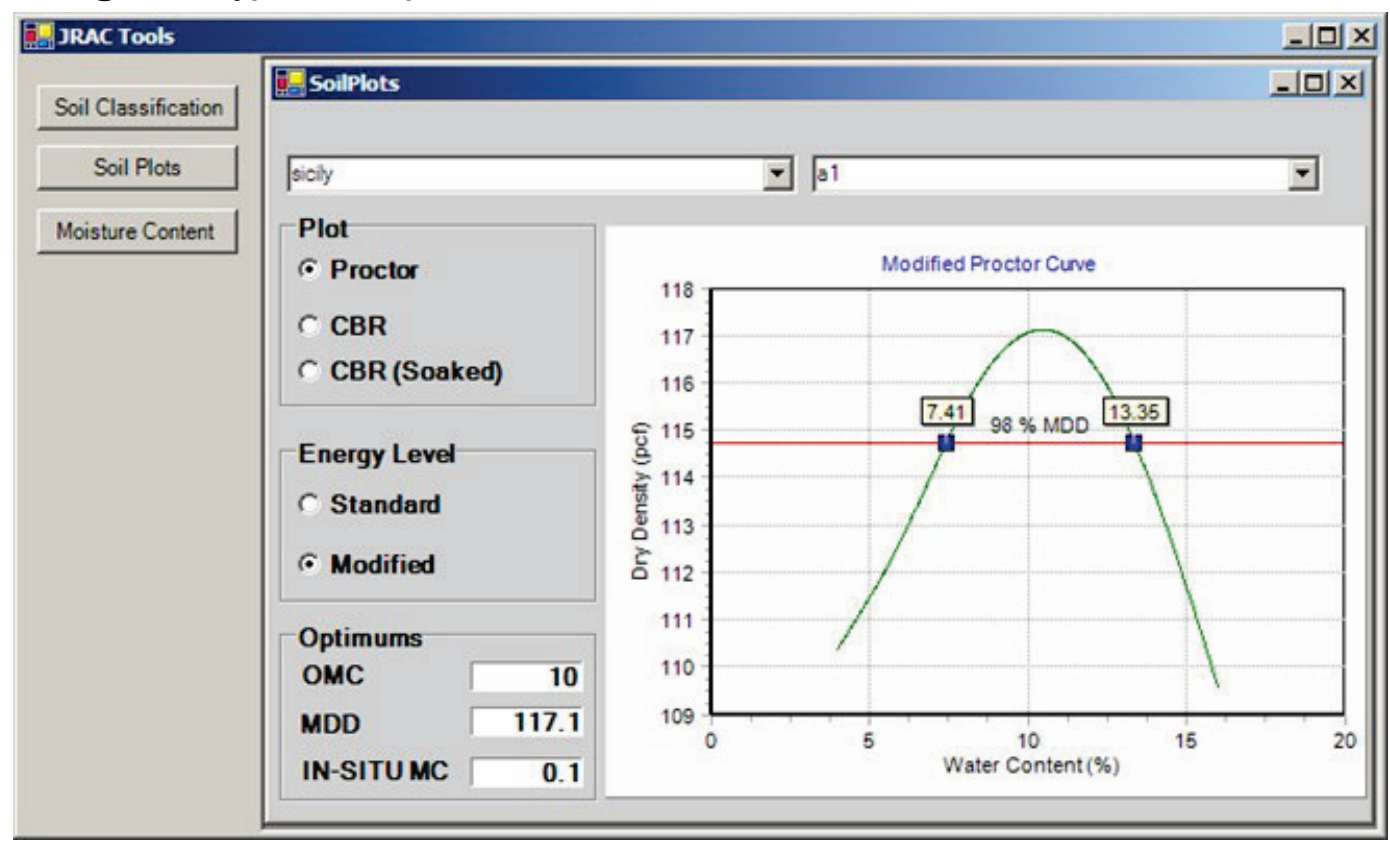

\subsection{Enhanced construction technology}

The construction and mining industry have been under constant pressure to improve the productivity and efficiency during earthmoving projects. Over the last four decades these attempts have been the traditional means in which the equipment has been made larger, more powerful, and with more efficient mechanisms. However, recent attempts to streamline the earthmoving process involve more innovative and non-traditional methods like the integration of satellite imagery, Global Positioning System (GPS), lasers, and onboard computers to the earthmoving equipment.

By integrating all components and technologies that are now available, it is possible to achieve an all-digital design and construction process that either avoids or eliminates sources of inefficiency in earthmoving operations. This potential increase in efficiency is important to military engineers because time is usually the most critical factor in a contingency situation. Initial planning for the JRAC program involved an investigation into emerging construction technologies in 2001, with the intent of defining the requirements for a new approach to constructing airfields (Tingle and Mann 2001). The ultimate goal is to equip the U.S. military with the tools necessary to rapidly and accurately construct airfields anywhere in the world to support the deployment of troops and equipment during contingency operations. 


\subsubsection{The all-digital process}

The design and construction process for a contingency airfield in its simplest form involves the following three steps: acquisition of initial topographic data of the proposed site, electronic design of the finished elevations for the proposed site, and earthmoving operations that will shape or create the finished elevations called for in the design. The current methodologies require lengthy survey work to obtain the initial topographic data. A relatively large amount of survey work is also required during the construction phase in the form of grade stakes that provide the equipment operators with information about the finished elevations. The JRAC process has undertaken the task of changing contingency airfield construction to a completely digital design and construction process, thus eliminating this type of survey work and increasing the overall efficiency of the project.

The all-digital process can be accomplished by taking advantage of recent advances in satellite imagery and GPS technology, which provides surveygrade accuracy on the job site. These GPS systems allow the user to rapidly and accurately obtain the required initial topographic data of the potential airfield site. Using the TerraModel ${ }^{\mathrm{TM}}$ software, soldiers can then design the proper $3-\mathrm{D}$ geometry of the airfield using already created templates that quickly overlay the existing topography. The cut and fill data along the length of the airfield can be used to manipulate the finished elevations so that optimum earthwork quantities are achieved for the project. Once this initial design is complete, the electronic design files can be transferred to an earthmoving system and construction can begin.

Earthmoving machines are equipped with GPS systems that are integrated into the blade control systems. In this configuration, the vehicle operator needs to steer the vehicle in the desired direction while the blade cuts to the design depth automatically as controlled by the digital design and the GPS positioning on the blade ends. This technology streamlines the design and construction phase by making the earthwork more efficient, less prone to error, and reducing the time required for grade staking and post checking of final grade.

The all-digital process also allows the monitoring of progress during construction. This powerful capability will be extremely beneficial during military operations because it dramatically increases the situational awareness on the project site and also identifies errors in construction before 
they create significant impact on the project timeline. Monitoring is accomplished at a project computer, which is linked to the machines via a radio network and displays the current elevation of the project as well as the machine locations in near real time. This technology offers the ability to communicate with the machines on the jobsite as well as to update design files, effectively allowing "design-on-fly" during construction. Although the systems employed during the 2004 demonstration did not meet all the objectives of the all-digital design and construction process as defined above, it is expected that the technology will be available in the near future.

\subsubsection{GPS surveying}

The major equipment components selected to perform the survey portion of the demonstration included GPS survey equipment and a small multifunctional construction site vehicle, the RAVEN, which is described in a subsequent section of this report. The GPS survey equipment chosen, which best met the needs for this program and demonstration, utilized high precision Real-Time Kinematic (RTK) technology manufactured by Trimble ${ }^{\circledR}$ Navigation Limited. The Trimble ${ }^{\circledR}$ equipment shown in Figure 10 included the 5800 GPS Receiver, the SiteNet 900 Radio (a multichannel $900 \mathrm{MHz}$ modem radio), the MS750 Receiver, the Multi-centered GPS Antenna, and the Survey Controller (TSCe ${ }^{\mathrm{TM}}$ ).

The Trimble system used a GPS signal in conjunction with a radio network to provide survey-grade accuracy for surveying applications. It consisted of a base station with power supply (12-volt battery that can be augmented with a solar power system) and a "rover." The base station was typically established over a point of known coordinates close to the job site but in a location away from vehicular traffic to minimize the potential for the signal being interrupted. The "rover" consisted of a GPS receiver with an internal radio and a data collector. It can be configured for use on a tripod, which is easily carried by one person, or mounted on a vehicle for rapid data acquisition. The "rover' was carried or driven around the jobsite in order to collect point data that were used to build a digital elevation model of the site. These data were then transferred into the design software where the digital design is created. 
Figure 10. GPS equipment used during the JRAC demonstration.

$\begin{array}{ll}5800 \text { GPS Receiver } \\ \text { Sulti-centered GPS Antenna } \\ \left.\text { (TSCe }{ }^{\mathrm{TM}}\right) & \text { Trimble Survey Controller }\end{array}$

The "rover" also served as an effective tool for horizontal and vertical quality control during the construction. Once the digital design was complete, the design file was transferred to the data collector on the "rover," which displayed any line work as well as cut/fill data from the design. This provided the surveyor with all the information necessary to quickly check the accuracy and progress of the earthwork during construction.

\subsubsection{Grade control systems}

Using the digital process, it is easy to transition from the design phase to the construction phase of an earthmoving project. Traditional methods require multiple sets of drawings that use different views and techniques to depict the three-dimensional object on a two-dimensional sheet of paper. Also, traditional methods rely on grade stakes to serve as a physical representation of the finished design elevations. This time-consuming process is very prone to human error and often requires a dedicated survey team to continuously provide new stakes as old ones are removed, as general operator error occurs, or because the amount of earth moved requires it.

Taking advantage of computer- and GPS-enhanced earthmoving systems can eliminate this process by continuously providing the equipment 
operators with a visual display that interprets the physical difference between the current elevation and the finished design elevation for the specific location of that piece of equipment. By providing machine locations relative to the project site for each piece of equipment, operators are constantly aware of project boundaries and earthwork geometry without having to rely on grade stakes. This method of construction can greatly reduce the risk of construction errors, thereby increasing the overall efficiency of the earthmoving operations.

Earthmoving systems of this type can also have an additional, stationary terminal that provides (via a laptop computer) machine locations for equipment on the jobsite as well as instantaneous progress reports about how much earth has been moved. This additional feature can further reduce construction errors because project officers can monitor construction operation in near real time and recognize errors before they happen. The additional, stationary terminal also is important because it adds tremendously to the situational awareness of the constructing unit by providing an accurate status of the project.

The grade control system used during the 2004 demonstration was the Trimble ${ }^{\circledR}$ GCS9oo system (Figure 11). A total of four systems were installed on a combination of earthmoving equipment including one Caterpillar $130 \mathrm{G}$ motor grader (dual antenna system), two Caterpillar 615 paddlewheel scrapers (single antenna system), and one Deployable Universal Combat Earthmover (DEUCE) (dual antenna system). The motor graders and DEUCE were equipped with fully automatic versions of the system, which allowed the blade of the machine to be automatically controlled by a computer when placed into automatic mode. This feature greatly improved the efficiency of the machine during final grading operations because the blade was automatically controlled to match the final design elevation. 
Figure 11. Trimble ${ }^{\circledR}$ GCS900 System installed on a U.S. Army DEUCE.

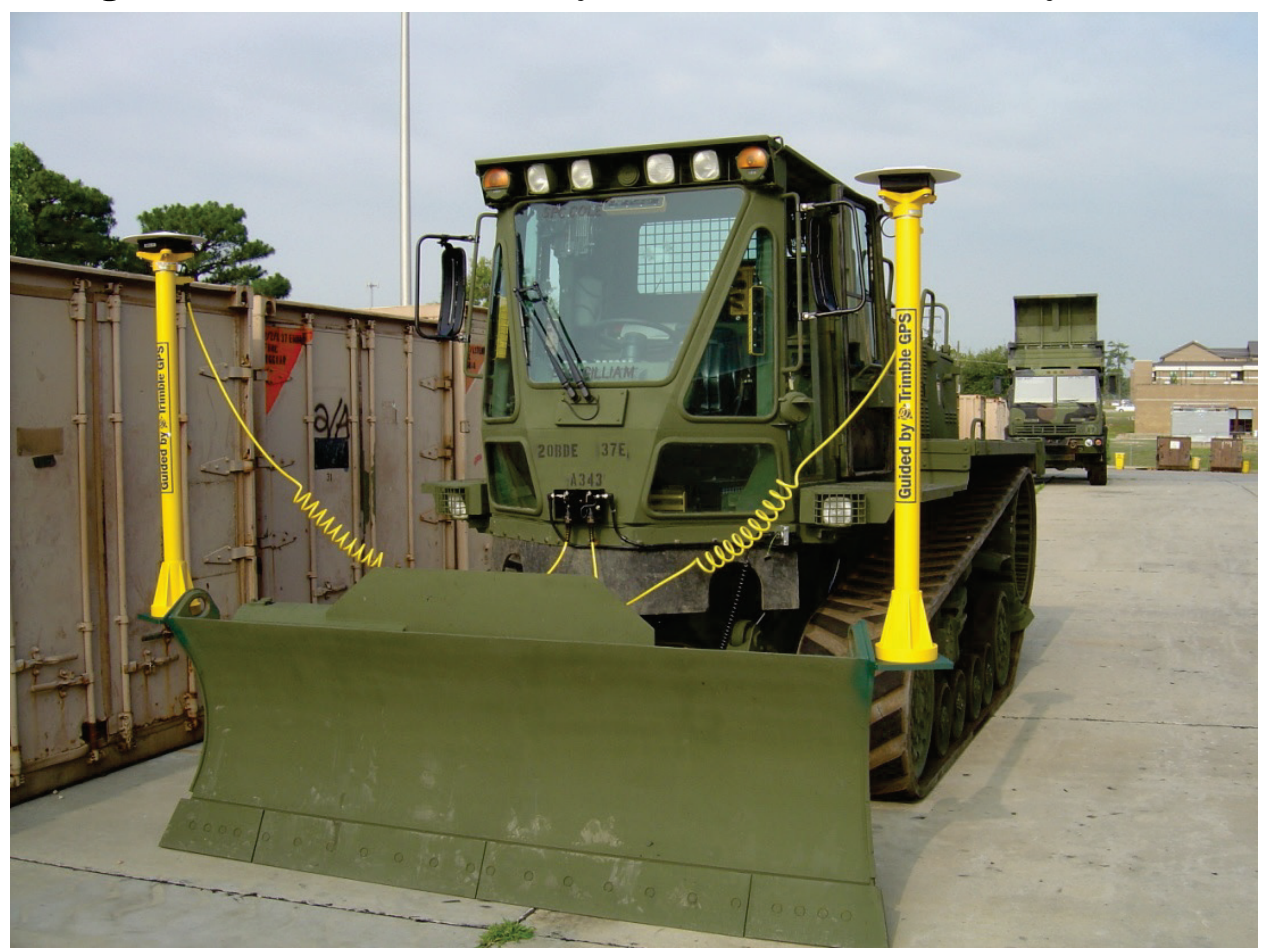

At the time of the 2004 demonstration, the GCS900 system did not have the capability to conduct two-way communication between the machine and a project computer, as previously described in the all-digital process. For the 2004 demonstration, the design files were manually loaded on the machines via a flash card, and there was no remote or on-site monitoring of progress or machine position during earthmoving operations.

\subsubsection{RAVEN (Rapid assessment vehicle-engineer)}

The RAVEN is a small, 4-wheel drive vehicular platform that houses a number of the JRAC technologies. Figure 12 shows a comparison of the commercial version of Bobcat's ToolCat and the JRAC modified version containing autonomous controls, a generator, a tool bin, a laser scanner, satellite communication, an on-board GPS receiver and survey controller, and an automated dynamic cone penetrometer (DCP) attachment. The vehicle is intended to provide all the tools and capabilities necessary to conduct a technical engineer assessment, design, and quality control for contingency airfield construction projects. 
Figure 12. Comparison of Bobcat ToolCat commercial version to the RAVEN.
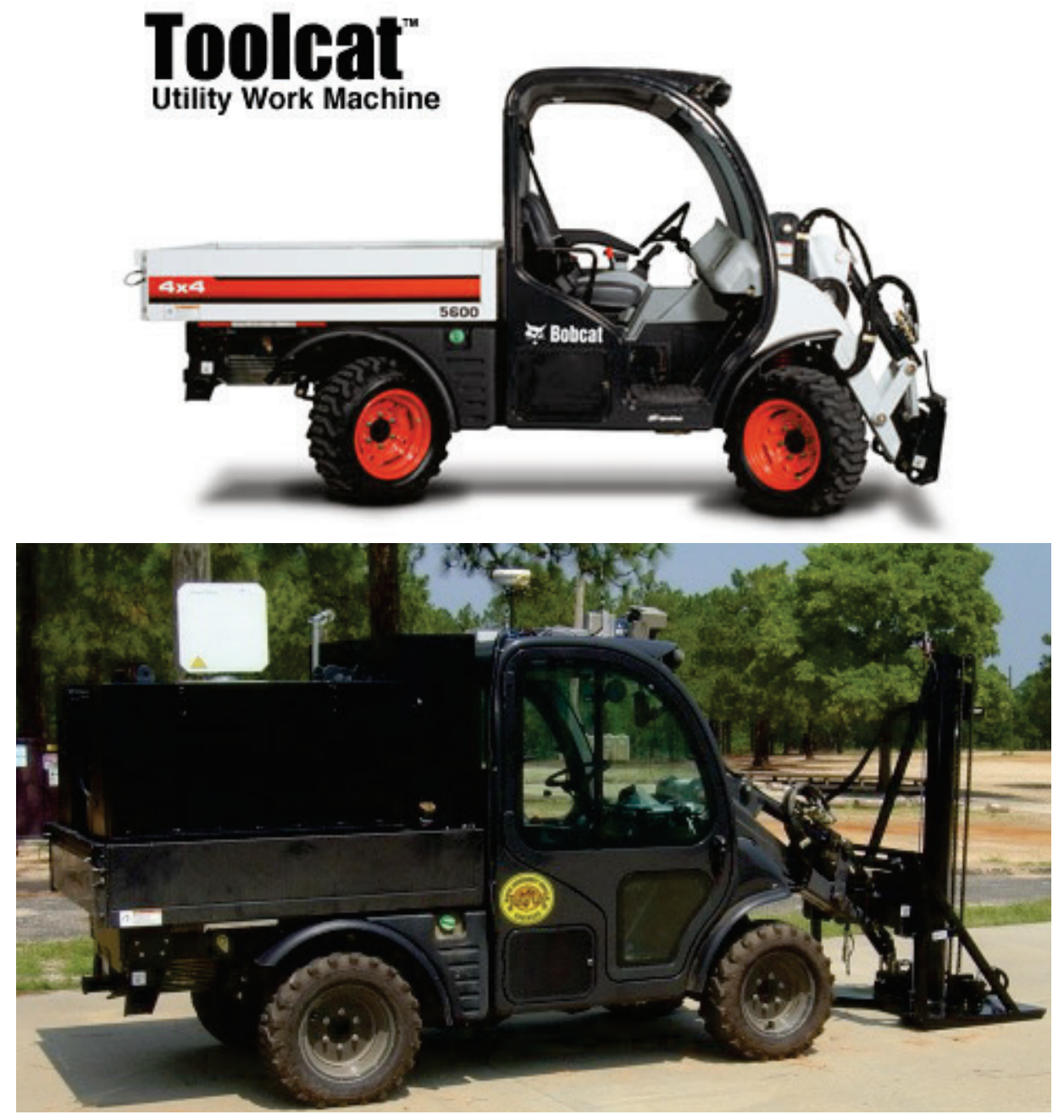

There were two primary workstations on the vehicle, both with a Panasonic Tough Book computer. One was in the cab of the vehicle, and the other was located in the utility box on the back of the vehicle. These workstations were equipped with all necessary software to conduct technical engineer operations for survey, design, and soils analysis. This all-in-one capability enabled the rapid design scenario critical to the JRAC mission.

The utility boxes on the rear of the vehicle provide storage for all GPS equipment, power generation via a diesel generator, and the RSAK described previously. The workstation on the rear of the vehicle also housed the components of the TeleEngineering Communications Equipment Deployable (TCE-D). This system allows the user to communicate via secure satellite transmissions all critical information being obtained. The 
utility box on the back of the vehicle can be separated from the vehicle, providing simultaneous use of the vehicle and the soils laboratory.

The Automated Route Reconnaissance Kit (ARRK) was also installed on the RAVEN. This system provides the capability to conduct engineer type reconnaissance and record information such as a GPS trace of the route, still images from the view of the driver, geometry of the route being driven, and location of critical facilities (bridges, intersections, etc.)

Because the RAVEN was based on the Bobcat Toolcat $®$ platform, there are several implement attachments that can be used on the front of the vehicle. The vehicle accepts standard attachments, fitting the more common skid steer loaders already present in many of the U.S. Army equipment fleets. Currently, the RAVEN has a bucket, extended forks for lifting pallets, and an automated DCP (Figure 13).

Figure 13. RAVEN vehicle with DCP attachment.

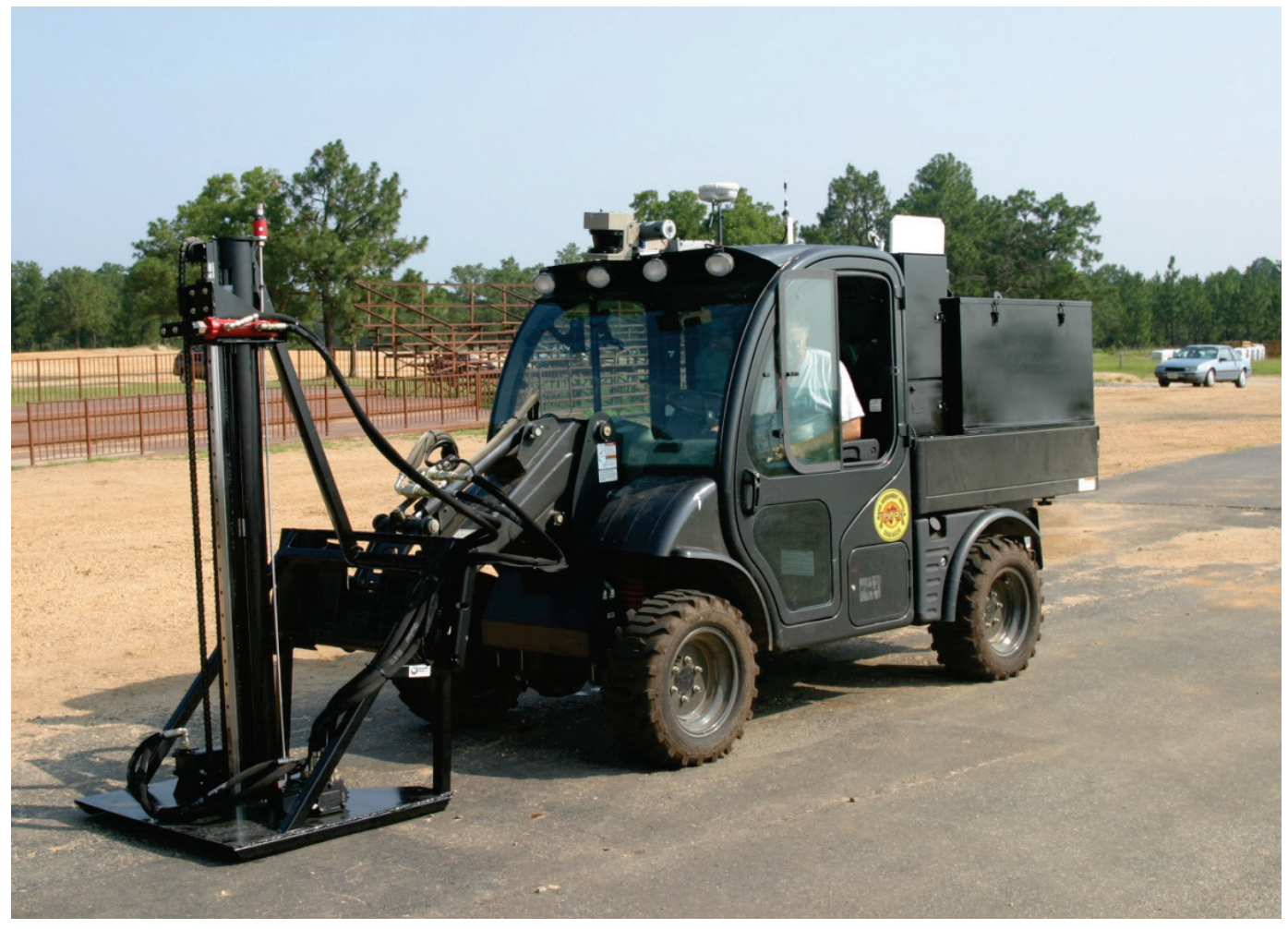

The automated DCP allows a soil strength test to be conducted automatically from inside the cab without human interaction. The test results are displayed and stored on the computer located inside the vehicle. The DCP attachment consists of a standard DCP inside a device that 
mechanically lifts and drops the hammer by using the auxiliary hydraulics on the front of the machine. Sensors on the side of the device accurately measure the penetration of the cone after each blow as well as the location of the hammer. This process is automatically controlled by software on the laptop in the cab of the vehicle and eliminates the need for any post processing of data as with current methods. The device provides an efficient way to conduct DCP tests by reducing the personnel requirement to one soldier, eliminating the physically demanding aspects of the manual method, and providing instantaneous results in a safe environment.

The RAVEN is also equipped with autonomous controls that allow the vehicle to be operated by a single soldier from remote locations via a joystick, a radio network, and a series of cameras mounted on board. The vehicle can also be controlled by the on-board computer and software in a completely autonomous mode, effectively requiring no human interaction. This type of operation allows the vehicle to conduct such tasks as surveying a large area with detailed coverage, conducting multiple DCP tests in an open and unsecured environment, or sweeping a large runway to eliminate debris with precision and minimum human interaction.

\subsection{Soil stabilization technology}

The objective of the soil stabilization effort was to develop or refine soil stabilization technologies to reduce the logistical effort necessary and time for construction. Soil stabilization is broadly defined as a largescale change in one or more soil properties, typically for improved engineering properties. This may be accomplished by compaction, blending with other soils to change gradation, and/or adding materials to the soil such as cement, lime, or bitumen.

For this work, additives were sought that would be applicable to a wide variety of soils and build strength quickly. This research effort began by evaluating a wide number of soil stabilization/modification additives that subsequently focused on agents with particle binding properties such as cements, emulsions, etc. These materials should be applicable to a wider variety of soil types than additives such as acids or enzymes that require some type of chemical action with the native soil particle. Geofibers also were of great interest as they provide a mechanical means for soil improvement. Finally, a combination of binders (emulsion polymers and rapid-setting cement) and fibers were investigated as a means of improving conventional Portland cement stabilization. 


\subsubsection{Methods for rapid soil stabilization}

After an exhaustive review and testing of commercially available soil stabilizers, no materials were found that met the JRAC objectives of rapid curing, easily constructible, adequate strength, worldwide and rapid availability, and applicability to a variety of soil types. It became clear that improving stabilization with Portland cement could achieve the JRAC objectives. Several problems arise, however, with the use of Portland cement as a soil stabilizer. A typical stabilization project requires from 9 to 12 percent by weight of soil. This dosage amount is logistically unwieldy. Cement also has a high specific gravity, meaning a low volume of adhesive per unit weight. Failure of soil cement is usually by cracking, which leads to foreign object damage (FOD) potential. The use of an organic co-stabilizer, such as polymer emulsion or fibers, reduces the weight of Portland cement necessary while improving the properties of the stabilized soil.

Experiments have shown that the polymer-cement- and fiber-cementstabilized soil have similar strength to a typical cement-stabilized soil but allows higher strains prior to failure. The higher strains should translate into improved cracking and FOD resistance. Type I Portland cementstabilized soils also suffer from relatively long curing times (7 days minimum) before traffic is allowed. The use of Type III high-early strength cement in combination with polymer emulsions should allow much shorter cure times without a significant increase in cost.

\subsubsection{Dust control technologies}

As with soil stabilization, a number of commercially available dust control agents were tested. The two best-performing materials were polymer emulsions and synthetic oils. Polymer emulsions were found to be best for soils with high strength, as the emulsions tend to form a surface crust that, if broken, may generate FOD (Rushing 2006). These emulsions could also be used on weak soils, as they do impart strength but must be mixed into the soils, not topically applied. Synthetic oils could be topically applied without dilution but do not provide strength. It was found that the synthetic oils are applicable to a wider variety of situations than the emulsions.

\subsubsection{Matting systems}

One of the primary goals of the stabilization pillar of the JRAC program was to identify suitable matting products that can be used to rapidly expand 
aircraft parking capacity. These matting products must be strong enough to support the aircraft loads (C-130 or C-17) over weak soils and must also be logistically attractive compared to current methods, e.g., AM2 mat. Several years of testing and evaluation were conducted to identify a solution for the 2004 demonstration and $\mathrm{C}-130$ aircraft. Multiple products were evaluated, and the $\mathrm{ACE}^{\mathrm{TM}}$ mat was selected as a primary technology to be used in the construction of the aprons during the Fort Bragg demonstration.

$\mathrm{ACE}^{\mathrm{TM}}$ Matting is a medium- to heavy-duty matting system composed of square fiberglass-reinforced panels. The matting was originally developed for expedient road construction over soft soils (CBR range of 1 to 10); however, they have been found to also be equally durable for application of light- and medium-weight aircraft wheel loading over soft, low-weightbearing soils. The primary application for this mat is parking and taxi aprons for contingency airfields, extensions or temporary additions to existing airfields, temporary helipads, and equipment storage pads.

$\mathrm{ACE}^{\mathrm{TM}}$ Matting Systems consist of square mat units measuring $6 \mathrm{ft}-8 \mathrm{in}$. long and wide with a thickness of approximately $0.35 \mathrm{in}$., and each mat weighs approximately $115 \mathrm{lb}$. A single mat provides $36 \mathrm{ft}^{2}$ of usable surface area, and the mats have an indefinite storage life. They can be easily moved and placed by two people. Once in place, the mats are connected using manufacturer-supplied bushing-style pins (Figure 43) that are tightened down with a standard wrench and Allen-head socket (power drills may be used to expedite the process). The site preparation required before placing the mats is minimal, typically accomplished by light grading and compaction to ensure the surface is flat. The area under the mats must be free of foreign objects and debris and should be compacted to the appropriate standard prior to placement of the mats. Additional mats and pins can be stored on site and used to replace any mats or pins damaged during operations.

$\mathrm{ACE}^{\mathrm{TM}}$ Matting is an effective matting system for use in contingency or short-term airfield operations for creating new or extending existing taxiways and parking aprons. This matting system offers good performance for high and medium strength in-situ soils. The mats are small in size, easily moved and placed, and offer good durability and structural stability. The $\mathrm{ACE}^{\mathrm{TM}}$ Matting System requires only a relatively flat, debris-free surface for installation using a simple pin system to connect and secure adjoining mats. Maintenance is simple with interior 
mats being easily released, removed, and replaced. The outer edges of a mat system are easily secured with any one of a number of stakes or pinand-cable anchor systems. It is recommended that additional mats and pins be stored onsite for replacement of those damaged during operations. Finally, the $\mathrm{ACE}^{\mathrm{TM}}$ Matting System is not recommended for use as a landing or take-off surface for fixed-wing aircraft. 


\section{JRAC Task Force Training}

\subsection{Training site}

Training for the JRAC project was conducted periodically throughout the months of May, June, and July at All-American Drop Zone at Fort Bragg, as shown in Figure 14.

Figure 14. All American training site at Fort Bragg.

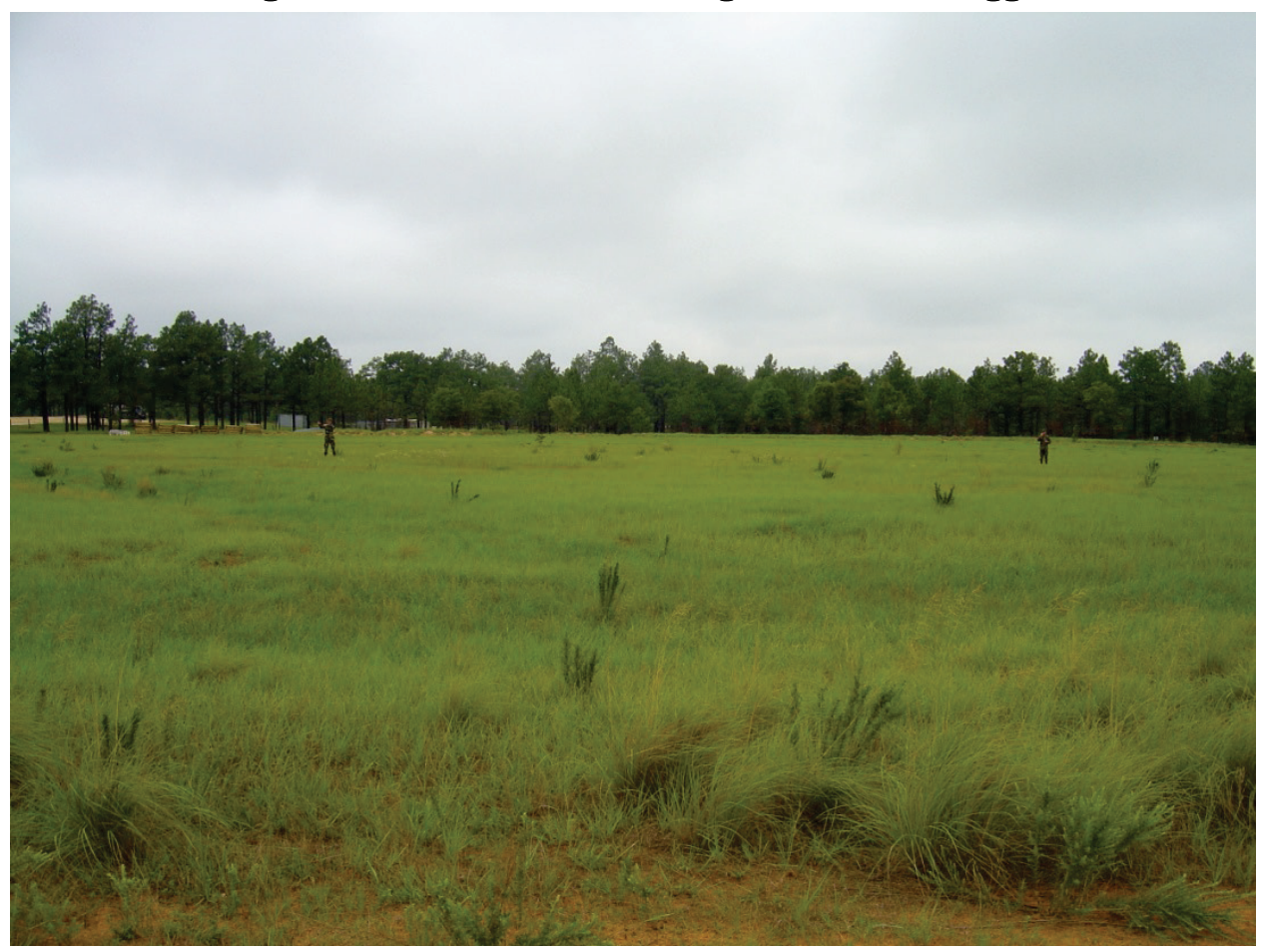

\subsection{RTK-GPS survey}

The soldiers, 21D- Facility Engineers, and 21T- Survey Technician specialties involved with this demonstration had little to no past experience with GPS surveying, yet had been familiarized or qualified at performing conventional surveys as a Survey Technician through the U.S. Army Corps of Engineer School at Fort Leonard Wood, MO.

The major equipment components utilized to perform the survey portion of the mission included GPS survey equipment and the RAVEN, as described in Chapter 2. The GPS survey equipment chosen, which best met the needs for this program, utilized high-precision Real-Time Kinematic (RTK) technology manufactured by Trimble Navigation Limited. Trimble's and Bobcat's equipment were introduced at the basic conceptual 
level for troop familiarization and then trained to a standard to meet this demonstration's mission objectives.

Troop training occurred over several dates and locations with various military personnel. Training was specifically tailored toward the individual soldier's task as the task applied directly to meeting the JRAC mission objectives. Training events included:

- A 3-day "train-the-trainer" on GPS surveying conducted at ERDC, Vicksburg.

- A 5-day training exercise that incorporated all participating soldiers (engineer, survey technicians, and equipment operators) in the familiarization and functionality of newly introduced equipment at the "All American" training site at Fort Bragg.

- A 2-day refresher with all software applications used during the demonstration also conducted at Fort Bragg.

GPS survey training occurred at ERDC 12-15 April 2004. The training targeted the Officer-In-Charge (OIC) and two Survey Technicians designated to be the trainers and primary points of contact for system functionality during the exercise. Training included basic familiarization via classroom time, followed by hands-on training that targeted the equipment's basic functionality. Once a basic ability to operate the machine had been achieved by the soldiers as determined by the Trimble representatives, training focused on setting up the equipment and operating in a remote location with no geodetic references. As training was conducted, both the Trimble and soldier representatives established standard operating procedures that targeted the mission objectives.

Collective troop training occurred 21-26 June 2004 at Fort Bragg. This training targeted specialized skill sets, i.e., survey technicians performed surveys and geotechnical testing, while equipment operators learned equipment functionality with on-board GPS controllers for various construction equipment (Figure 15). Several additional Survey Technicians were incorporated into this training event to increase exposure to GPS surveying. Trimble representatives provided an introduction to their products followed by hands-on operation. The GPS familiarization task included surveying, downloading to TerraModel, performing a TerraModel design, uploading to various construction equipment fitted with GPS Site Vision controllers, and operating the 
construction equipment with the GPS Site Vision controllers. Other trained tasks included general operation of the RAVEN.

Figure 15. Collective troop training on GPS survey equipment at All-American site.

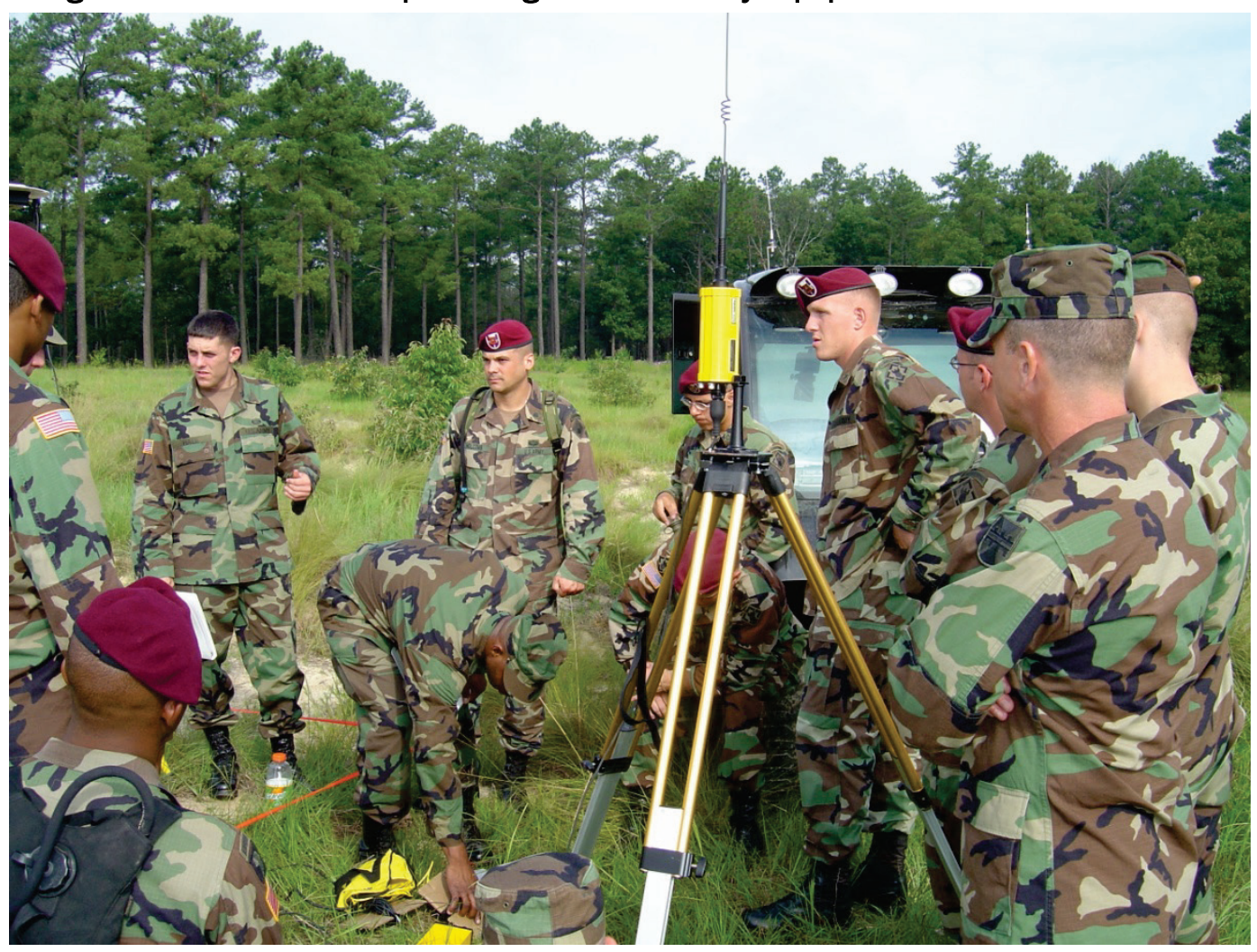

Rehearsals occurred 10-11 July 2004 at Fort Bragg. These two days were instrumental in recapping all previous training. Teams were devised, and drills were rehearsed. Equipment was tested for functionality and brought to a pre-mission-ready status before being moved to the demonstration site. Operating procedures were reviewed and packaged for quick reference. All software programs were tested with some procedures being refined for more efficient use. Lastly, a walk-through at the site occurred to point out specific coordination and timing of certain events, as well as point out key technical consideration for events about to occur.

\subsection{GPS-instrumented earthmoving system}

Training of the installed Trimble grade control systems was led by Spectra Integrated Systems. Spectra was the contracted agency that instrumented the various construction equipment with the GPS masts and sensors to provide real-time monitoring of the earthmoving process. Spectra representatives trained six soldiers with limited total station and GPS 
experience on the surveying equipment over a period of $41 / 2$ days leading up to the commencement of the demonstration. These six personnel would be the system experts to monitor the performance of additional equipment operators in a "train the trainer" format. Later, eight additional soldiers without previous GPS experience were trained on the system. These eight soldiers would be the principal equipment operators who would rotate shifts throughout the 4-day demonstration. Supervision would be provided by the 6-man expert team, and technical questions would be handled by Spectra, whose staff remained onsite for the duration of the exercise.

\subsection{RSAK training}

Personnel trained prior to the JRAC Demonstration for soils analyses were Engineer Qualified Soldiers (EQS) with training from the engineering school at Fort Leonard Wood concerning field classification of soils. Interviews with the soldiers following the training exercises suggested that the engineering school training provided enough background to allow familiarity with all the classification equipment contained in the RAVEN and the physical processing of the soil to allow a soil classification. The inclusion of a step-by-step procedure card was beneficial in reminding the EQS of the classification process, especially those EQS who were not routinely conducting these tests.

Training of the EQS occurred over two separate exercises prior to the demonstration. During the week of June 22-25, EQS from the $412^{\text {th }}$ and $37^{\text {th }}$ engineering brigades were given an afternoon (approximately $4 \mathrm{hr}$ ) of instruction at the "All-American" site with the ERDC engineering team (Figure 16). The EQS were trained to conduct the complete suite of tests required for soil classification, including use of an accompanying Alpha version of the Classification 1.0 software (Figure 17). This was the first field test of the soil classification process and the first time the procedure had been conducted on the RAVEN with equipment mounted, the Toughbook computer available, and an outdoor environment to endure. Research prior to this exercise involved controlled laboratory set up of equipment and commercial laptops for data entry. Prepared soil samples from ERDC laboratories with known properties were provided to allow the EQS a baseline from which to compare their training results. 
Figure 16. Training of soldiers on soils analysis kit at All American site.

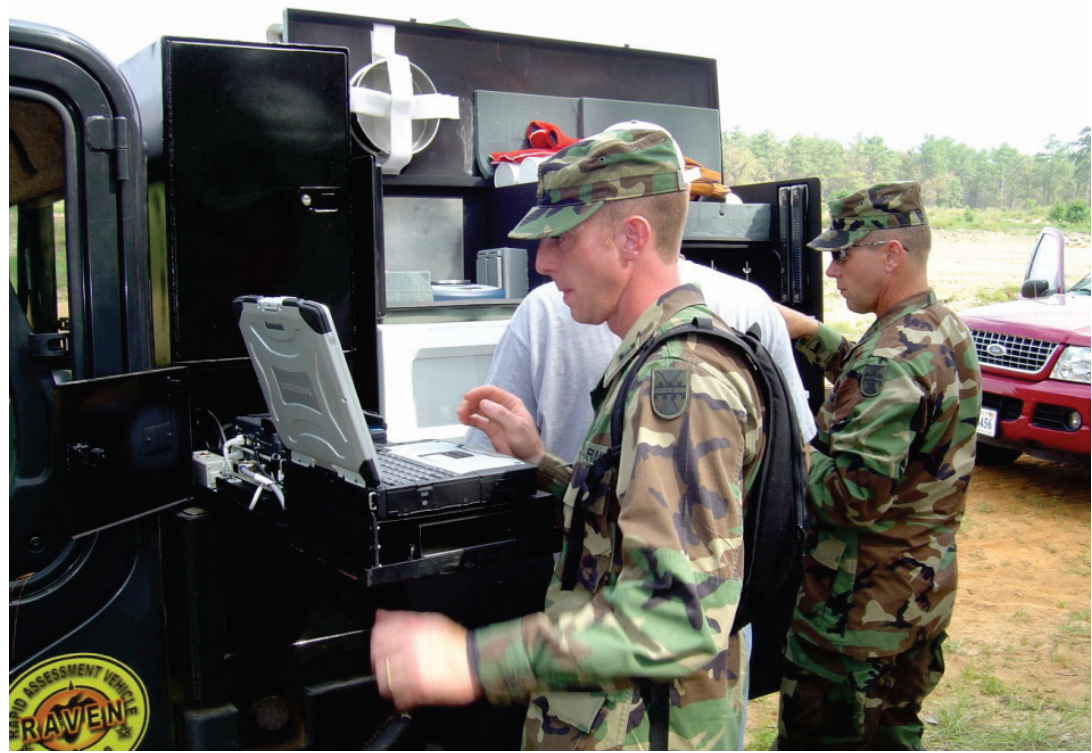

Figure 17. Training results from soils sampled at All-American site.

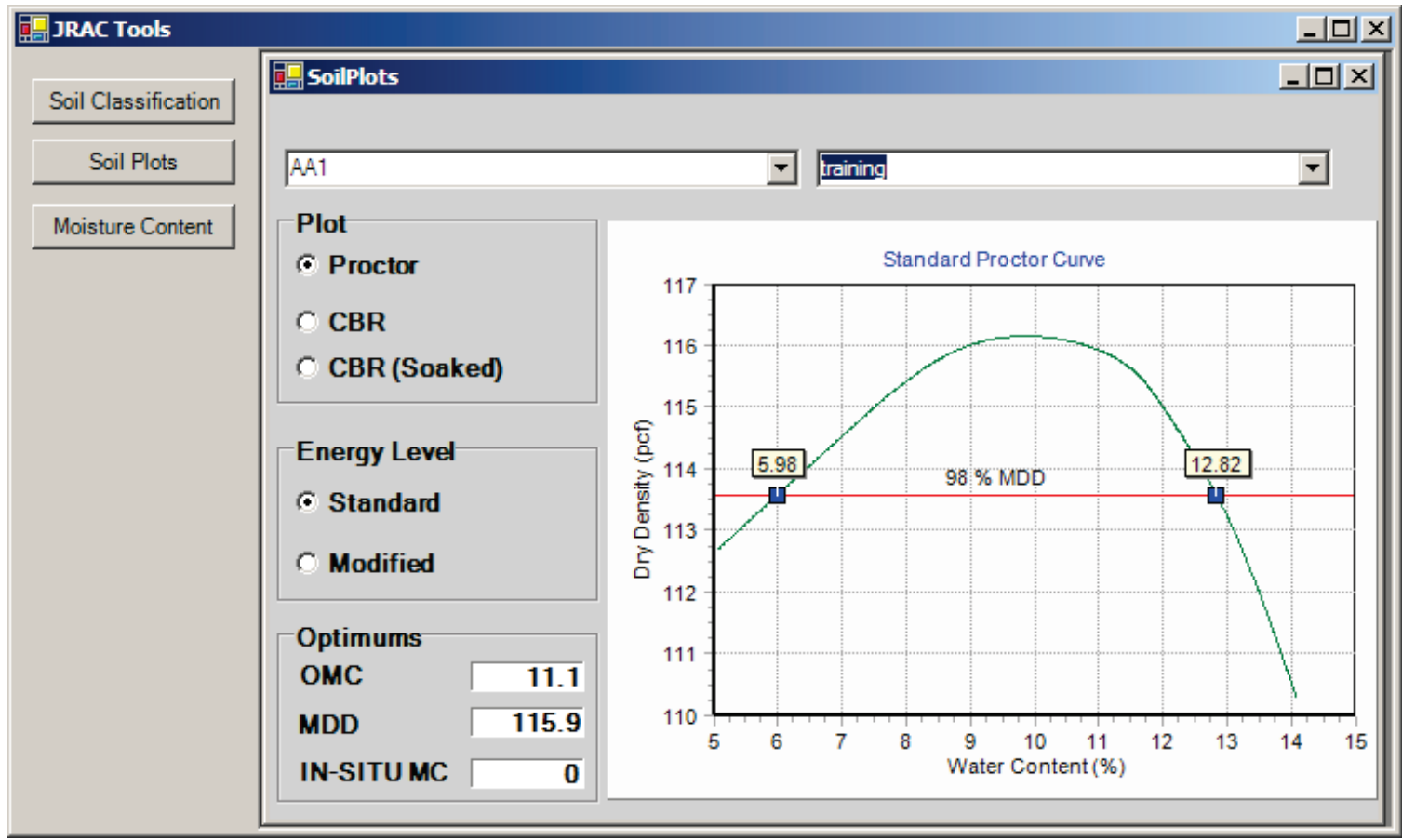

During the week of July 6-9, 2004, a select group of EQS from the $412^{\text {th }}$ and $37^{\text {th }}$ engineering brigade was assigned as the classification team prior to the JRAC demonstration and were provided another afternoon (approximately $4 \mathrm{hr}$ ) of supervised instruction on the classification process on the RAVEN vehicle with the ERDC engineering team. This exercise was 
intended to instruct the EQS on more efficient ways to manipulate the classification equipment and use of a Beta version of the Classification 1.0 software optimized for Toughbook use and correcting many of the flaws of the Alpha version. Practice soil samples for the EQS were obtained from the anticipated Sicily LZ aprons to provide the ERDC engineering team expected soil properties to be encountered during the JRAC demonstration project. However, no data collected during the practice exercises were used during the JRAC demonstration. The execution of the design and construction during the actual JRAC demonstration relied solely on data collected during the timed exercise.

For the JRAC demonstration, the soldiers trained to perform the soil classification and field DCP tests were entry-level engineers with basic soils training with a $21 \mathrm{~T}$ team leader who oversaw the operation. The responsibility of the $21 \mathrm{~T}$ was to interpret the moisture-density and CBR strength output from the software and selection of soil sampling sites in the field. The technicians were responsible for processing, drying, and testing of the soils and entering the data into the software package. All team members were to be instructed on the soil testing process.

Training for the soldiers was required on the following instruments and techniques.

1. Proper selection and storage of representative soil sample(s).

Soldiers were instructed as to the proper location, depth, mass, and number of samples to take over the span of a typical apron to provide data that would represent a typical soil for the area or interest.

2. Preparation of soil sample(s) for sieve analysis.

Soldiers were instructed on ensuring that a maximum amount of weight was not exceeded for the initial soil specimen, drying, and pulverizing of the soil, and splitting and weighing of the soil samples prior to sieving.

3. Operation of microwave drying technique.

Soldiers were instructed on the ASTM process of determining water content of soil samples using a microwave oven (ASTM D4643 2000). 
Attention was paid to maximum weights of soil placed in the microwave and proper use of the moisture content software to aid in the process to ensure repeatable results.

4. Use of sieves and sieve shaker.

Procedures for weighing, shaking and cleaning sieves in an orderly fashion and in the necessary stages for classification were covered.

5. Use of plastic limit tool.

For those soldiers who had not used the plastic limit roller, instruction was given to allow a more reproducible result for determining the plastic limit of soils for those less experienced with hand-rolling soil specimens.

6. Operation of software to compute moisture content from microwave data.

See number 3 above.

7. Operation of software to compute soil classification from sieve analysis.

EQS were instructed on the process of opening the software, naming and saving files, and inputting data in a strict procedure as information was obtained from the classification tools to allow a soil classification to be returned.

8. Operation of software to visualize proctor and CBR curves.

Once the soil was successfully classified, EQS were trained on the types of moisture-density and CBR relationships that can be obtained with the use of the included soil database and regression software. This training also involved interpretation of the available curves for construction and stabilization design.

\subsection{Rapid design system}

The suite of programs used to rapidly design the target feature of aprons included TerraModel version 10.3, Classification version 1.0, Soil Stabilizer Excel $^{\mathrm{TM}}$ Spreadsheet, and TeleEngineering Toolkit. The same soldiers, 21D- Facility Engineer and 21T- Survey Technician specialties, involved 
with the surveying task were the target users. Background information was provided by ERDC and Trimble representatives that specialized in each of the software applications, followed by hands-on exercises. These commercial and newly developed programs from the ERDC provided design solutions within $4 \mathrm{hr}$ of beginning the design task. This, in turn, greatly enhanced planning time for the engineer and supervisors on the ground. Reference the Rapid Soil Classification Test and Soil Stabilization sections of this report for more detailed information.

TerraModel version 10.3 training occurred at ERDC 25-26 May 2004. As with the GPS survey equipment training, the training targeted the OIC and five Survey Technicians. The training highlighted the basics of TerraModel use from developing the steps to load a raw survey data file to laying out the apron. In addition, a task-specific toolbar with buttons specifically targeting the JRAC mission objectives was constructed, and several drills were conducted that exercised usage of each step, which improved soldier's time and efficiency.

A key implementation to the process was the development of an apron template, which was inserted at any desired location of the terrain data. By doing this, more time was made available for finding a suitable location for the apron. The drawback was that it was up to the user's keen eye and repetitious locating to determine the best position for the apron that would make the best use of both construction equipment and time. Another very helpful product was the integration of a geo-referenced Tagged-Image File (geoTIFF) of the site, which was rotated and rendered to the points that had been surveyed and downloaded. This gave the user a much better understanding of where he was working on the ground. The training session ended with a brief look at other TerraModel functionalities, including road and hydrology features, that may be used in future operations.

The soil classification and soil stabilization programs, Classification 1.0 and the soil stabilizer spreadsheet, were used to access the soil conditions and determine polymer and water requirements to meet the targeted design specification for this mission. Troop training occurred 21-26 June 2004 at Fort Bragg. The programs, as well as the procedures, were simple to use. Several soldiers asked if versions of the software could be provided them immediately for their units involved in Operation Enduring Freedom, since the typical time to receive the results of the soil samples 
was approximately one to two weeks. With these simple programs, user time was $1 \mathrm{hr}$ for the testing procedures and user input.

The TeleEngineering Toolkit version 2.6.8, previously developed and fielded by ERDC, was used to provide user interface for reviewing satellite imagery of the site. Controlled Image Based (CIB) 1 imagery of the desired area was used for viewing and planning. Once the airfield had been zoomed down to the desired magnification, the image was exported to a geoTIFF for use with TerraModel. Several of the soldiers had basic knowledge and use of the application, which greatly reduced the training time.

\subsection{Army Corps of Engineers (ACE) Matting System}

Many of the soldiers involved in the training had some familiarity with matting but had not seen the ACE Matting System before this event. The training involved only a small demonstration with about 100 mats and the associated pins and duckbill anchors. As stated earlier, the mat assembly training occurred at the All-American Drop Zone at Fort Bragg.

The training began by gathering the group together and discussing the matting from the standpoint of weight, construction, and size. Some key points, such as the need to handle fiberglass mats with protective gloves and installing duckbill anchors as a last step, were covered. The troops also had a chance to look at a plan view of Apron 1 as it would be constructed at the demo site on Sicily Assault Landing Zone (LZ). The next step was to pick a flat area at All-American and perform an actual assembly to understand the matting system (Figure 18). 
Figure 18. Training on mat assembly at All-American site.

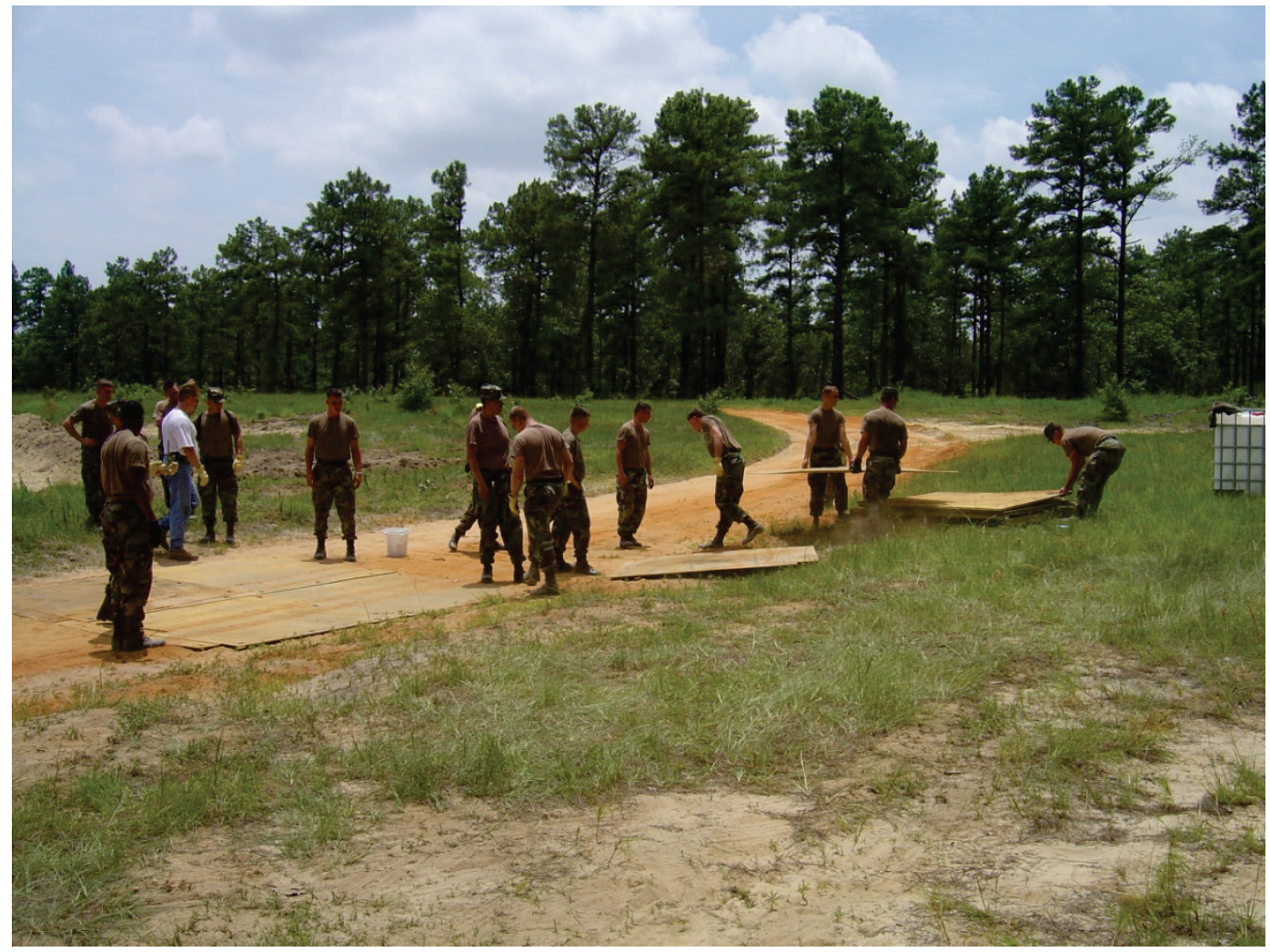

A total of 100 mats (10 pallets of 10 mats each) were brought to the training event. Four of these mats were used during earlier closedgroup discussions to show all those participating how the mats fit together and the proper way to install and secure the pin assemblies. The remaining 96 mats were used to do the large-assembly training exercise. The area chosen had been stripped and graded by troops practicing the use of automated grading equipment and, although not extremely flat, the area was adequate for the purposes of training.

The mats were assembled with 10 mats running north to south and 10 mats running east to west, although this shape did lack the four mats used earlier during the closed-group discussions. Initially, the troops found it difficult to organize themselves and ensure that all personnel had a task to perform. Within the first 10-20 mats installed, the group began to organize, with some individuals transporting and placing mats, some inserting and fitting pins, and some tightening pins and ensuring the pins were secure. By the end of the training, the group had achieved a pace of about $3,600 \mathrm{sf} / \mathrm{hr}$ with a 12-man crew, which correlates to 300 $\mathrm{sf} / \mathrm{man} / \mathrm{hr}$. This was considered a low number with such a large crew, but with the factors of heat, inexperience, and learning curve of assembly 
techniques and crew organization, it was anticipated that this production rate would rise with increased exposure and use of the system.

During discussions at the after-action review, Staff Sgt. Houser talked about the assembly practice session. He commented on the ease of using the system and how the size and shape of the mats were perfect for use by troops. He also noted that assembly during the day was easy, and it is anticipated that night operations would be just as simple but might progress somewhat slower due to the aspects of working in darkness. In addition, three key points were discussed that warranted attention. First, it is critical that at least two assembly team crew members be dedicated to checking assembled mats to ensure that all connecting pins are in place and secure. Second, when assembling the mats, it is crucial to have the mats flat against each other when pins are installed to guarantee that the connection between mats is made when the pins are turned. Finally, only one-quarter turn is required to engage the pin connection. Once engaged, further tightening only serves to pull the mat edges tighter together.

Overtightening can lead to a lack of mat system flexibility, which can cause problems during thermal expansion in hot environments.

\subsection{Soil stabilization}

The soldiers had no prior experience with soil stabilization, so a general overview of soil stabilization, construction techniques, and quality control was presented to familiarize them with the topic. Following this, specific details about polymer-cement and fiber-cement stabilization were presented, along with the equipment and techniques to be used in the upcoming demonstration. Some of the critical points necessary for a quality stabilization project identified were:

- Proper compaction of the soil at the optimum moisture content. Good compaction means slow, careful work to make sure the desired number of passes are met over a given area.

- Compaction beginning as soon as possible after mixing of the cement with the soil. This is especially true when using fast-setting cements at high temperatures.

- Compaction in lifts of no more than 8 in. of loose soil.

- Proper placement of cement and fiber bags, even spreading of the cement and fiber over the lane width, and good mixing. 
The All-American training area at Fort Bragg was used to train for stabilization. An area approximately 150 by $150 \mathrm{ft}$ was chosen, then cleared and leveled by a DEUCE and a grader. The troops were trained on the operation of the Terex 325 Reclaimer/Stabilizer and the Automated Liquid Proportioning System (ALPS) by both ERDC personnel and Terex contractors. A Medium Tactical Vehicle Replacement MTVR was fitted with a 1500-gal agricultural tank after attempting the use of the $613 \mathrm{~B}$ water truck. Several practice runs were made with the MTVR and Terex linked by the boom but not using the ALPS system. After becoming more familiar with the operation of the Terex and the cutter head, trials began with operation of the ALPS. After less than a day of practice, the soldiers were ready for stabilization trials. The stabilization training was designed such that multiple Terex lanes were required, so the operators could aim towards minimizing the overlap of the machine to adjacent lanes.

At the end of the stabilization training, the soldiers, ERDC personnel, and the Terex personnel were very confident with the process. For an aircraft parking apron sized project with a trapezoidal geometry, there was considerable discussion on how to time the process, spot the cement and fiber bags, refill the MTVR liquid tank and the water truck, and refuel the vehicles to maintain a high rate of stabilization. A system of ropes was devised that could be used to mark the Terex lanes with colored tape indicating where to spot the cement and/or fiber bags. During the exercise, the timing issues were worked out such that very little down-time occurred.

\subsubsection{Polymer-cement stabilization}

The specific steps used to conduct the polymer-cement stabilization are as follows.

1. Selection of stabilizer amounts. For this training, 3 percent polymer emulsion and 3 percent Type III (high-early strength) cement by weight of soil were chosen.

2. Soil OMC for compaction and soil moisture levels are needed prior to construction.

3. Use the Excel spreadsheet "Stabilizer Calcs Ft. Bragg.xls" to determine:

a. The proper amount of dilution water for the polymer needed to meet the OMC of the soil. 
b. Cement bag spacing to meet the selected dosage rate by weight of dry soil.

c. Proper Terex 325 speed and Automated Liquid Proportioning System (ALPS) settings to reach the OMC of the soil and the selected dosage rate of the emulsion polymer.

4. Timing of the cement bag placement, compaction patterns, polymer/water refills, and Terex refueling such that a consistent train of cement placement, Terex operation, and compaction is achieved. Compaction is the rate limiter of this process as the compaction must immediately follow the Terex such that cement hydration does not occur prior to compaction of the soil.

The Excel spreadsheet used for calculations of the pertinent variables for the polymer-cement stabilization training is shown in Figure 19. Input variables were apron size (in this case, for a square or rectangle geometry), stabilization depth, maximum soil density OMC, optimum soil moisture content, starting soil moisture content, percent solids of the emulsion, the weight of the emulsion per gallon, the effective lane width of the Terex 325 RS cutter drum, the percent concentration of emulsion and cement desired, and the coverage rate for the polymer cap to be sprayed over the surface. The CMI 325RS speed was also an input variable, but depending on the amount of moisture necessary, may require adjustment to meet the optimum flow rate range of between 30 and 180 gal of water $/ \mathrm{min}$.

Due to a heavy rainfall the evening prior to stabilization training, it was not necessary to add any dilution water to the emulsion polymer. The OMC of the native soil was determined to be approximately 9 percent. Using the spreadsheet in Figure 19 yielded a total of 152 gal of emulsion needed to reach 3 percent emulsion polymer dosage rate for the specified training area. As the emulsion contains water, it contributes 1.62 percent of added moisture to the soil. Approximately 1,450 lb (15 94-lb bags) of cement was required to be added to the soil to meet the 3 percent cement dosage level, 46 gal of emulsion was needed for the surface, and no dilution water was needed. The spreadsheet also calculates the spacing of the cement bags per lane width of the Terex to reach the chosen 3 percent cement concentration for a 6 -in. stabilization depth. The bag spacing in this case was $9.74 \mathrm{ft}$. 
Once the spreadsheet calculations were completed, laying out the grid for the cement bag placement was needed. For the small area needed for training, this was accomplished with flagging. For the liquid application, a 1,500-gal plastic agricultural tank was placed in the back of a MTVR. A 2in.-diam hose was connected from the tank to the pump on the Terex. The liquid was gravity-fed from the tank and pumped by the Terex to the spray bar located inside the mixing chamber of the Terex.

Figure 19. Screenshot of spreadsheet used to calculate pertinent variables for polymer-cement stabilization training using the Terex 325RS. Input variables are in green, outputs in yellow.

\begin{tabular}{|c|c|c|c|c|c|}
\hline \multicolumn{3}{|c|}{ Calculations for Apron 1 stabilization } & \multirow{2}{*}{$\begin{array}{l}\text { Inputs } \\
\text { Outputs }\end{array}$} & & \\
\hline & & & & & \\
\hline \multicolumn{6}{|l|}{ Stabilization Info } \\
\hline Longest length of area, $\mathrm{ft}$ & $50^{\circ}$ & & Width of area, $\mathrm{ft}$ & & 16.5 \\
\hline Depth of stabilization, inches & 6 & & \multicolumn{2}{|l|}{$\%$ starting soil moisture content } & $9.00 \%$ \\
\hline Density of compacted soil, lbs/cu ft & $117^{7}$ & & \multicolumn{2}{|l|}{ Weight of Emulsion, lbs/gallon } & 9.53 \\
\hline$\%$ optimum moisture content of soil & $9.00 \%$ & & \multicolumn{2}{|l|}{ CMI effective lane width, $\mathrm{ft}$} & 5.5 \\
\hline$\%$ solids of polymer emulsion & $46 \%$ & & & & \\
\hline CMI lanes, $5.5 \mathrm{ft}$ wide pass & 3.0 & & \multicolumn{2}{|c|}{$\%$ moisture added from emulsion to soil } & $1.62 \%$ \\
\hline Area to be stabilized, sq.ft. & 825 & & $\%$ mix water needed & & $0.00 \%$ \\
\hline Area to be stabilized, sq. yds. & 92 & & \multicolumn{2}{|c|}{ Mix water to be added to emulsion, gallons } & 0 \\
\hline Volume of soil to be stabilized, cu. ft & 413 & & \multicolumn{2}{|c|}{ Total volume of liquid, gallons } & 152 \\
\hline Volume of soil to be stabilized, cu. $y d s$. & 15 & & Final target water content & & $10.62 \%$ \\
\hline Weight of Soil to be stabilized, lbs & 48,263 & & & & \\
\hline \multicolumn{2}{|l|}{ Calculations for CMI RS 325} & Pump rate, gallons/min & Minimum time, minutes & Estimated time, $\mathrm{hrs}$ & \\
\hline What is the CMI speed in $\mathrm{f} / \mathrm{min}$ ? & 30 & 30.4 & 5 & 0.20 & \\
\hline \multicolumn{2}{|c|}{ Calculations for Polymer Emulsion } & Percent solids in soil & Weight, 1bs & Volume, gallons & $\#$ of totes \\
\hline What percent of emulsion do you want? & $3.00 \%$ & $138 \%$ & 1,448 & 152 & 0.55 \\
\hline \multicolumn{2}{|c|}{ Calculations for Cement Amounts } & Weight, lbs & $\#$ of $94 \mathrm{lb}$ bags & $\#$ of pallets & Bag Spacing, ft/lane \\
\hline What $\%$ of cement do you want? & $3.00 \%$ & 1,448 & 15 & 0.4 & 9.74 \\
\hline \multicolumn{2}{|l|}{ Calculations for Polymer Cap } & Weight, lbs & gallons & \# totes & \\
\hline How many gallons/sq.yd do you want? & 0.50 & 437 & 46 & 0.2 & \\
\hline
\end{tabular}

A stabilization 'train' was then formed with the MTVR in the lead connected by a boom and nurse hose to the Terex. A compactor followed the Terex. The speed of the process was controlled by the Terex. The ALPS unit on the Terex was set to the desired pump rate of $30 \mathrm{gal} / \mathrm{min}$ based on the spreadsheet calculation in Figure 19. The only significant difficulty in this process was the starting and stopping of the Terex. During startup, the pumps must be started prior to engaging the cutter head and lowering to the desired stabilization depth (6 in.). This results in 10-20 gal of liquid spillage. When stopping, the Terex progress must be halted before the cutter head can be lifted, resulting in another small trench at the end of each lane.

The compactors were set to vibrate when going forward and smooth roll (no vibration) in reverse. The compactor should go as slow as possible 
to maximize the amount of energy imparted to the soil that results in densification. A total of 8 passes along each lane was made. It was found through previous work with these small compactors and a similar soil type that after 8 passes across a given point, approximately 95 percent of the maximum compaction was achieved.

The final step was placement of the polymer emulsion 'cap.' The cap was a spray coating of the same emulsion used for stabilization of the soil. It was intended to provide a temporary wearing surface and serve as a weatherproof/dustproof layer over the stabilized soil. The amount of soil stabilizers used in a JRAC scenario is much lower than what is needed for long-term durability. Thus, to provide adequate durability during precipitation, the polymer cap helps keep water from penetrating the surface and weakening the stabilized soil. The cap was placed using a spray device developed for mounting on a High Mobility Multipurpose Wheeled Vehicle (HMMWV) truck and at an application rate of $0.5 \mathrm{gal} / \mathrm{sq}$. yd. The polymer emulsion penetrates approximately 1/8-1/4-in. into the surface. Depending on the level of traffic and use of the apron, the polymer emulsion cap will need to be reapplied as necessary.

\subsubsection{Fiber-cement stabilization}

The specific steps needed to conduct the fiber-cement stabilization are as follows.

1. Selection of stabilizer amounts. For this training, 0.4 percent fibrillated polypropylene fibers and 4 percent Type III (high-early strength) cement by weight of soil were chosen.

2. Soil OMC for compaction and soil moisture levels are needed prior to construction.

3. Use the Excel spreadsheet "Stabilizer Calcs Ft. Bragg.xls" to determine:

a. The proper amount of water needed to meet the OMC of the soil.

b. Cement and fiber bag spacing to meet the required dosage rate by weight of dry soil.

c. Proper Terex 325 speed and Automated Liquid Proportioning System (ALPS) settings to reach the OMC of the soil. 
4. Timing of the cement and fiber bag placement, compaction patterns, water refills, and Terex refueling such that a consistent train of cement placement, Terex operation, and compaction was achieved. Compaction is the rate limiter of this process as the compaction must immediately follow the Terex such that cement hydration does not occur prior to compaction of the soil.

A modified version of the spreadsheet used for polymer-cement stabilization was used for calculations for fiber-cement stabilization (Figure 20). Due to a heavy rainfall the evening prior to stabilization training, it was not necessary to add any water to the soil. The OMC of the native soil was determined to be approximately 9 percent. Using the spreadsheet in Figure 20, approximately $200 \mathrm{lb}$ of fiber, 1,950 lb (21 94-lb bags) of cement were required to be added to the soil, and $46 \mathrm{gal}$ of emulsion were needed for the surface. The spacing of the fiber bags was $15.5 \mathrm{ft}$ and $7.3 \mathrm{ft}$ for the cement bags.

The fibers were placed first and tilled into the soil followed by placement of the cement bags and a second pass of the Terex to blend in the cement. After a review of this process, it was noted that the extra time necessary for a second pass of the Terex to complete an aircraft parking apron was several hours. To meet the strict JRAC timelines for the Fort Bragg parking apron construction, only a single pass of the Terex could be used. This was an important point that was highlighted during the training.

A second aspect of doing multiple passes of the Terex was the 'defibrillation' of the fibrillated fiber. The fibers appear as a strand of black tape approximately $1 / 16$-in. wide by 2 in. long. The tape actually consists of many small fibers connected at various points such that, when it 'defibrillates,' it appears web-like with a network of fibers connected together. However, it was noted during testing of this fiber that it required multiple passes of the Terex to cause defibrillation of the fiber. The defibrillation should result in more efficient fiber utilization. However, given that multiple passes are required to achieve this condition, further work using these types of fibers for rapid construction is not recommended. 
Figure 20. Excel spreadsheet used for fiber-cement soil stabilization calculations for training.

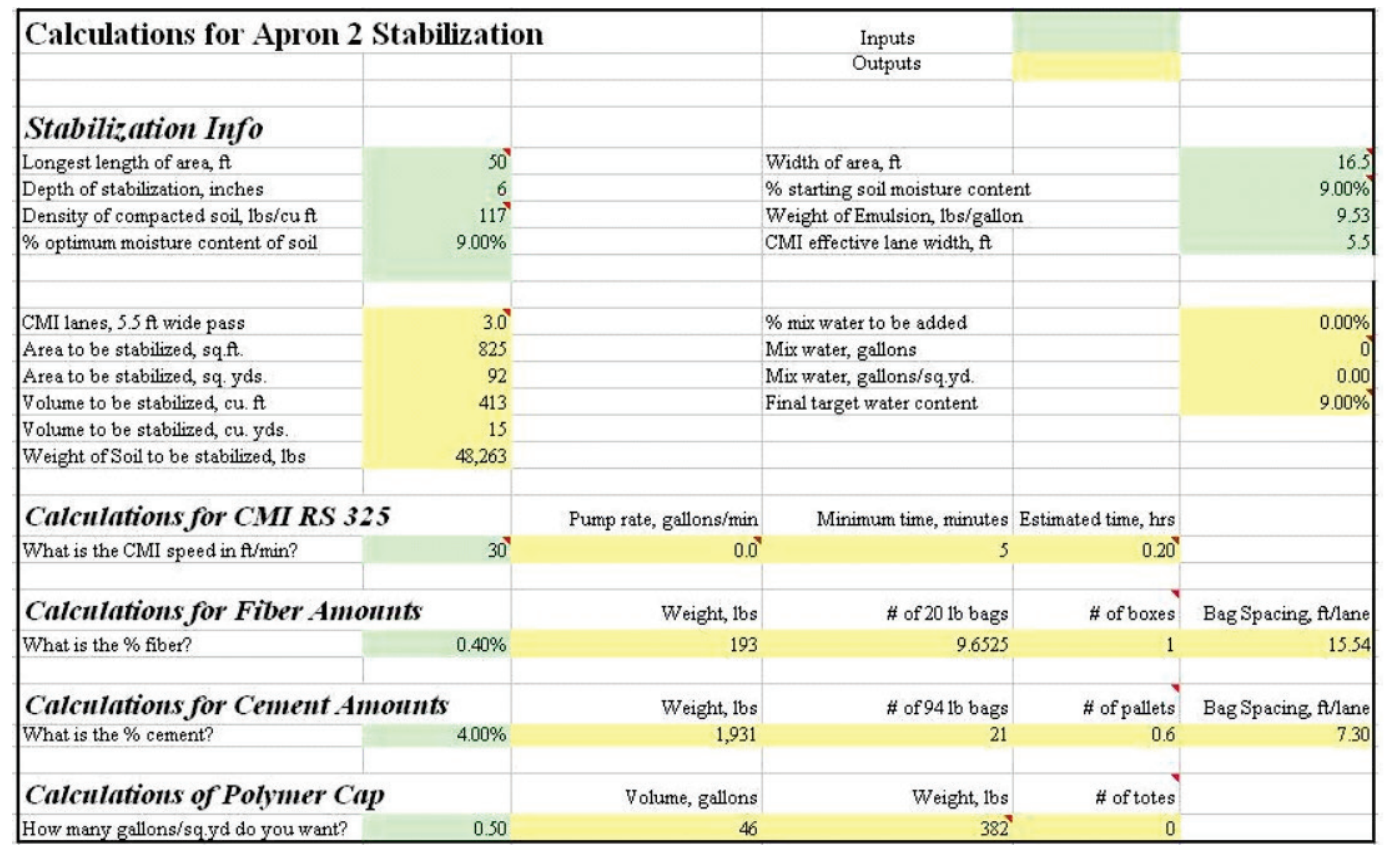

\subsubsection{Dust control training}

Dust control training consisted of operation of the HMMWV sprayer, the use of emulsions and synthetic oils, and cleanup. Cleanup is extremely important with the emulsions as they may dry and clog in the spray wand. This is not a problem with synthetic fluid. Operation of the HMMWV sprayer is simple, requiring a HMMWV driver and a passenger to control the sprayer. Calibration of the sprayer requires the driver to operate at a consistent speed such that the flow rate of the nozzles can be adjusted to achieve the target application rate. In this case, the application rate was 0.25 gal per square yard. The flow rate was measured by pumping the dust control liquid into 5-gal buckets and measuring the time necessary to fill the buckets. The HMMWV speed was then measured and the flow rate adjusted to meet the application rate, taking into account the total width of the spray pattern. The driver must ensure that a slight overlap with adjacent lanes occurs to achieve a double overlap spray pattern. Cleaning was simple with ample water flushing but must be conducted as soon as the spray operation stops with emulsions to prevent clogging. 


\section{JRAC Demonstration Exercise}

\subsection{Overview}

The 2004 JRAC demonstration consisted of a series of activities, each highlighting the functionality of each technology described in Chapter 2. The intent of the exercise was to allow the soldiers to autonomously execute the mission without assistance or direction from the ERDC or contract support agencies. This allowed the ERDC team to evaluate the effectiveness of the training and technologies so that both could be improved for a future demonstration in 2007.

\subsection{Demonstration tasks}

The demonstration began at 00:30 July 12, 2004, under blackout conditions (Figure 21). This was to assess how well the sight-intensive tasks could be accomplished in the dark, and to prove that the activities could be conducted under cover of night for increased protection. Beginning with the deployment of the survey team and the RAVEN, the following tasks were accomplished in a 75-hr period as they coincided with the major research areas within the JRAC program. A detailed timeline of the sequencing of events is presented in Table 1. Daily construction reports and test data from the field can be found in Appendix C. Detailed descriptions of the demonstration tasks are provided in the following sections.

\subsubsection{Site assessment}

1. Topographic survey of apron sites and the surrounding taxiway using the RAVEN and hand-held GPS devices.

2. Collection and testing of soil samples to determine soil classification and in-situ moisture content.

3. Estimation of moisture-density, CBR, and water requirements for the materials on Aprons 1 and 2. 
Figure 21. RAVEN deployed at 00:30 to Sicily LZ jobsite.

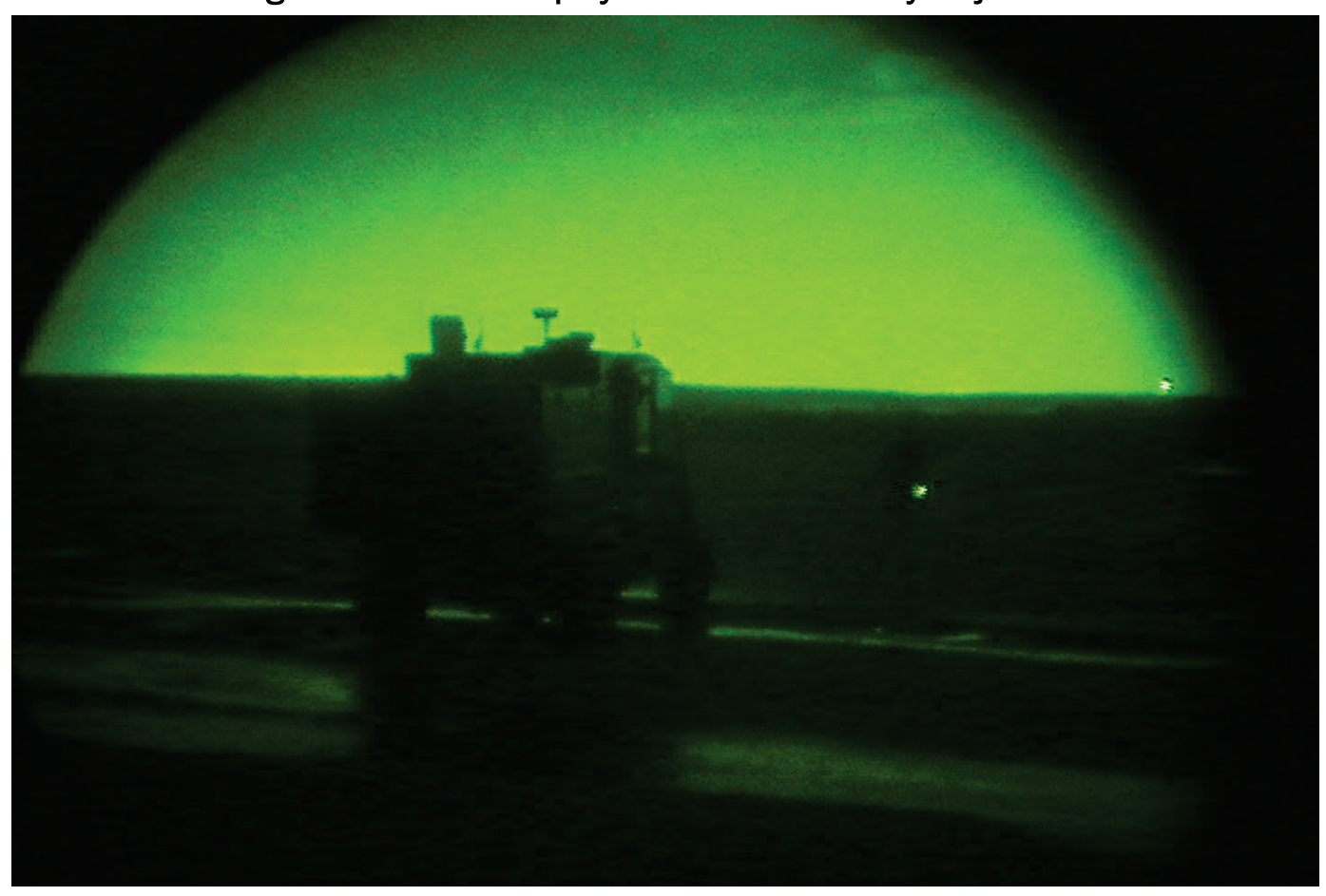

\subsubsection{Enhanced construction}

1. Terramodel design of Aprons 1 and 2 including balanced cut and fill and drainage basins.

2. Uploading of digital designs to construction vehicles.

3. Clearing and grubbing of Apron sites 1 and 2.

4. Leveling to finished grade by cutting Apron 2 and filling Apron 1, including construction of drainage basins.

\subsubsection{Soil stabilization}

1. AceMat installation on rear half of Apron 1.

2. Polymer/Cement stabilization on front half of Apron 1.

3. Fiber/Cement stabilization on all of Apron 2. 
Table 1. JRAC demonstration construction timeline.

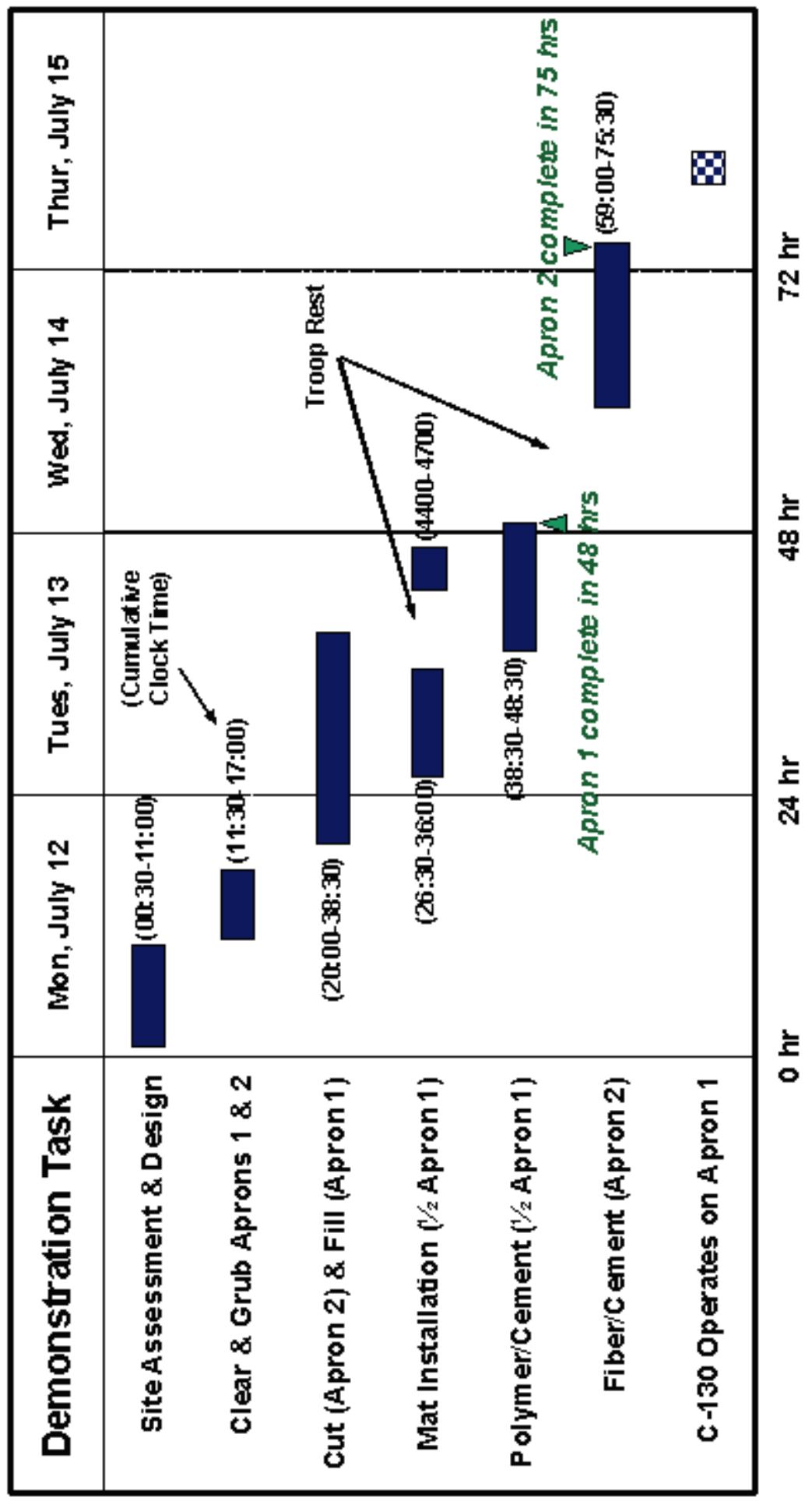




\subsubsection{Supply and logistics}

Most of the supplies and equipment necessary to perform the exercise were staged onsite prior to the start of the demonstration. Appendix D provides a detailed listing of all equipment required for the demonstration. All of the raw construction materials, construction equipment, and rental support equipment were staged at the Sicily LZ in the week prior to the exercise.

Safety considerations were always at the front of consideration during planning and execution of this mission. The 37th Engineer Battalion provided a Combat Medic to address any medical issues immediately on the site as well as their emergency and evacuation Standard Operating Procedures for range operation on Fort Bragg.

Heat was the primary health concern during the operation since the demonstration occurred in mid-July. One soldier was treated for mild heat exhaustion during the exercise. The soldier had been recovering from an illness prior to participation.

Since this was a 24-hr operation, an adequate number of flood lights were used during the construction phase. Continuous night operations were paramount. Construction plans were adjusted after daytime installation of the MP mats began to negatively impact the soldiers' performance due to the heat. It was quickly noted that the soldiers performed better during the night operations as opposed to the day operations due to cooler temperatures.

\subsection{Site assessment}

The JRAC exercise commenced at 00:30 hours July 12, 2004. The JRAC exercise began with the launching of the RAVEN from the staging area driven by two EQS soldiers. The RAVEN was driven to an area situated between the two potential apron construction sites based on satellite imagery to begin setup of a GPS base station geodimeter. Site assessment continued through the night under blackout conditions using only chem-light lightsticks (KEM) and dampened LED lighting systems located in the RAVEN toolboxes. 


\subsubsection{Topographic survey}

Day 1: 00:30-01:30

The base station and geodimeter calibration were both established under blackout conditions using only limited light sources from KEM lights and dampened LED lighting systems located in the RAVEN toolboxes. The assembly process of the base station was completed within $1 \mathrm{hr}$ of RAVEN deployment.

Day 1: 01:30-06:00

The survey of the site was performed in two stages after the base station was established. The first stage involved assigning a team of soldiers with a survey rod to shoot points along important boundaries of the airfield site such as the taxiway edges and connecting roads, and berms in the proximity of the aprons. The second stage began at approximately the same time as the manual survey and involved driving the RAVEN across the site to collect topographic data for areas in which apron construction was to occur. The RAVEN was driven across the apron and taxiway areas taking survey shots every 3 m over approximately 25 acres $(0.101 \mathrm{~km})$ of surface area.

Although blackout conditions were specified, the uneven ground of the apron site required the use of the forward lighting systems on the RAVEN to safely navigate the vehicle across the terrain. The survey process took approximately $4 \mathrm{hr}$ between the two stages, ending at 05:30 hours in the early morning, at which point the manual survey was completed.

At 06:00 the soldiers were remobilized back at the RAVEN vehicle to begin soil processing (described in following section) and reduction of topographic shots into the TerraModel program. Both tasks were performed simultaneously on the RAVEN with the soil classification team operating on one side of the RAVEN using the RSAK and the design team working on the other side of the RAVEN with a Toughbook and an additional portable laptop to reduce the topographic data.

An engineering specialist with the $412^{\text {th }}$ ENCOM reduced the topographic data. An engineering specialist is required to perform this task. A high level of expertise in Terramodel is necessary to correct any errors in the survey and to produce a valid geometric design to import to the GPS- 
enabled construction vehicles. Terramodel was used for the cut and fill estimation and elevation design plan of the site.

\subsubsection{Soils classification}

\subsubsection{Soil sampling}

Day 1: 00:30-01:15

As the GPS base station was being setup, a team of four soldiers (ESQs) were deployed to gather soil samples from the general areas in which apron construction was to occur.

The ESQs equipped themselves with a shovel, KEM lights, sample containers, marking posts and ribbon, and proceeded on foot to each apron. General apron locations were identified from satellite photographs of Sicily LZ. The soldiers were instructed to go out into the general area identified as being the location for each apron and take four soil samples per apron and retain them in separate sample containers for later analysis.

The operation required the soldiers to dig a test pit approximately 6 to 12 in. deep at each of three locations triangulated about the center point of each potential apron site (Figure 22). The test pit depth provided soil samples that were sufficiently below the organic surface material and most likely representative of the scarified soil surface to be stabilized after clearing and grubbing. At each test pit, soil was scooped into a sample container for later determination of moisture content. The fourth sample was a separate container filled approximately in thirds with soil taken from each test pit dug for a specific apron. This average soil sample was later used to determine the average grain size distribution, plasticity, and soil classification for the apron.

Once each test pit was sampled, they were marked by a stake, ribbon, and KEM light so that a manual GPS shot could be taken of the test pit location for later referencing. Once Apron 1 was completed, Apron 2 was sampled in a similar fashion. All soil samples were labeled and taken back to the RAVEN for storage and later processing at dawn. The sampling of the soil took approximately $45 \mathrm{~min}$. Once the soil sampling was complete, those soldiers then assisted in the GPS survey of the site. 
Figure 22. Digging of soil test pits for sampling using KEM lighting.

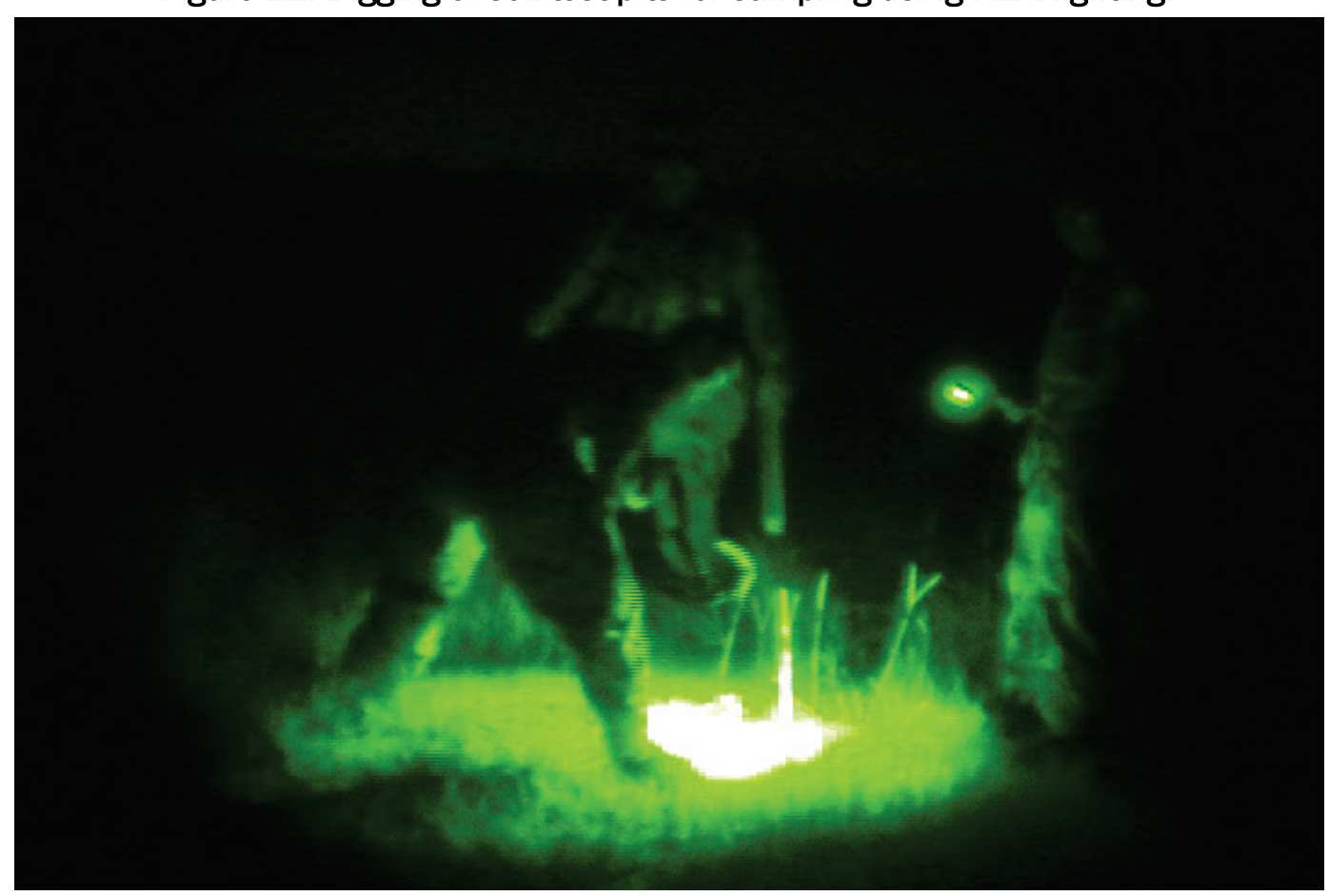

\subsubsection{Soil processing}

Day 1: 06:45-09:00

Under the morning light, the soil sampling team began processing the soil taken from each apron. This process took approximately 75 min per apron to classify and establish in-situ moisture conditions. This time was divided into two parts: approximately 55 min to classify the soil following the steps outlined in Appendix $\mathrm{C}$ and 20 min to perform moisture content analysis for each of the three samples taken from each apron (Figure 23).

Soil classification was performed using the average soil sample by drying, pulverizing, splitting out 100 to $150 \mathrm{~g}$ of dried soil and placing it through the required sieves in two equal portions ( 50 to $75 \mathrm{~g}$ ), sieving for $4 \mathrm{~min}$, and recording the weights of the filled sieves in the Classification 1.0 program on the Toughbook. Soil passing the \#40 sieve was collected to perform the plastic limit test. The plastic limit test revealed the in-situ soil was non-plastic and was similar for both aprons. A non-plastic soil has a PI equal to zero. A location and label for each sample was recorded to allow later referencing to the GPS shots taken at the sample pits. 
Figure 23. Operation of RSAK on samples soils.

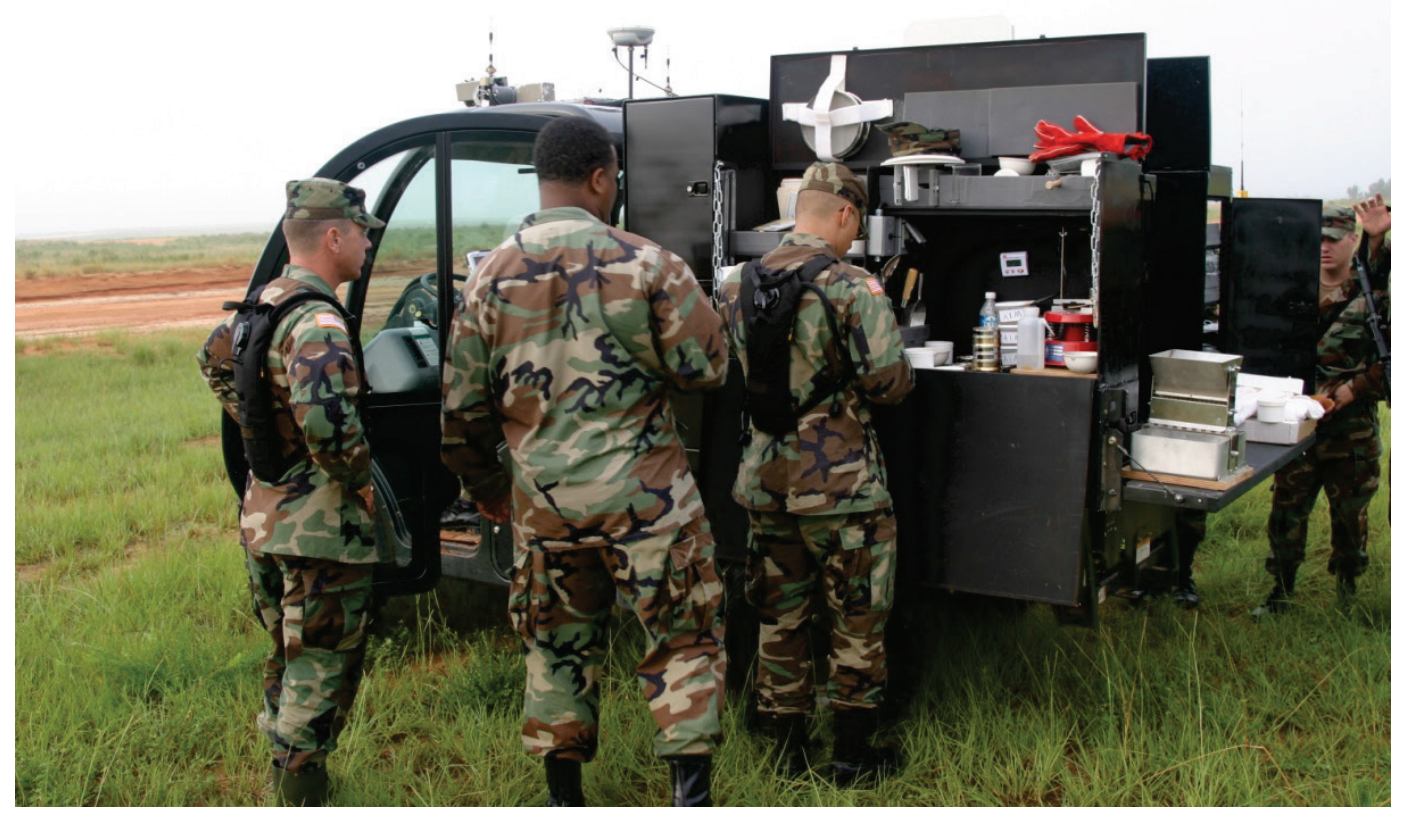

The computer program Classification 1.0 performed the Unified Soil Classification System (USCS) analysis on the data inputs, resulting in a non-plastic silty-sand (SM) soil type along with the appropriate compaction curve indicating the maximum dry density and moisture content for a standard proctor compaction effort. The analysis produced similar soil classifications for both Aprons 1 and 2; however, variability in the grain size distribution created differing moisturedensity curves for the two aprons as shown in Figure 24 and Figure 25. Figure 26 and Figure 27 show the corresponding CBR curves for ascompacted conditions determined from the program.

Moisture content was recorded for each of the three samples taken from Apron 1 and 2. An average of the three readings provided the in-situ moisture content used for determining water requirements for the stabilization and compaction. Apron 1 had an average moisture content of 6.1 percent, and Apron 2 had an average moisture content of 3.2 percent.

The moisture contents revealed that additional water must be brought to the site to achieve a dry of optimum compaction condition at 98 percent of standard proctor for both aprons, with Apron 2 requiring the most water. A rain shower occurring in the evening prior the start of the demonstration increased the water content on the low-lying Apron 1 
as determined from preliminary moisture contents taken in the days leading up to the project. However, little change in moisture occurred for the upland Apron 2. The rainfall raised the in-situ moisture content sufficiently on Apron 1 such that only minimal quantities of water were necessary to reach optimum (9.0 percent) and to hydrate the cement for the cement-polymer stabilization. Apron 2 contained a finer gradation of soil requiring considerable quantities of water to be brought in to meet optimum moisture conditions (9.7 percent) for construction along with additional water for hydration of the higher cement concentration placed on the cement-fiber stabilized section.

Figure 24. Standard Proctor moisture-density curve for Apron 1.

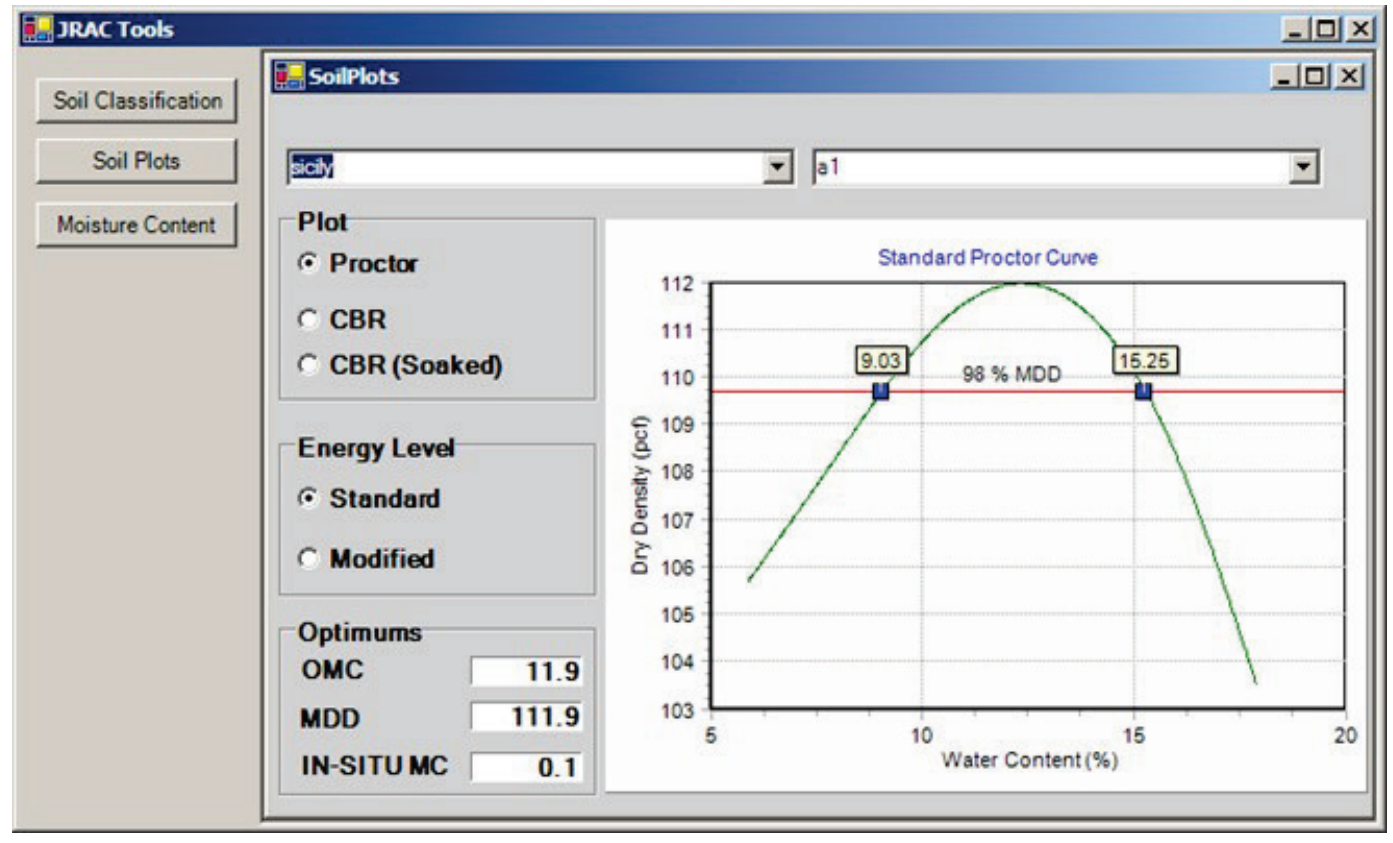


Figure 25. Standard Proctor moisture-density curve for Apron 2.

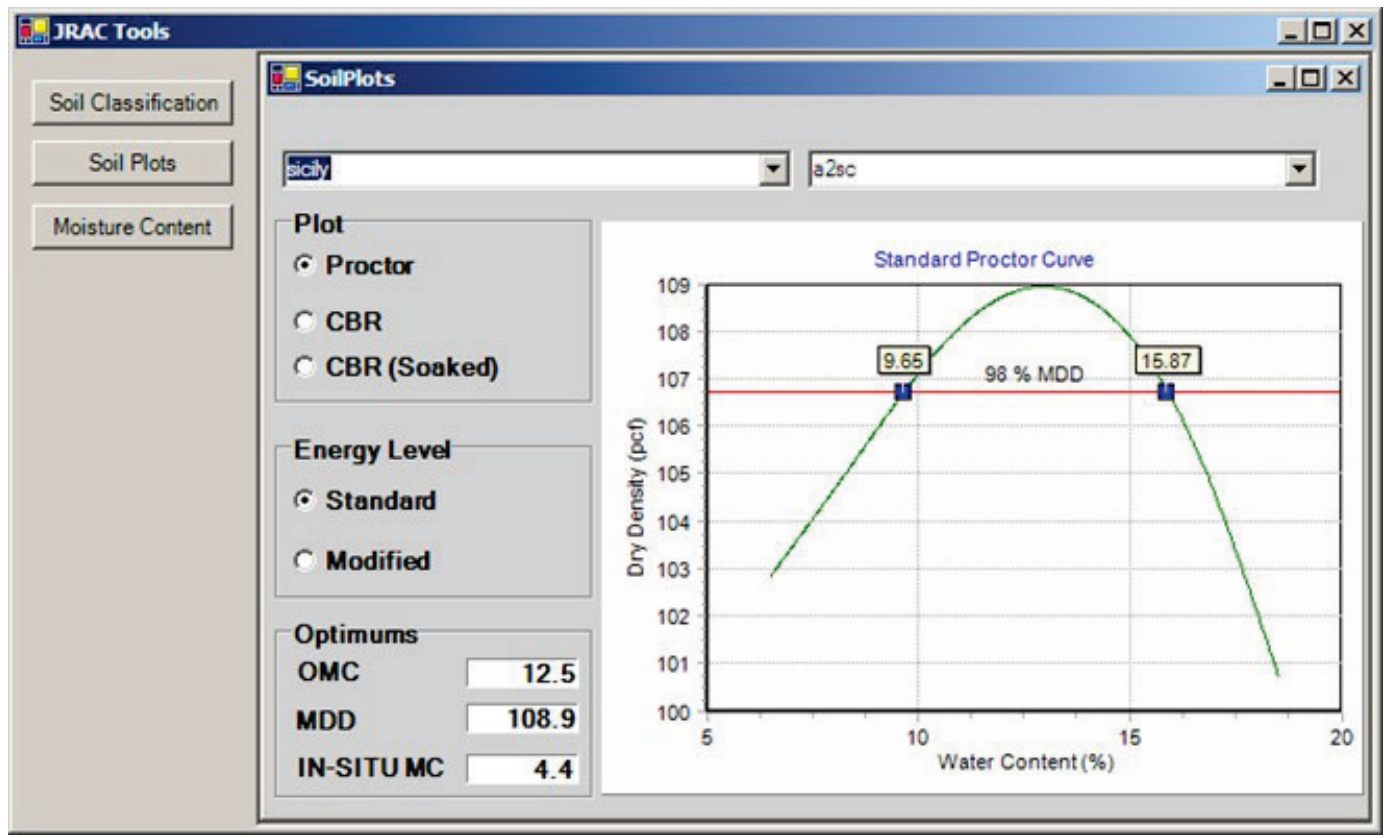

Figure 26. Unsoaked CBR design curve for Apron 1.

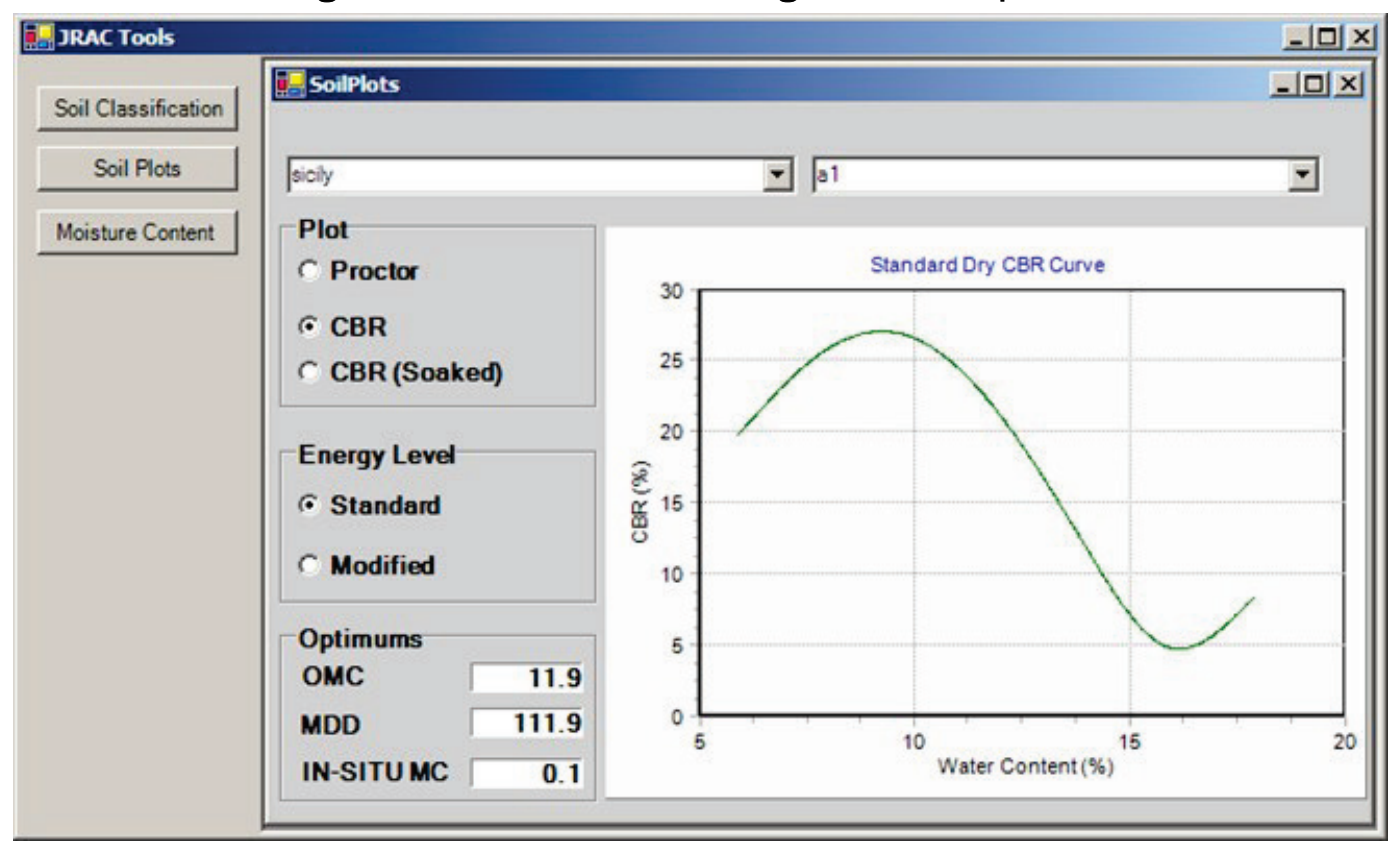


Figure 27. Unsoaked CBR design curve for Apron 2.

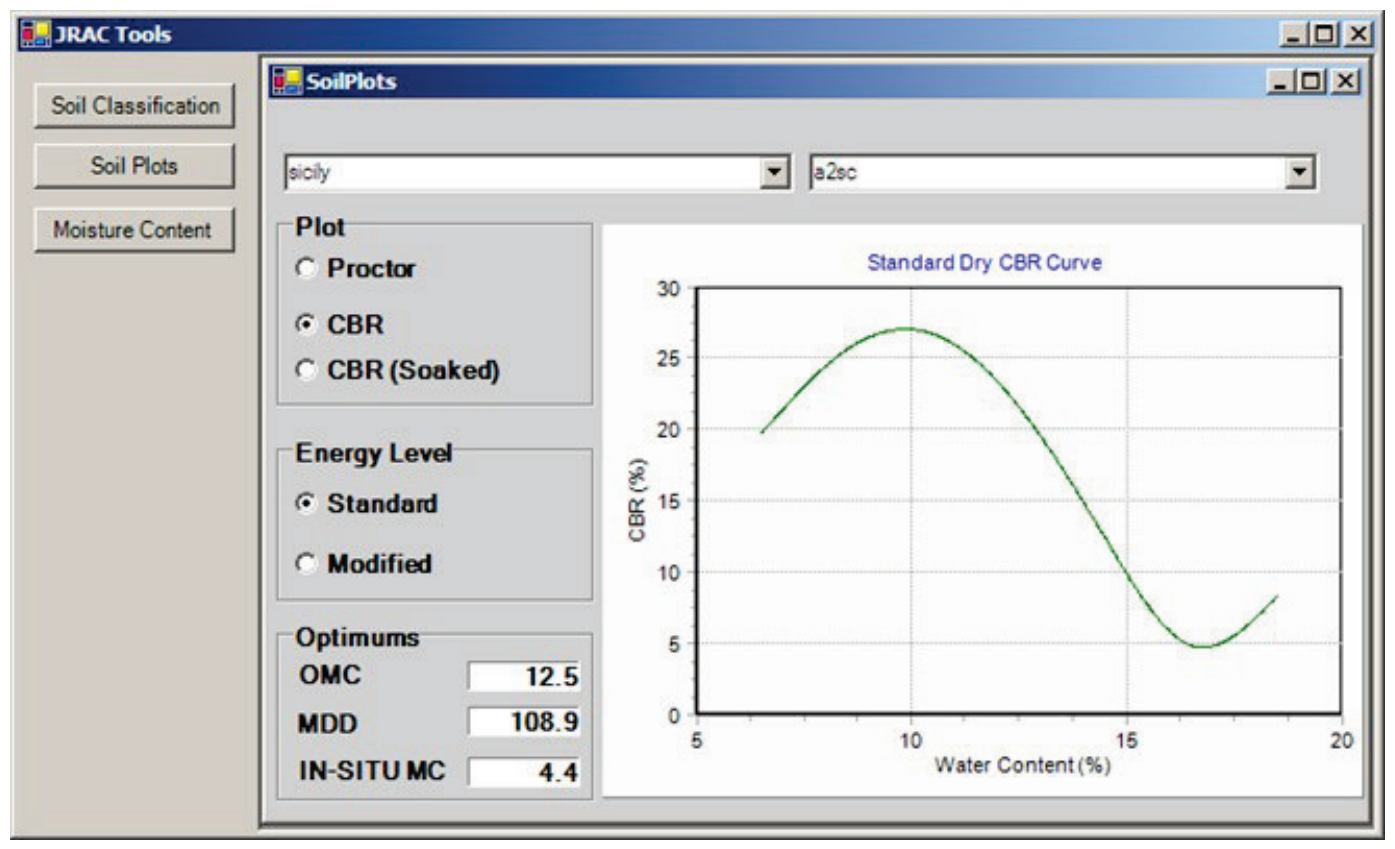

\subsubsection{Soil strength analysis}

To determine the baseline structural characteristics of the site, it was necessary to establish the in-situ strength using the dynamic cone penetrometer (DCP). The DCP correlates with the CBR, a soil parameter that is the basis for pavement design work for the Department of Defense (Webster et al. 1992). CBR is expressed as a percentage based on the strength of the soil relative to a crushed limestone aggregate.

For brevity in this report, the percentage designation for CBR will be absent. For the design of airfields using matting systems and stabilized layers, the in-situ and as-built CBR are important parameters. The insitu CBR establishes whether stabilization is required. The stronger the in-situ material, the less preparatory work is needed to make the site sustainable for a contingency airfield effort. Nowhere is it more important to establishing the structural characteristics of the foundation material than for contingency construction, where all effort should be made to take advantage of the natural conditions of the site minimizing the need for mechanical improvement.

Manual DCP testing conducted on Sicily LZ in the days prior to the JRAC demonstration provided a DCP profile with depth, suggesting an average CBR of approximately 10 in the upper layers of the silty-sand material with some clay pockets ( 2 to 3 feet) at depth on Apron 1. This JRAC 
demonstration required an airfield design capable of handling 500 passes of a C-130 aircraft. To achieve this, a 6-in. layer of stabilized material over a CBR 10 subgrade was required to provide adequate support for the $\mathrm{C}-130$ operations. In areas where only matting was to be used, JRAC design criteria required a minimum CBR 20 for the subgrade. Therefore, it was determined that compaction of the top 6 in. of the scarified surface required only six passes of the Caterpillar 433 vibratory roller to provide a CBR 20 material based on moisture-density-strength curves during the soil classification procedure. Eight passes were deemed necessary for proper compaction of the stabilized layers as described later in the report.

\section{Day 1: 12:00-13:30}

This pre-site inspection work was performed using the concept of having some initial site selection data available prior to actually deploying the RAVEN. With the RAVEN in place, the soil strength was established during the demonstration using the automatic DCP on Aprons 1 and 2 to a depth of at least 2 feet (Figure 28). DCP results taken at the Apron 1 site (Figure 29) and Apron 2 site (Figure 30) show that on average, a 6 CBR was found in the upper 3 in. of soil; a 10 to 20 CBR between depths of 3 and 7 in.; and a 20 to 35 CBR between depths of 7 and 14 in. Since the top 6 in. would be removed from the surface on Aprons 1 and 2, the remaining subgrade soil would be at a CBR of at least 10 or greater.

For the matted portion of Apron 1, six passes of the roller were used to compact the scarified surface to increase the soil strength to a minimum CBR of 20. For Apron 2, all the soil beneath the upper 6 in. was found to have a CBR in excess of 10 , requiring no further ground improvement through compaction to meet the subgrade requirements of the cementfiber-stabilized layer design. 
Figure 28. DCP tests being conducted on Apron 1 prior to construction.

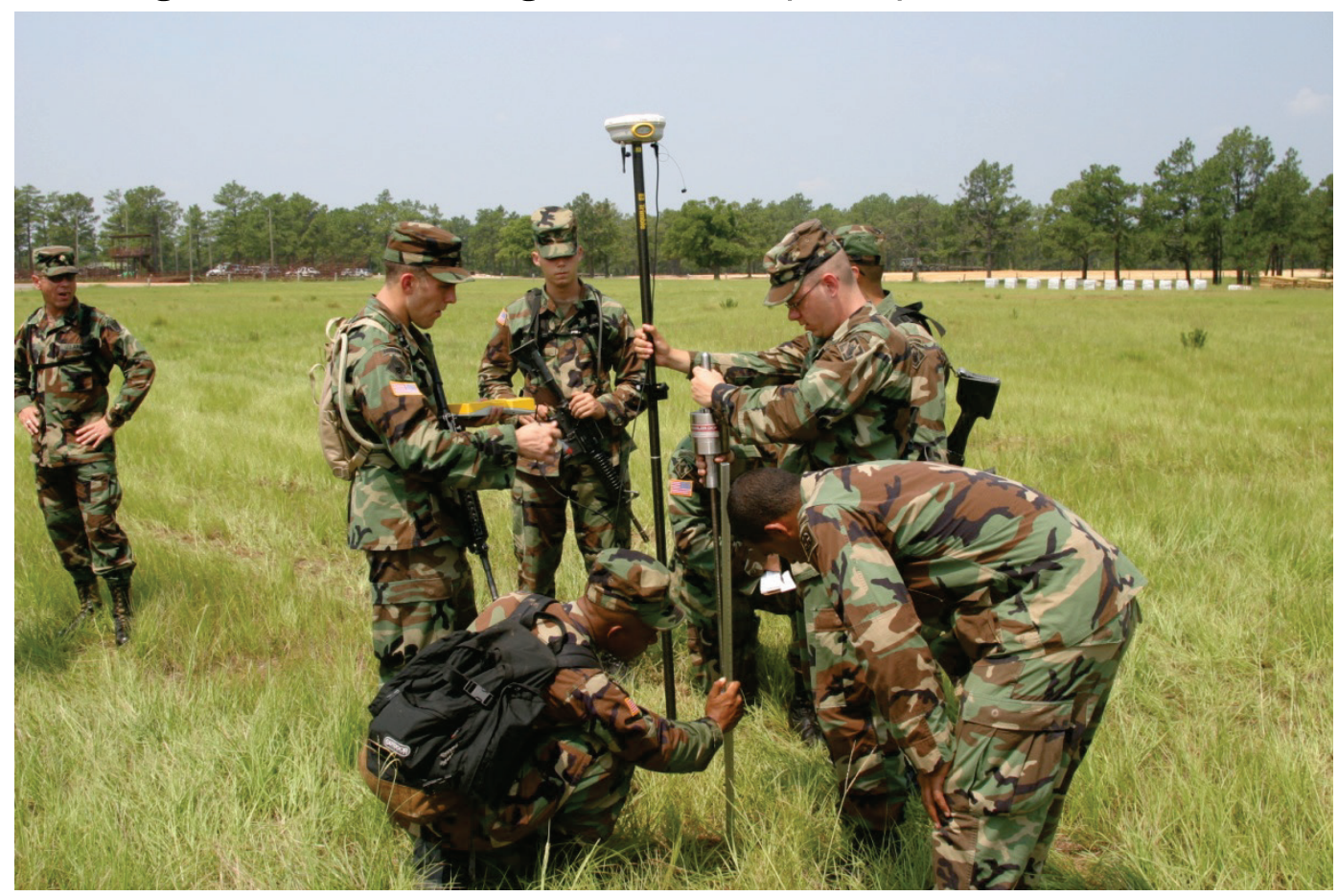

Day 4: 00:00-03:30

DCP testing was also used for quality assurance (QA) to verify that the CBR of the stabilized layer was a minimum of 30 to satisfy the Air Force Special Tactics (STS) team, who requested this before allowing trafficking of the $\mathrm{C}-130$ aircraft. This was conducted early in the morning on July 16, approximately $24 \mathrm{hr}$ after completion of stabilization of Apron 1 and less than $12 \mathrm{hr}$ before touchdown, owing to the JRAC timeline that the surface would sustain C-130 operations 24 hr from the completion of construction.

The plot of CBR with depth in Figure 31 shows that the CBR measured on the stabilized surface had been improved considerably. In the upper 6 in. of the stabilized material, the CBR had been increased from an average surface value of 6 to a CBR of 50 and the compaction process produced residual strength increases at depths below 6 in., bringing the CBR strength up from between 20 and 35 up to a minimum of 35 . This was more than sufficient to supply the required strength necessary to support both matted and stabilized C-130 operations for the design JRAC condition of 500 passes. DCP data were not collected on the cured stabilized layer on Apron 2 due to difficulty inserting the rod into the hardened cement surface. 
Figure 29. CBR averages for Apron 1 before construction for top 24 in.

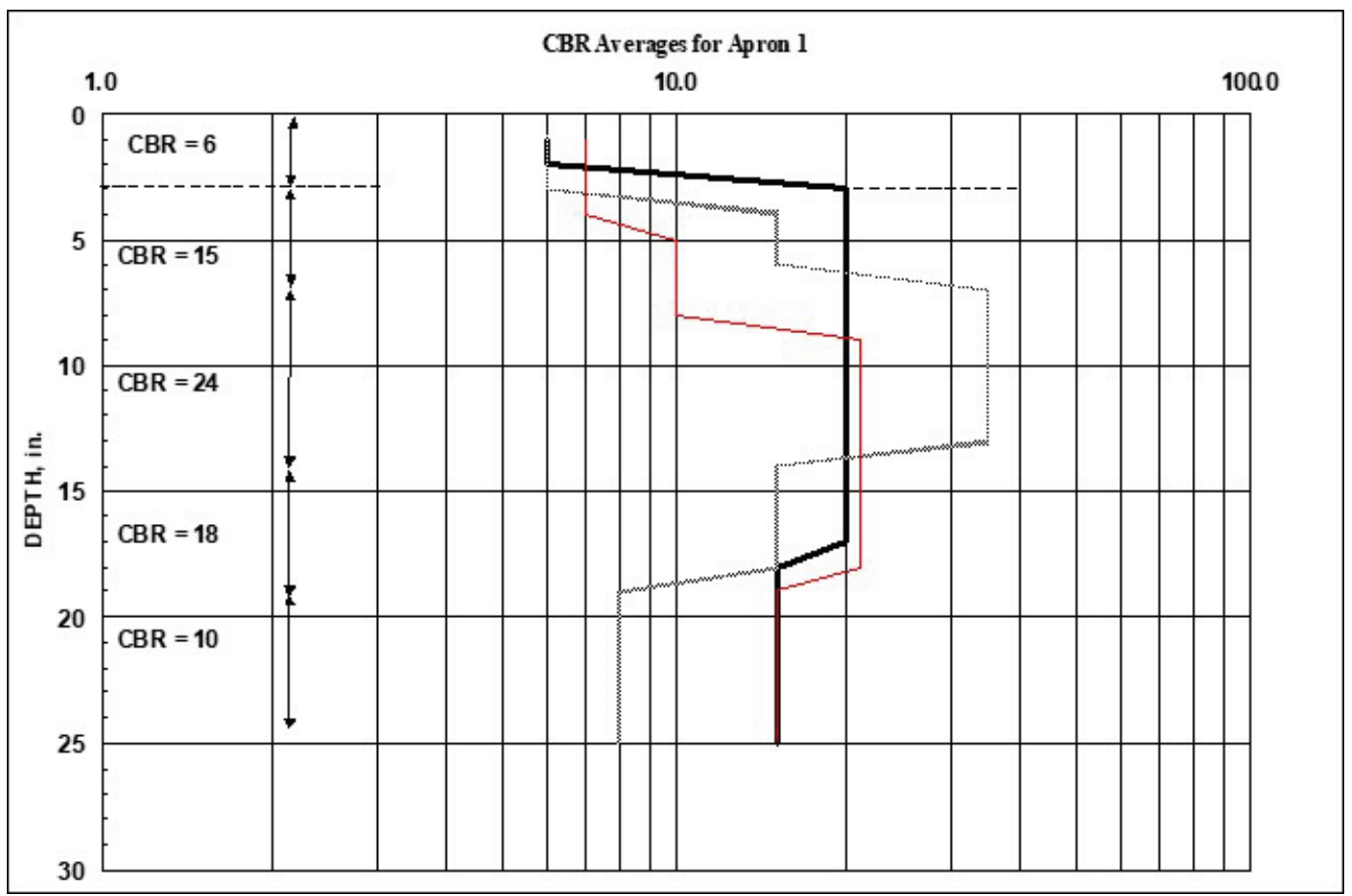

Figure 30. CBR averages for Apron 2 before construction for top 24 in.

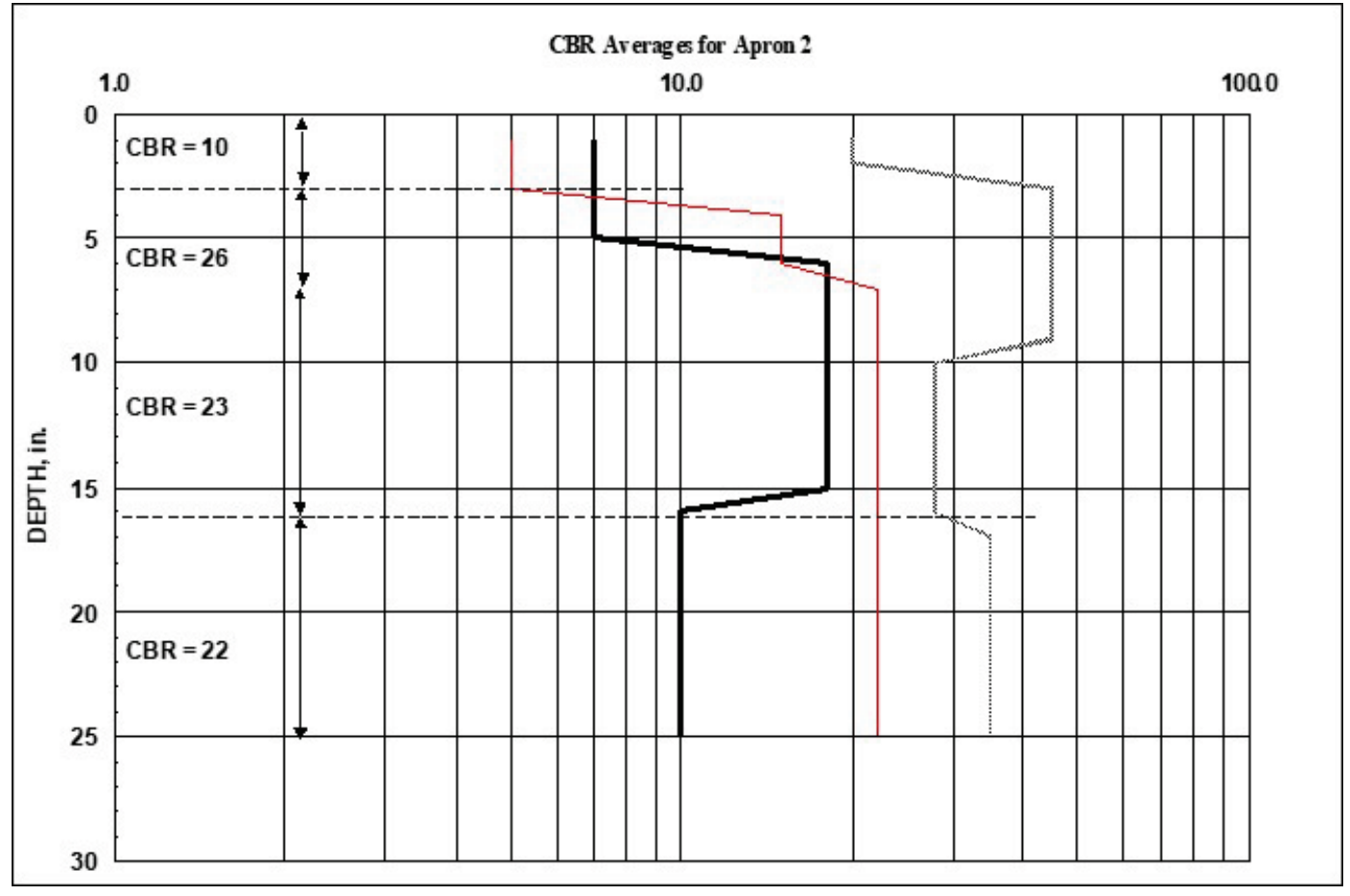


Figure 31. CBR averages for Apron $124 \mathrm{hr}$ after stabilization to a depth of $24 \mathrm{in}$.

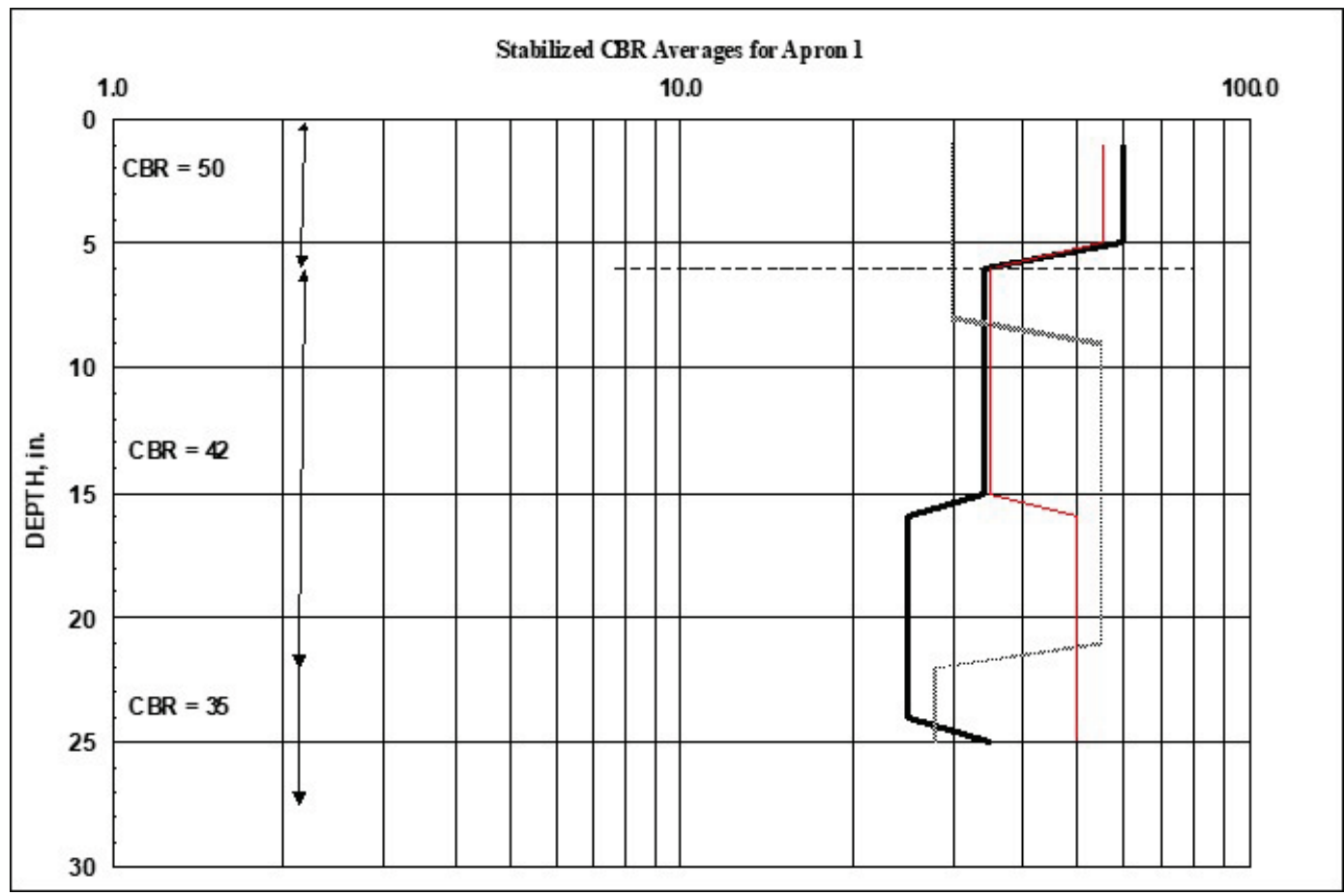

A design analysis using the ERDC Pavement-Transportation Computer Assisted Structural Engineering (PCASE) software system was performed on Apron 1 to demonstrate the significant improvement in contingency C130 operations obtained by stabilizing the apron. Assuming a contingency $\mathrm{C}-130$ load of 175, ooo $\mathrm{lb}$, the initial site would only support approximately 7 passes of a $\mathrm{C}-130$ before rutting would render the site unusable, limiting its effectiveness. However, following stabilization, the structurally improved apron could support over 5,000 passes of a C-130, more than sufficient to meet almost any mission requirement.

\subsection{Enhanced construction}

\subsubsection{Geometric design}

Day 1: 06:30-11:30

Survey operations were complete by 06:00 on the first day at which point the 21T survey technicians began analyzing the survey data in Terramodel (Figure 32). Using preformatted apron templates that defined the trapezoidal surface geometry designed prior to the JRAC exercise, a balanced cut and fill was made between the location of Apron 1 (requiring fill) and Apron 2 (requiring cut). Further, drainage areas were designed around the apron perimeters. The design process required approximately 
$4 \mathrm{hr}$ to complete, followed by time to download the design elevations onto flash memory cards to be inserted into the onboard RTK-GPS systems. This task required about $1 \mathrm{hr}$ as soldiers had to enter the digital design onto flash memory cards individually (Figure 33). This task was completed, and cards were loaded into the earthmoving equipment at about 11:30. At that point, the earthmoving equipment was then ready to move to Apron 1 to commence clearing and grubbing.

Figure 32. Analysis of survey data to obtain Terramodel design.

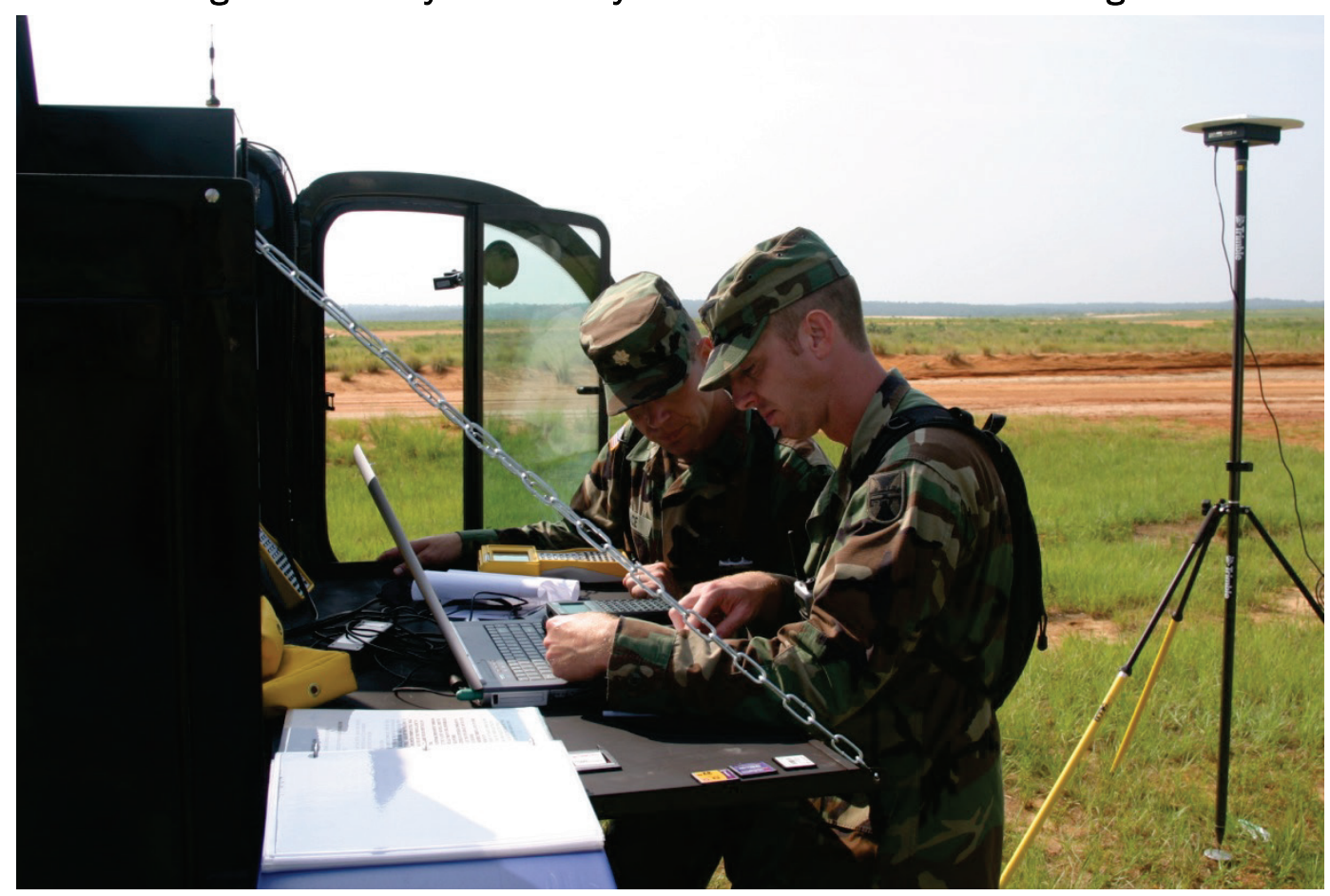


Figure 33. Uploading of digital design onto flash memory cards.

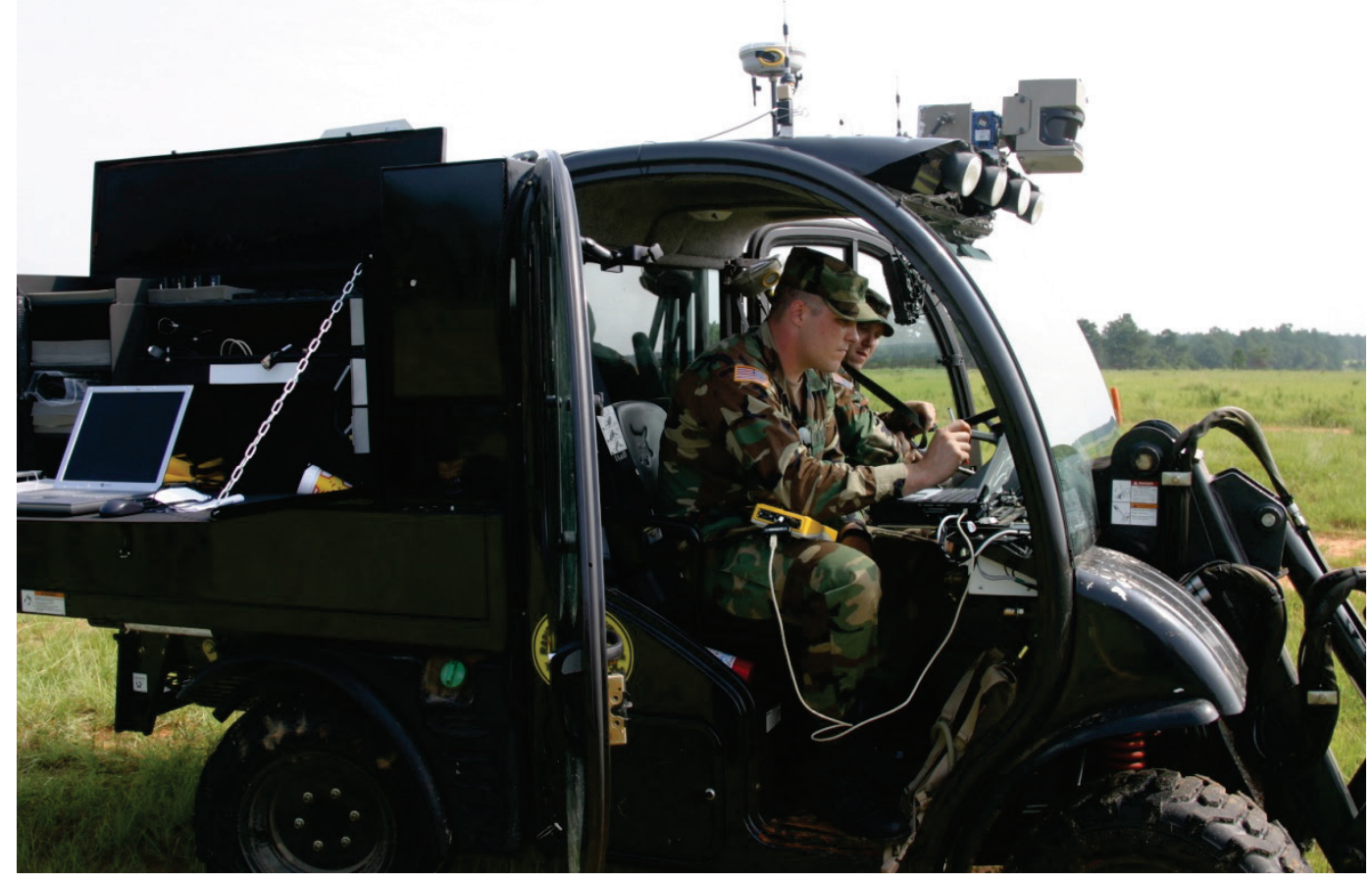

\subsubsection{Uploading digital designs and clearing/grubbing}

Day 1: 11:30-17:00

Earthmoving began with uploading of the finished digital Terramodel design at approximately 1130 . Once upload was complete, the vehicle operators could see a display of the vehicle position on the jobsite along with a color-coded screen indicating where cut or fill was required based on current elevations (Figure 34). 
Figure 34. On board display showing vehicle position and elevation data.

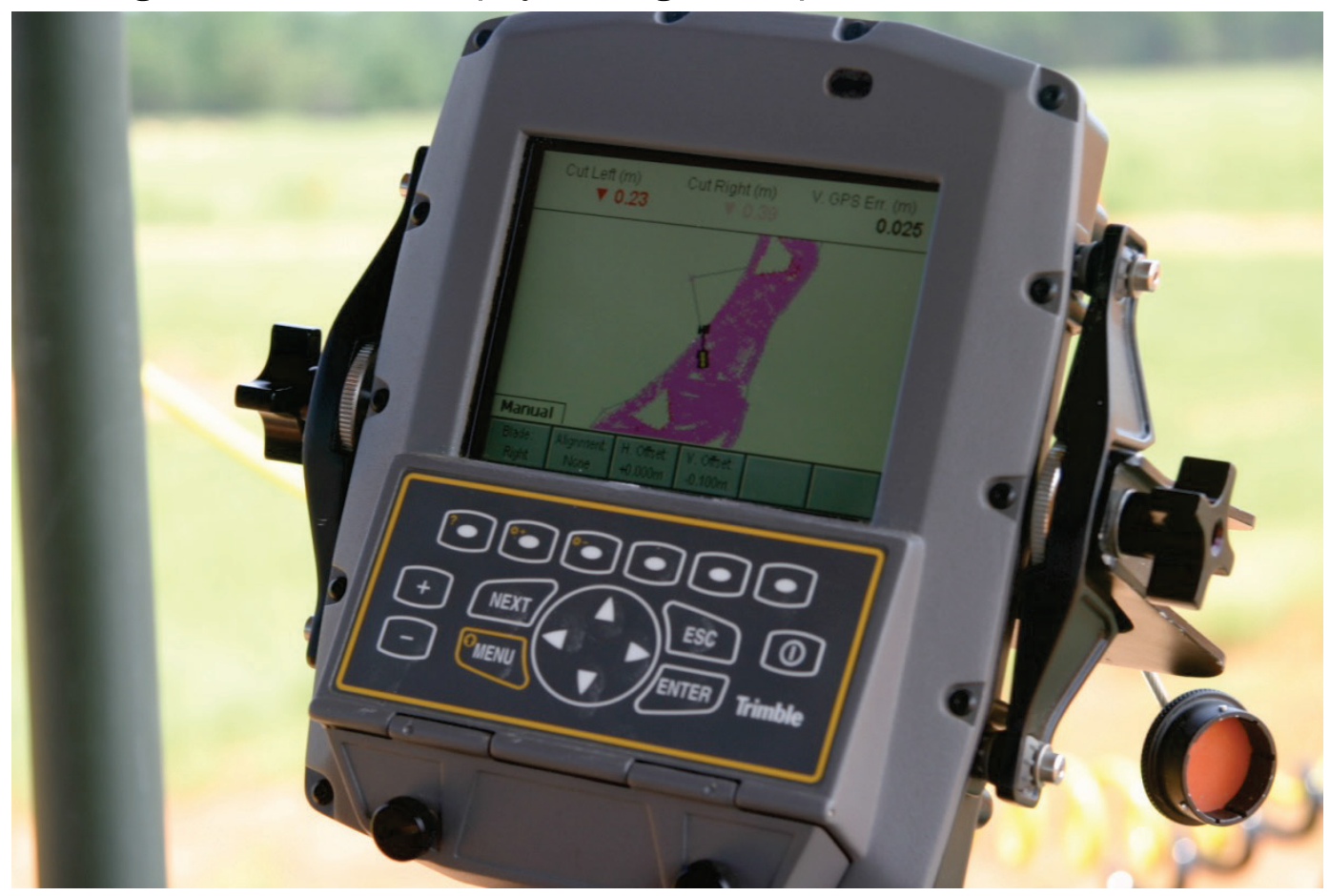

The motorgrader, DEUCE, and scrapers (Figure 35) were first deployed to Apron 1 to begin clearing and grubbing of the natural ground surface (Figures 36-38). The ground surface was relatively flat and devoid of trees, allowing earthmoving to progress quickly. A small slope was present for natural drainage away from the taxiway and, therefore, to bring the apron up to a level surface, some fill was required with the fill material originating from material cut from Apron 2. Additionally, a drainage basin was required to be cut into the perimeter surrounding the apron to allow proper drainage of surface water to keep it from ponding on the apron and adjoining taxiway due to a slope into which the apron was built. As noted previously, final grade on Apron 1 required fill taken from Apron 2 , so there was a delay in achieving final grade until enough cut occurred on Apron 2. However, a majority of the grading and the completion of the drainage basin occurred by roughly 14:40, a time span of only $3 \mathrm{hr}$ to clear, grub, and level a 1-acre $\left(3,600 \mathrm{~m}^{2}\right)$ area. 
Figure 35. Deployment of RTK-GPS-enabled construction equipment to Apron 1.

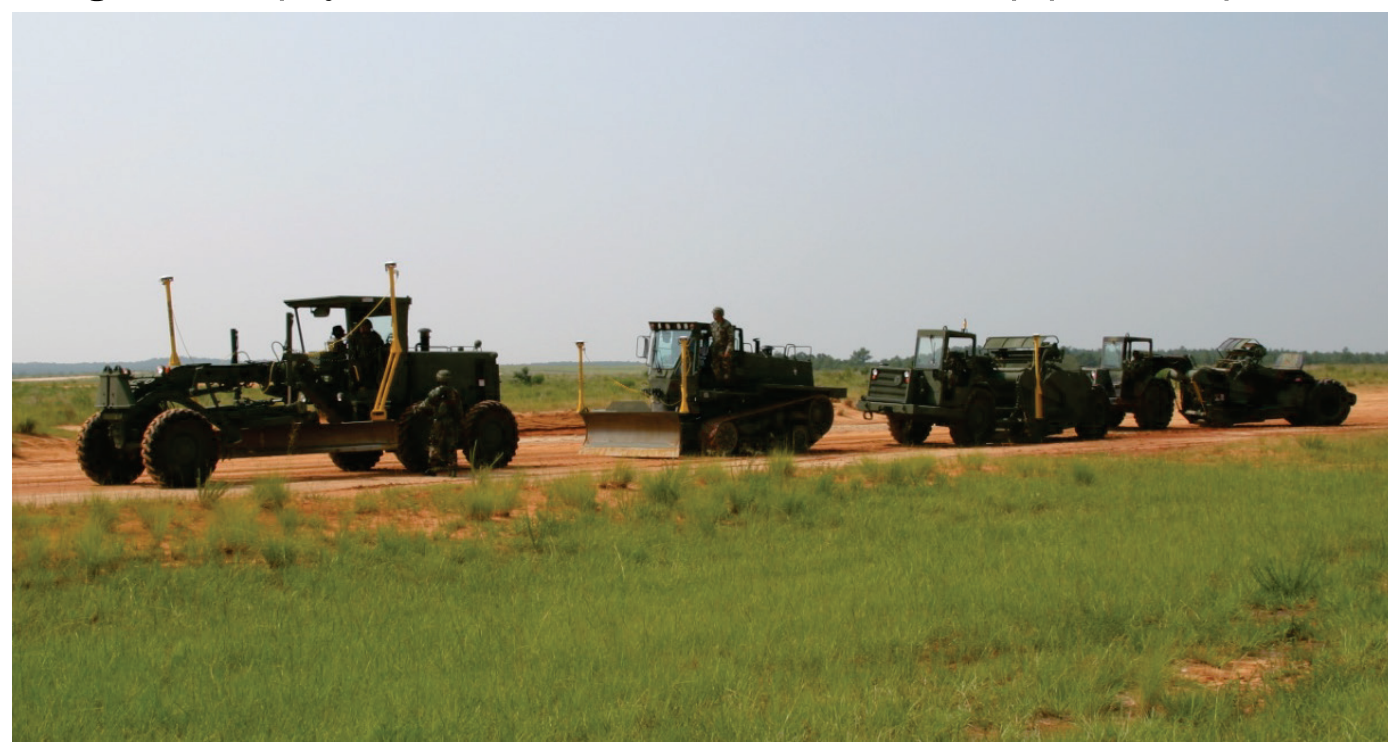

Figure 36. GPS-enabled motorgrader beginning clearing and grubbing operations.

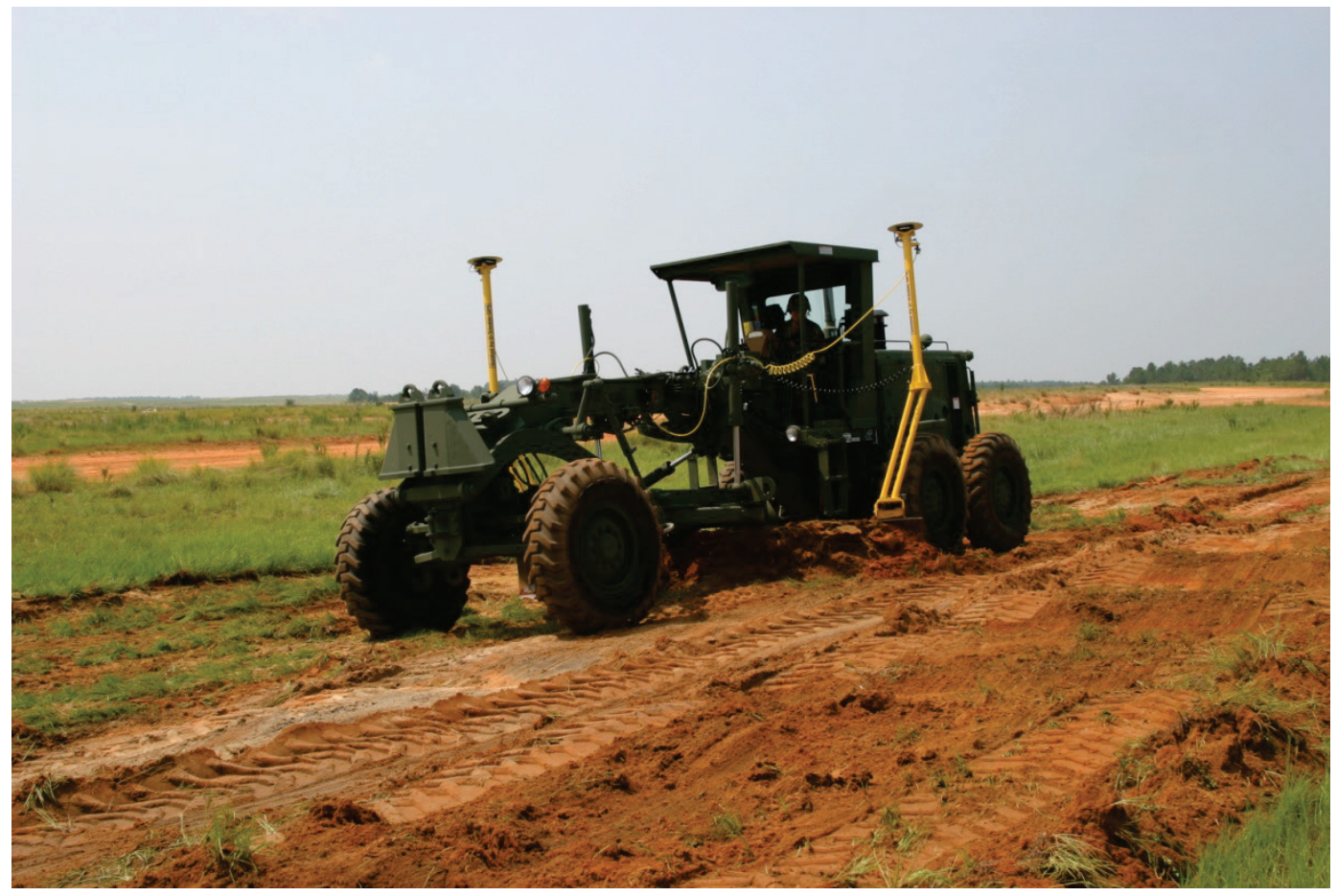


Figure 37. GPS-enabled scraper beginning clearing and grubbing operations.

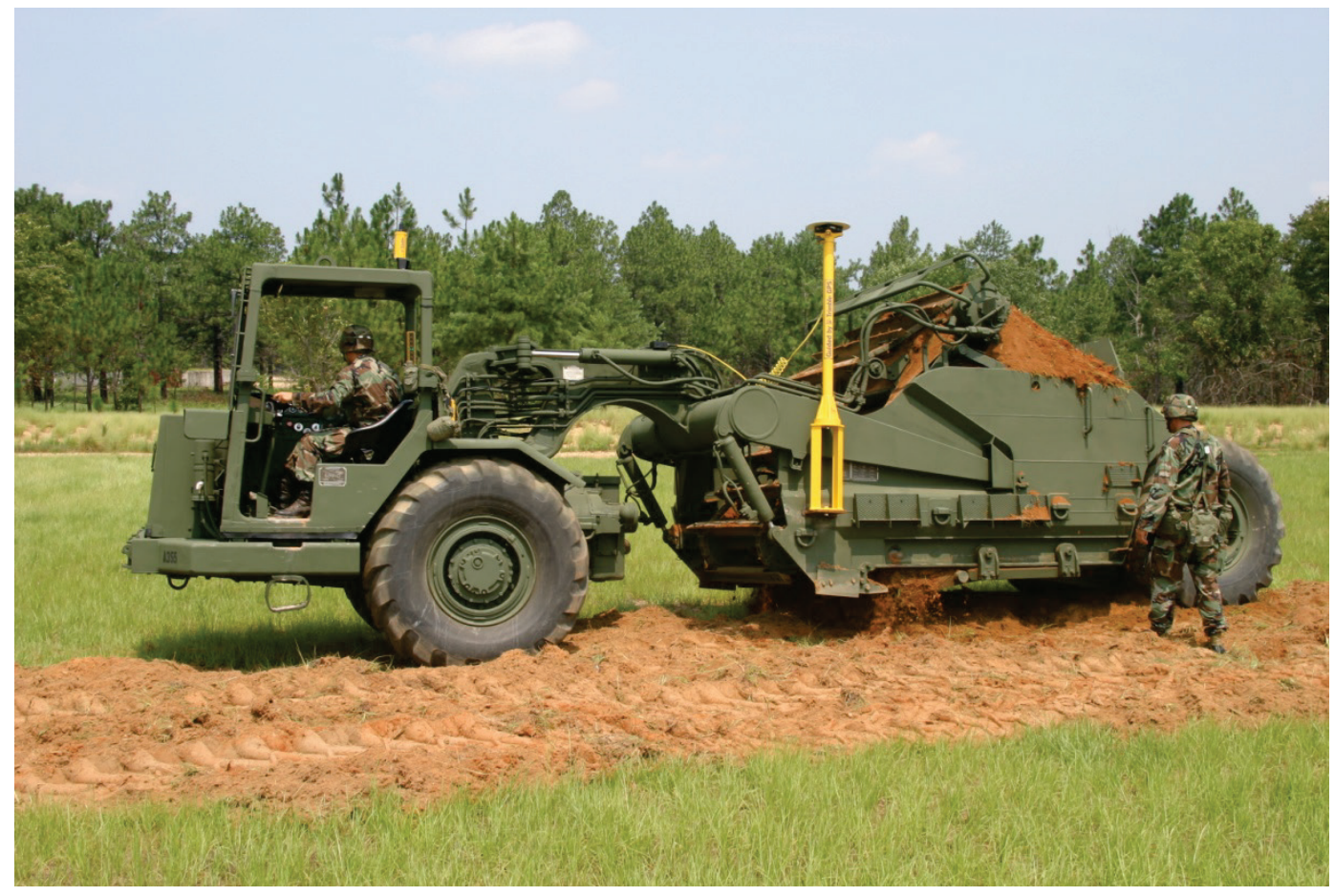

Figure 38. GPS-enabled DEUCE beginning clearing and grubbing operations.

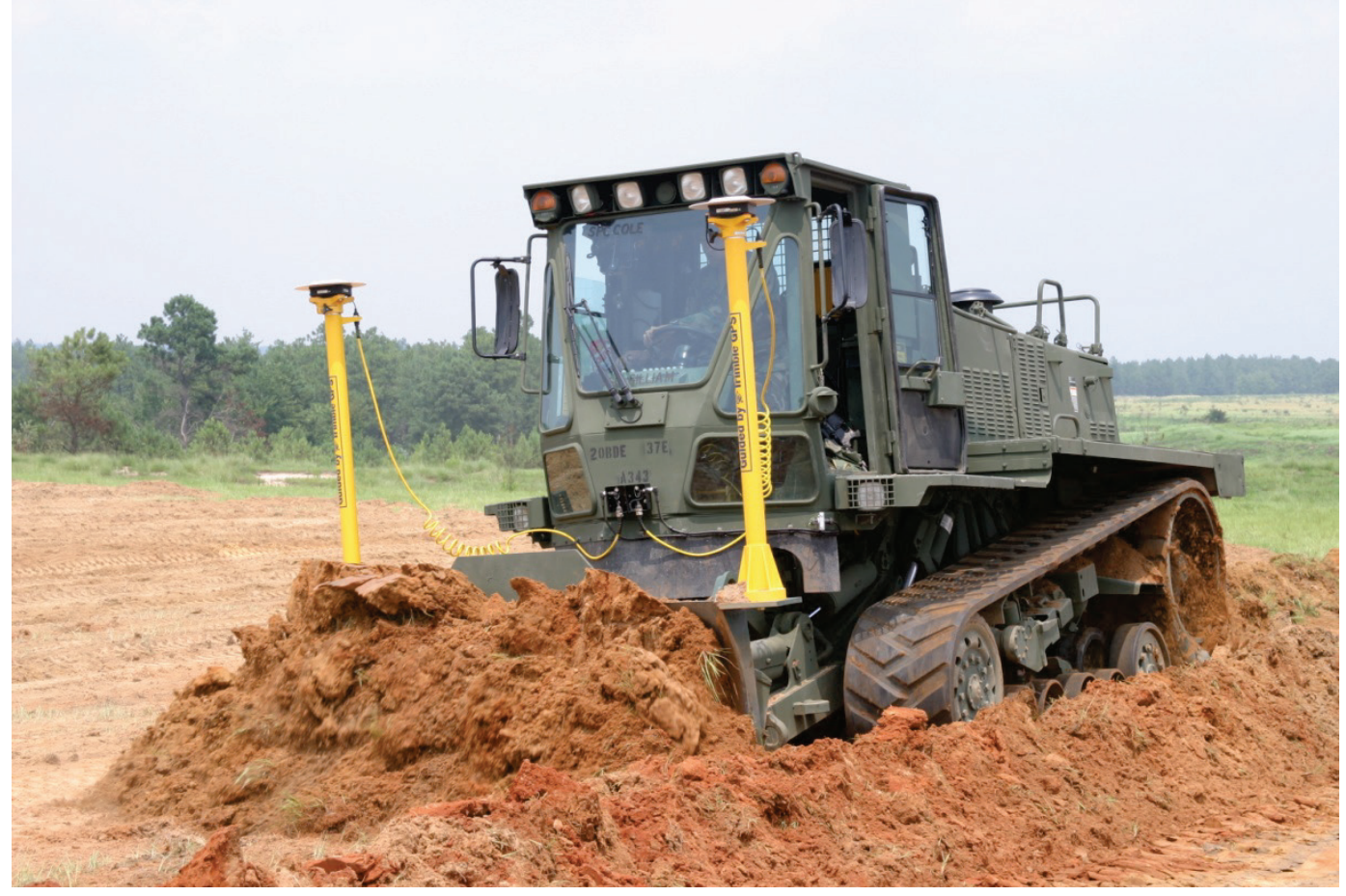


As soon as scrapers were available from Apron 1, they were moved to Apron 2 to begin clearing and grubbing operations. All equipment was deployed to Apron 2 by 15:0o hours. Apron 2 required all cut with excess material either transferred to Apron 1 or stockpiled around the perimeter of Apron 2. A drainage basin was required around the perimeter of the apron, similar to Apron 1. Clearing and grubbing operations for both Aprons 1 and 2 were completed at about 17:00 hours, a time span again of about $6 \mathrm{hr}$ for clearing, grubbing, and leveling two 1-acre $\left(3,600 \mathrm{~m}^{2}\right)$ areas (Figure 39 and Figure 40).

\subsubsection{Final grading}

Day 1 and 2: 20:00-38:30

Following clearing and grubbing, adjustments were made to the digital design that were uploaded into the equipment to continue leveling operations on the two aprons. Cutting of Apron 2 and filling of Apron 1 continued through the night using light stands to illuminate the jobsite. Grading and compaction of Aprons 1 and 2 were complete by 14:00 on July 13 (Figure 41).

Soil samples were taken periodically throughout the construction process, and the microwave included on the RAVEN was used to determine the moisture content of the in-situ material. It was found in general that the moisture content of Apron 1 remained close to the OMC of the soil such that steel-wheeled vibratory rollers could compact the surface without the addition of water. However, the cut material that originated from Apron 2 was dry of OMC for that gradation. Therefore, water had to be added to Apron 2 and to any material that was used as fill on Apron 1.

One water truck was available at the jobsite to spray moisture onto the soil surface. This caused a delay in construction, as the truck had to be continually refilled from a location several miles from the demonstration site. However, during stabilization, the water truck was able to keep up the pace of the construction, which progressed much slower than the cut/fill operations. 
Figure 39. Apron 1 before (top) and after (bottom) clearing and grubbing activity.

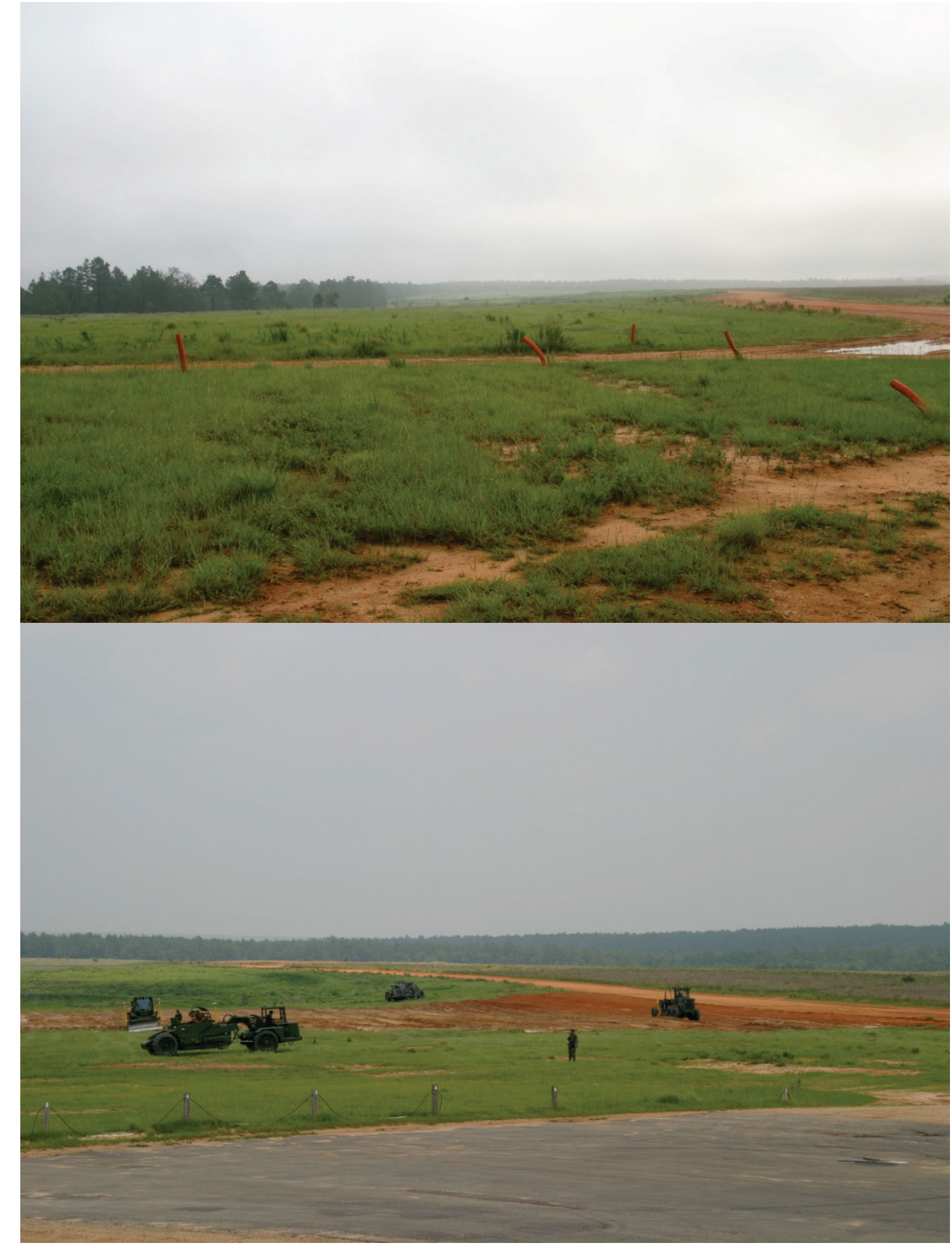


Figure 40. Apron 2 before (top) and after (bottom) clearing and grubbing activity. 
Figure 41. Cut and grading complete on Apron 2 on afternoon of July 13.

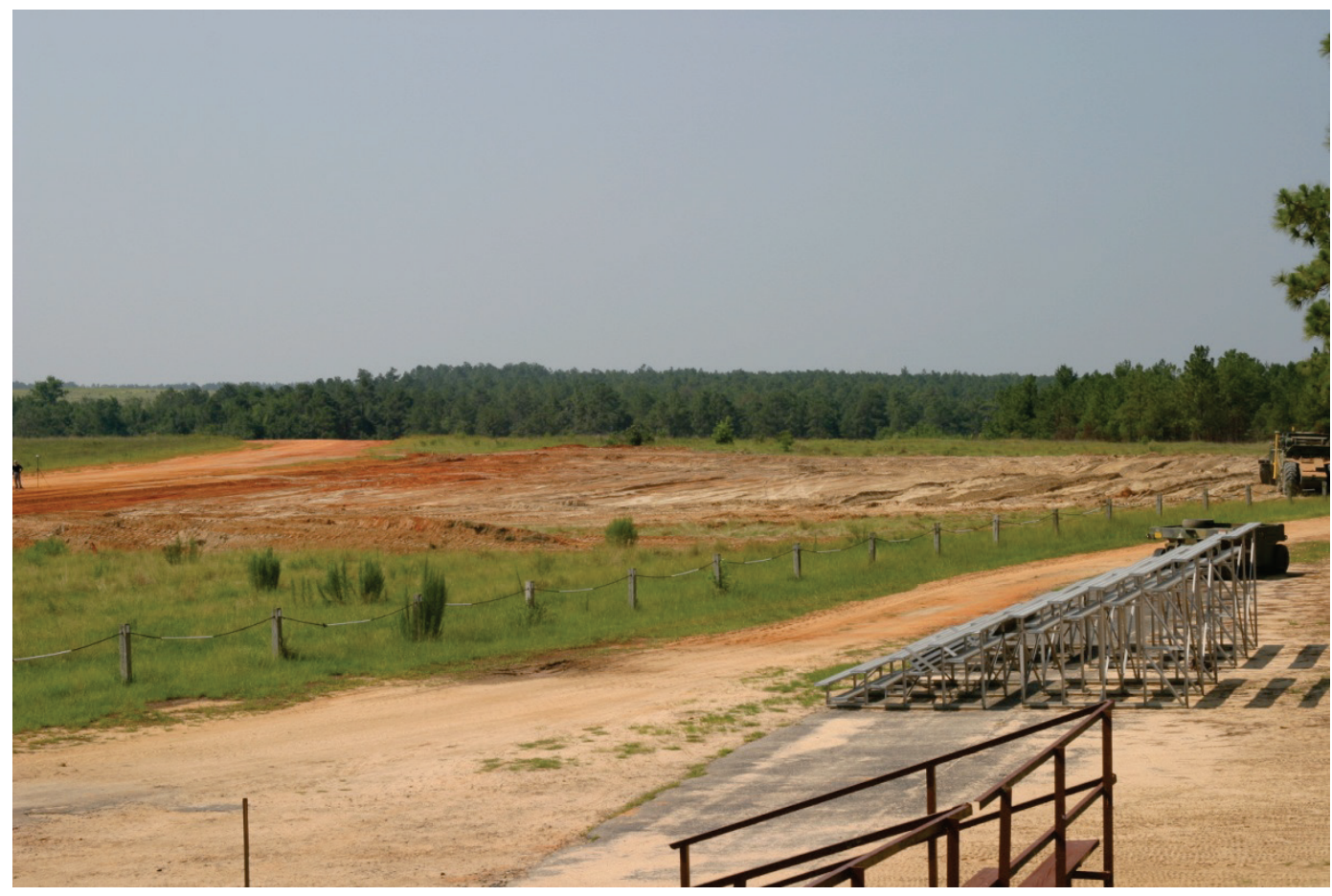

\subsubsection{Construction quality control}

Quality control was monitored on site by the construction team. The project used a method specification for compaction that dictated a specific number of roller passes on the given soil to achieve adequate density. Significant areas of focus for the quality control team included roller pass count, construction elevations, and construction moisture content. Ensuring proper quantities of stabilizer (cement, polymer, and fibers) is discussed in the Rapid Stabilization section.

\subsubsection{Roller pass count}

The method specification called for six roller passes to achieve soil improvement under the matting and eight passes for compaction of stabilized material. It was determined in field trials conducted at the ERDC test site in Vicksburg that after eight passes of the Caterpillar 433 roller, a majority of the roller efficiency would be achieved resulting in a 95 to 98 percent standard proctor compaction effort. Therefore, it was critical to ensure that at least eight roller passes were counted over each roller width as the rollers moved across the aprons. Two rollers moved in tandem with a slight offset to ensure that no weak seams were evident in the aprons. One person was stationed at the edge of the apron and proceeded to count the rollers as they moved forward and backward along the same path for a given 
roller width on the apron. This was done so that roller operators could concentrate on staying on a given path. Once eight passes were achieved, the rollers were instructed to move over to the next lane for compaction. An onboard digital process to track roller passes for the roller operator would alleviate the need for manual counting on the ground.

\subsubsection{Construction elevations}

Periodic manual checks of the elevations of the aprons were made using a manual GPS rover as shown in Figure 42. This served to identify the following problems that could be missed by the coarser elevations detected by the on-board RTK-GPS systems.

1. Depressions in the ground surface caused by:

a. Areas where too much material was excavated

b. Areas that received too much compaction

2. Raised humps on the ground surface caused by:

a. Areas where too much fill material was placed

b. Areas that have not received enough compaction

Smooth final wearing surfaces were a critical aspect of the apron construction to ensure a smooth ride of the aircraft when turning and parking. Since the surface of the hardened stabilized surface could not be reworked or graded, it was important to identify any elevation discrepancies during the final soil grading and immediately follow with several passes of the roller over stabilized soil lanes. 
Figure 42. Use of manual GPS rover to spot check elevations after RTK grading.

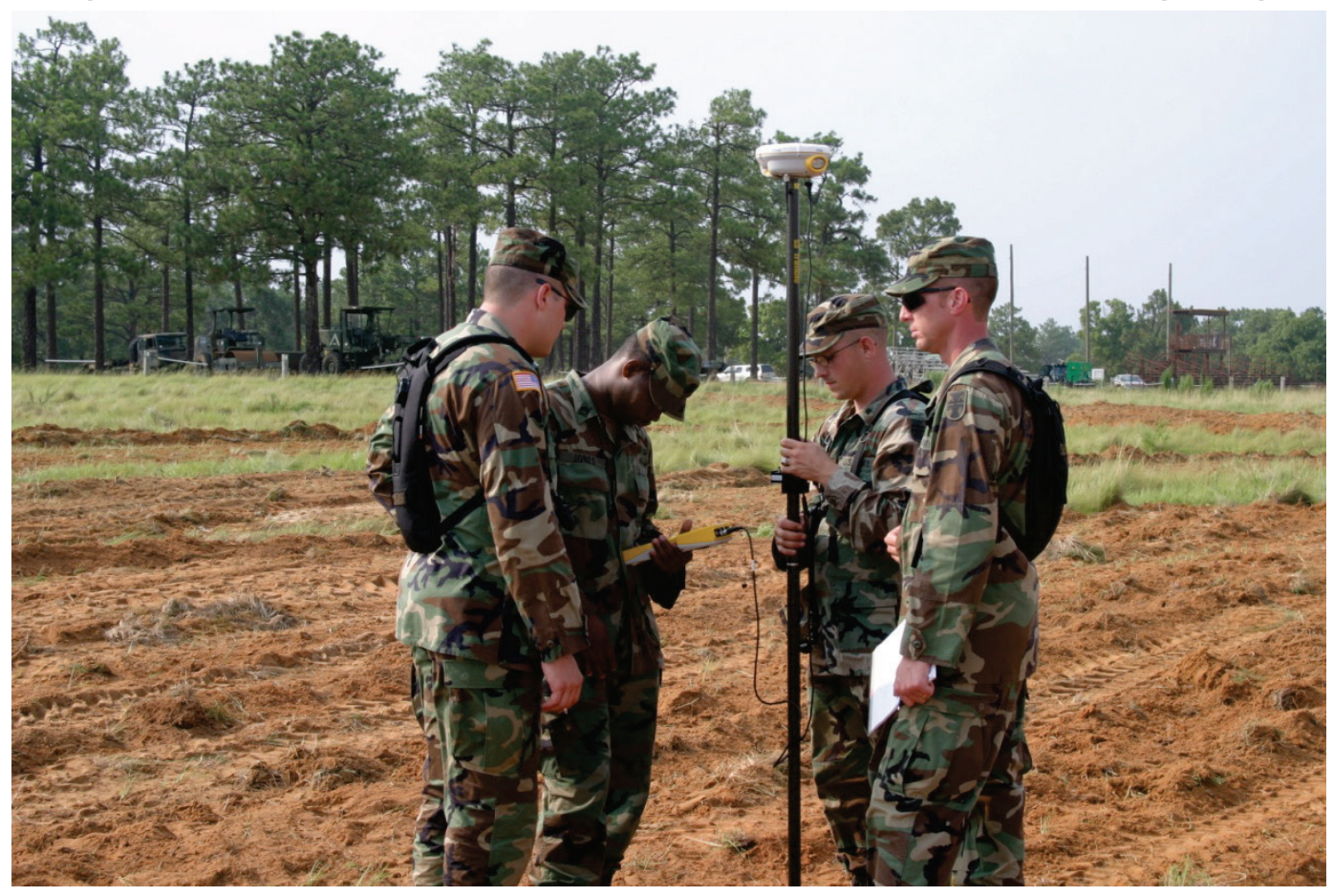

\subsubsection{Construction moisture content}

Moisture contents were taken frequently throughout the construction on July 13 as it was critical to determine the amount of water present in the in-situ soil. The hydration of the cement blended into both aprons is very sensitive to moisture content, and enough needs to be present for cement hydration and to obtain a maximum density during compaction. Since a rain event had occurred the day prior, large changes in moisture occurred over the duration of the exercise. Soil moistures were high the morning following the rain, followed by rapid drying due to the porous nature of the sandy soil layers and evaporation during the high heat experienced. Further, the natural ground runoff tended to flow towards Apron 1 from Apron 2 and, therefore, moistures remained higher for Apron 1 and lower for Apron 2. Careful attention to in-situ moisture resulted in the proper amounts of water necessary for each apron during stabilization. 


\subsection{Rapid stabilization (Apron 1)}

Apron 1 was constructed using a lightweight matting system for half of the apron and an emulsion polymer-cement combination for the other half. The emulsion polymer-cement combination was further 'capped' with a spray of the same polymer emulsion to provide a weatherproof and dustproof surface. In a real scenario, the polymer emulsion cap will need reapplication as necessary depending on surface wear. The entire stabilization process for Apron 1 from survey to matting and surface capping was completed in just over $48 \mathrm{hr}$. Approximately $30 \mathrm{hr}$ after completion of Apron 1, a C-130 aircraft was operating on the surface.

\subsubsection{ACE mats}

Day 2: 02:30-23:00

$\mathrm{ACE}^{\mathrm{TM}}$ mats are laminated polyester/fiberglass mats that weigh approximately $115 \mathrm{lb}$ each. They are joined using a locking pin-type fastener. The construction of the matted half of Apron 1 was begun near 01:00 on Tuesday, July 13. The surface was prepared to final grade and compacted with one pass of a military Caterpillar 433 compactor. The first row of mats was placed without problems, but the second row of mats required some adjustments to achieve proper alignment with the first row. Once the alignment problems were overcome, the installation of the mats proceeded without further problems (Figure 43). Mat placement continued until approximately 14:00 on July 13 (Figure 44). Due to temperatures over $95^{\circ} \mathrm{F}$, low wind, and direct sun, the soldiers installing the mats were given a rest period until dusk. Mat placement resumed at dusk and continued until 23:00. The final three rows of mats were left unfinished so they could be completed on 15 July during the visitors' day. From start to finish, the mat installation time for $20,000 \mathrm{ft}^{2}$ was approximately $12 \mathrm{hr}$. 
Figure 43. Placement of the ACE'M mats at 0300 on 13 July 2004.

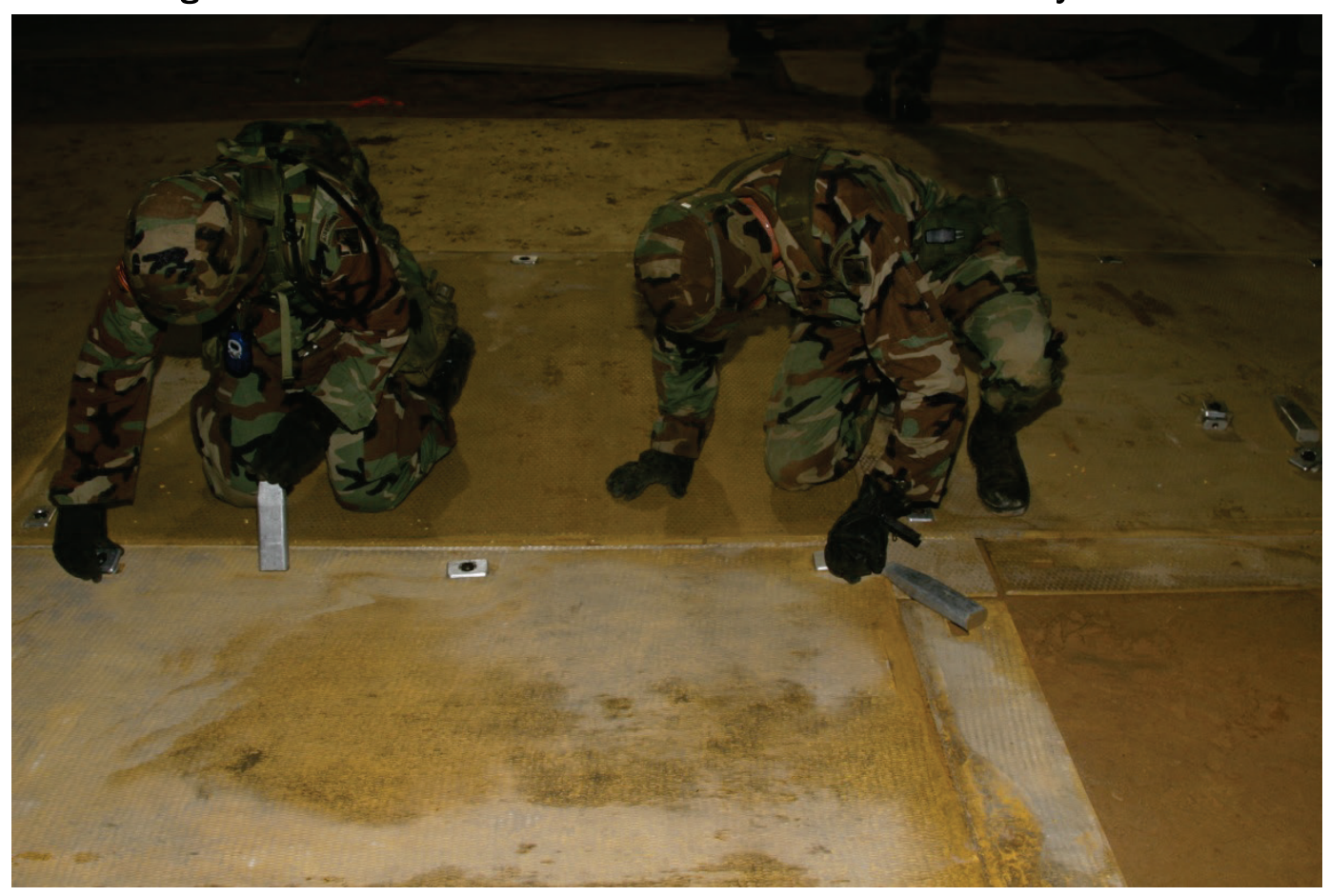

Figure 44. Completion of matting on Apron 1 on afternoon of July 13.

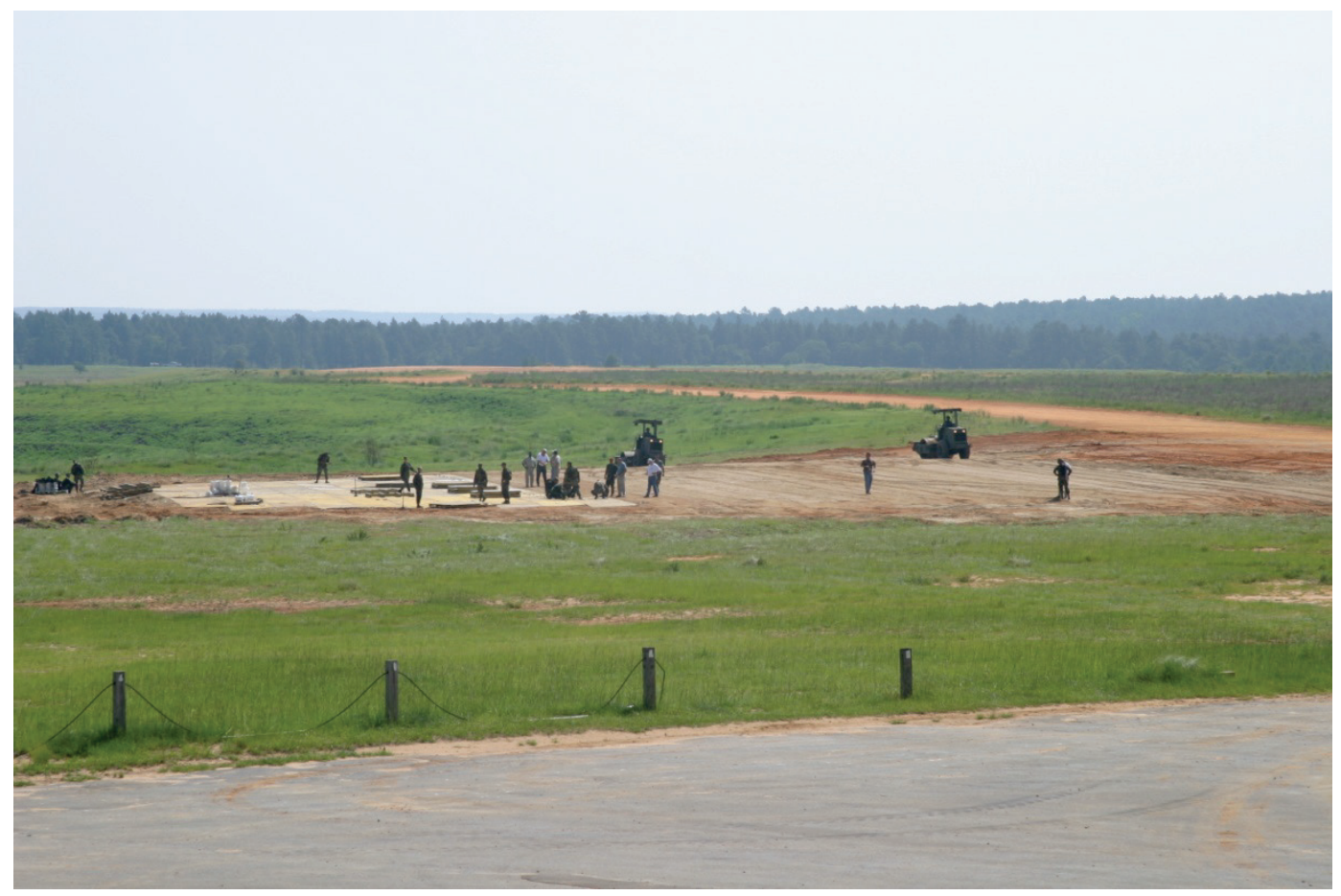




\subsubsection{Polymer-cement stabilization}

Day 2 and 3: 14:30-00:30

The construction of the polymer-cement-stabilized portion of Apron 1 began near 13:00 on Tuesday, 13 July 2006. The emulsion polymer used was Soil Cement Engineered Formula ${ }^{\mathrm{TM}}$. The cement was Type III (high-early strength) purchased from local suppliers. This work required considerable planning prior to construction. Planning requirements involved:

1. Using the RAVEN portable soils kit to determine soil type, OMC, and soil moisture levels prior to construction.

2. Cement bag spacing to meet a 3 percent dosage rate by weight of dry soil.

3. Measurement of soil moisture content to determine the proper dilution water for the polymer and to meet the OMC of the soil placement.

4. Proper Terex 325 speed and Automated Liquid Proportioning System (ALPS) settings to reach the OMC of the soil and the 3 percent dosage rate of the emulsion polymer.

5. Timing of the cement bag placement, compaction patterns, polymer/water refills, and Terex refueling such that a consistent train of cement placement, Terex operation, and compaction was achieved. Compaction was the rate limiter of this process as the compaction must immediately follow the Terex such that cement hydration does not occur prior to compaction of the soil.

A simple Excel spreadsheet was constructed to aid in calculations of the pertinent variables for polymer-cement stabilization as shown in Figure 45. Input variables were apron size (in this case, for a trapezoidal geometry), stabilization depth, maximum soil density at OMC, OMC, starting soil moisture content, percent solids of the emulsion, the weight of the emulsion per gallon, the effective lane width of the Terex 325 RS cutter drum, the percent concentration of emulsion and cement desired, and the coverage rate for the polymer cap to be sprayed over the surface. The Terex 325 ground speed was also an input variable, but depending on the amount of moisture necessary, required adjustment to meet the optimum flow rate range of between 30 and 180 gal of water $/ \mathrm{min}$. 
Figure 45. Screenshot of spreadsheet used to calculate pertinent variables for polymer-cement stabilization using the Terex 325RS. Input variables are in green, outputs in yellow.

\begin{tabular}{|c|c|c|c|c|c|}
\hline \multicolumn{3}{|c|}{ Calculations for Apron 1 stabilization } & \multirow{2}{*}{$\begin{array}{l}\text { Inputs } \\
\text { Outputs }\end{array}$} & & \\
\hline & & & & & \\
\hline \multicolumn{6}{|l|}{ Stabilization Info } \\
\hline Longest length of area, $\mathrm{ft}$ & \multicolumn{2}{|l|}{$300^{\prime}$} & Shortest length of area, $\mathrm{ft}$ & & 217.5 \\
\hline Depth of stabilization, inches & \multicolumn{2}{|l|}{6} & Width of area, $\mathrm{ft}$ & & 82.5 \\
\hline Density of compacted soil, lbs/cu ft & \multicolumn{2}{|l|}{$117^{\pi}$} & \multicolumn{2}{|l|}{$\%$ starting soil moisture content } & $6.10 \%$ \\
\hline$\%$ optimum moisture content of soil & \multicolumn{2}{|l|}{$9.00 \%$} & \multicolumn{2}{|l|}{ Weight of Emulsion, lbs/gallon } & 9.53 \\
\hline$\%$ solids of polymer emulsion & \multicolumn{2}{|l|}{$46 \%$} & CMI effective lane width, ft & & 5.5 \\
\hline CMI lanes, $5.5 \mathrm{ft}$ wide pass & 15.0 & & \multicolumn{2}{|c|}{$\%$ moisture added from emulsion to soil } & $1.62 \%$ \\
\hline Area to be stabilized, sq.ft. & 21,347 & & $\%$ mix water needed & & $1.28 \%$ \\
\hline Area to be stabilized, sq. yds. & 2,372 & & \multicolumn{2}{|c|}{ Mix water to be added to emulsion, gallons } & 1,919 \\
\hline Volume of soil to be stabilized, cu. $\mathrm{ft}$ & 10,673 & & \multicolumn{2}{|c|}{ Total volume of liquid, gallons } & 5,850 \\
\hline Volume of soil to be stabilized, cu. yds. & 395 & & Final target water content & & $9.00 \%$ \\
\hline Weight of Soil to be stabilized, lbs & $1,248,792$ & & & & \\
\hline \multirow{2}{*}{\multicolumn{2}{|c|}{ Calculations for CMI RS 325}} & & & & \\
\hline & & Pump rate, gallons/min & Minimum time, minutes & Estimated time, hrs & \\
\hline What is the CMI speed in $\mathrm{ft} / \mathrm{min}$ ? & 30 & $45.2^{\top}$ & 129 & $4.35^{5}$ & \\
\hline \multicolumn{2}{|c|}{ Calculations for Polymer Enulsion } & Percent solids in soil & Weight, lbs & Volume, gallons & $\#$ of totes \\
\hline What percent of emulsion do you want? & $3.00 \%$ & $1.38 \%$ & 37,464 & 3931 & 14.30 \\
\hline \multicolumn{2}{|c|}{ Calculations for Cement Amounts } & Weight, lbs & \# of $94 \mathrm{lb}$ bags & \# of pallets & Bag Spacing, $\mathrm{ft} / \mathrm{lane}$ \\
\hline What $\%$ of cement do you want? & $3.00 \%$ & 37,464 & 399 & 11.4 & 9.74 \\
\hline \multicolumn{2}{|l|}{ Calculations for Polymer Cap } & Weight, lbs & gallons & \# totes & \\
\hline How many gallons/sq.yd do you want? & 0.50 & 11,302 & 1186 & 4.6 & \\
\hline
\end{tabular}

Immediately following final grading of the portion of Apron 1 set aside for stabilization, soil moisture contents were measured using the RAVEN microwave system. The OMC of the native soil was 9 percent. Studies of similar soils stabilized with 3 percent polymer-3 percent cement blends did not show drastic shifts in the OMC from the unstabilized soil. The average moisture content measured just prior to stabilization was 6.1 percent for the cement-polymer-stabilized portion of Apron 1. The total weight of soil to be stabilized in Apron 1 was approximately 1,250,000 lb of soil. Using the spreadsheet in Figure 45 yields a total of 3,931 gal of emulsion needed to reach 3 percent emulsion polymer dosage rate. As the emulsion contains water, it contributes 1.62 percent of the moisture necessary to reach the target optimum moisture content of 9 percent. Approximately 37,500 lb (400 94-lb bags) of cement were required to be added to the soil; 1,200 gal of emulsion were needed for the surface; and 2,000 gal of dilution water were needed in addition to the emulsion to reach the optimum soil moisture content. The spreadsheet also calculated the spacing of the cement bags per lane width of the Terex.

Once the spreadsheet calculations were completed, laying out the grid for the cement bag placement was needed. This was accomplished with two ropes with colored tape markers along the rope at the proper intervals; one rope for the Terex lane width $(5.5 \mathrm{ft})$ and one for the cement bag spacing 
(9.75 ft). Due to the trapezoidal geometry, the spacing for the Terex lane width rope along the perimeter was calculated to be $6.1 \mathrm{ft}$. This rope was stretched along the edge of the apron at the starting lane for the Terex and the intervals staked on both sides of the apron. The cement bag spacing rope was then stretched across the apron from stake to stake so the colored tape markings clearly showed where the cement bags were to be spotted. The MTVR truck was loaded with two pallets of cement and two soldiers stood in the back of the truck dropping bags as the truck drove along the middle of the rope so two lanes could be spotted with a single truck pass. A soldier followed the MTVR signaling where to drop the bags (Figure 46). The initial four Terex lanes were spotted with cement bags. Only four lanes were spotted to make sure that this process did not get too far ahead of the mixing and compaction process. The bags were then busted open and spread evenly across the area (Figure 47).

Figure 46. Spotting of cement bags.

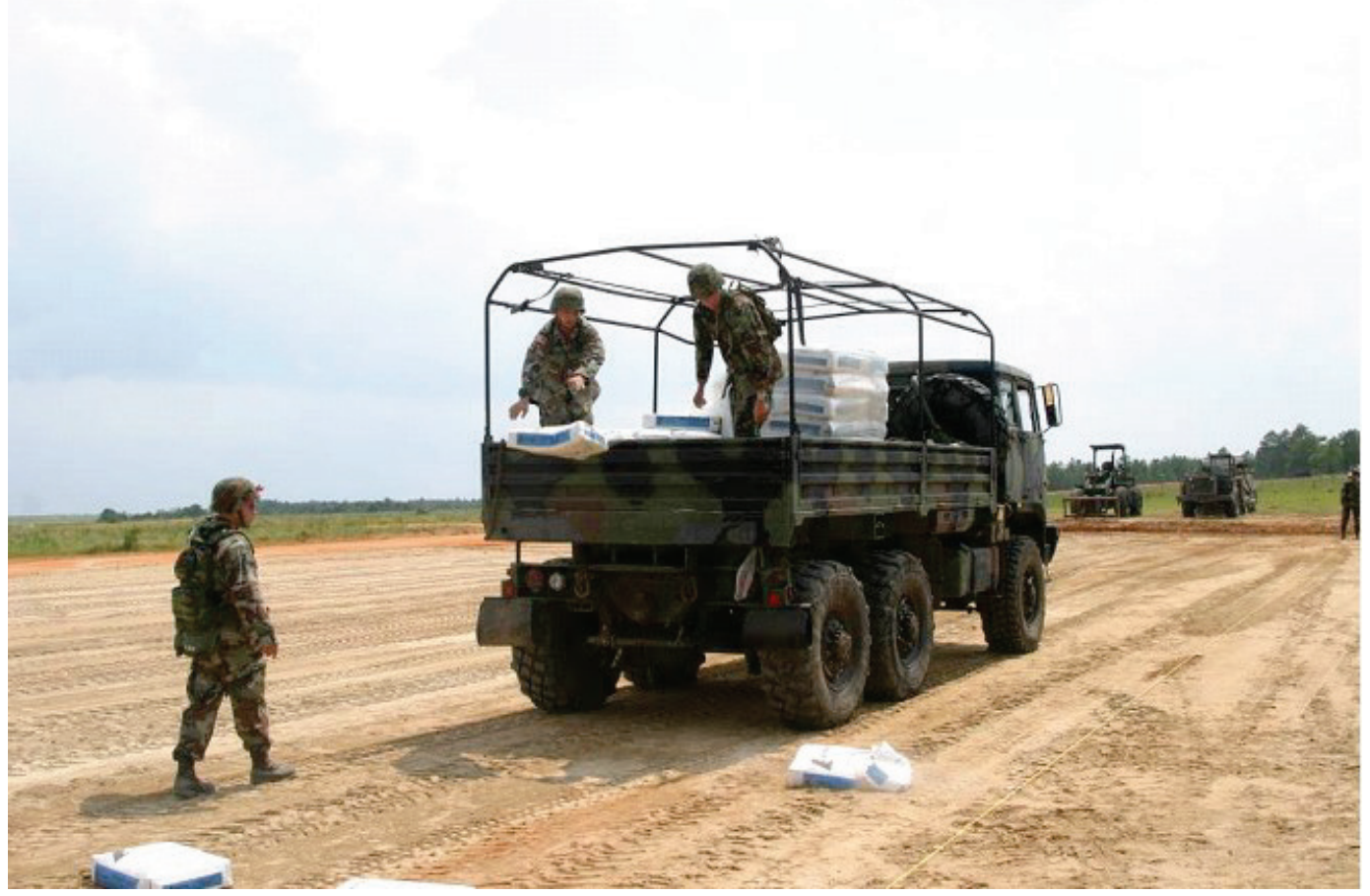


Figure 47. Spreading of cement.

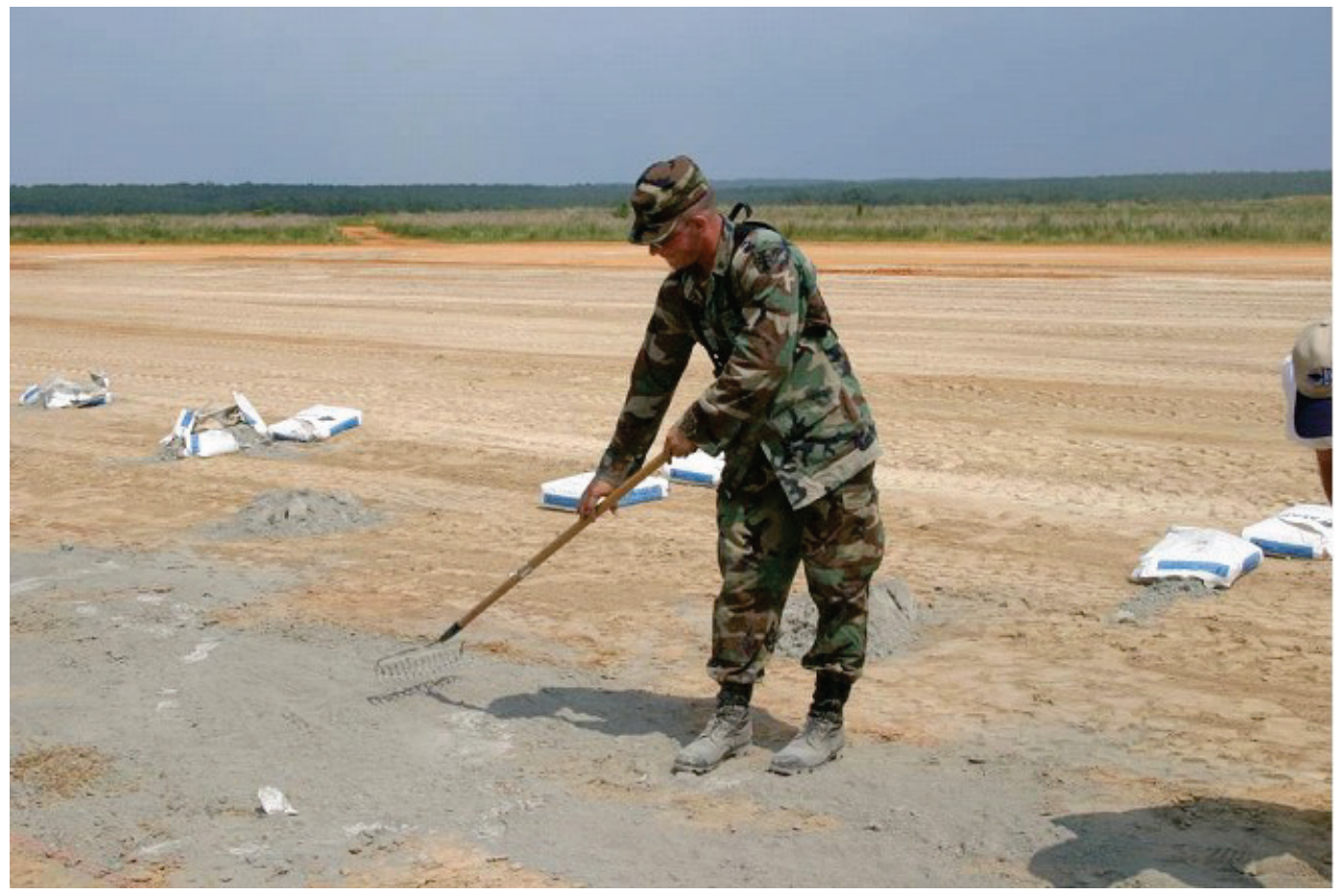

For the liquid application, a 1,500-gal plastic agricultural tank was purchased and placed in the back of a second MTVR. Based on the spreadsheet calculations, approximately 6,000 gal of liquid (3931 gal of emulsion plus 1,919 gal of mix water) were needed. This is a dilution ratio of approximately 2:1 emulsion to water, which equated to approximately one full tank to cover every four Terex lanes. The dilution water was supplied from a 6,000-gal water truck. This needed to be monitored closely such that each lane across the whole of the trapezoid was completed. If it appeared that a complete pass from one side of the apron to the other could not be completed without a refill, then the process was halted and a refill made. Stopping the Terex in the middle of the apron caused problems such as spillage of liquid from start/stop of the pumps and surface gouging due to lifting of the cutter head.

A stabilization 'train' was then formed with the MTVR in the lead connected by a boom and nurse hose to the Terex (Figure 48). The Terex was closely followed by two military Caterpillar 433 compactors. The speed of the process was controlled by the Terex. The ALPS unit on the Terex was set to the desired pump rate of $45 \mathrm{gal} / \mathrm{min}$ based on the spreadsheet calculation in Figure 45. The only significant difficulty in this process was the starting and stopping of the Terex. During startup, the pumps must be started prior to engaging the cutter head and 
lowering to the desired stabilization depth ( 6 in.). This results in 10 to 20 gal of liquid spillage and a small trench the width of the cutter head. During stopping, the Terex progress must be halted before the cutter head can be lifted, resulting in another small trench at the end of each lane. The compactors were set to vibrate when going forward and smooth roll (no vibration) in reverse. The compactors were instructed to go as slow as possible to maximize the amount of energy imparted to the soil that results in densification. A total of 8 passes along each lane was made. It was found through previous work with these small compactors that after 8 passes across a given point, approximately 95 percent of the maximum compaction was achieved (Figure 49).

Figure 48. Stabilization 'train' showing MTVR with nurse tank attached to the Terex.

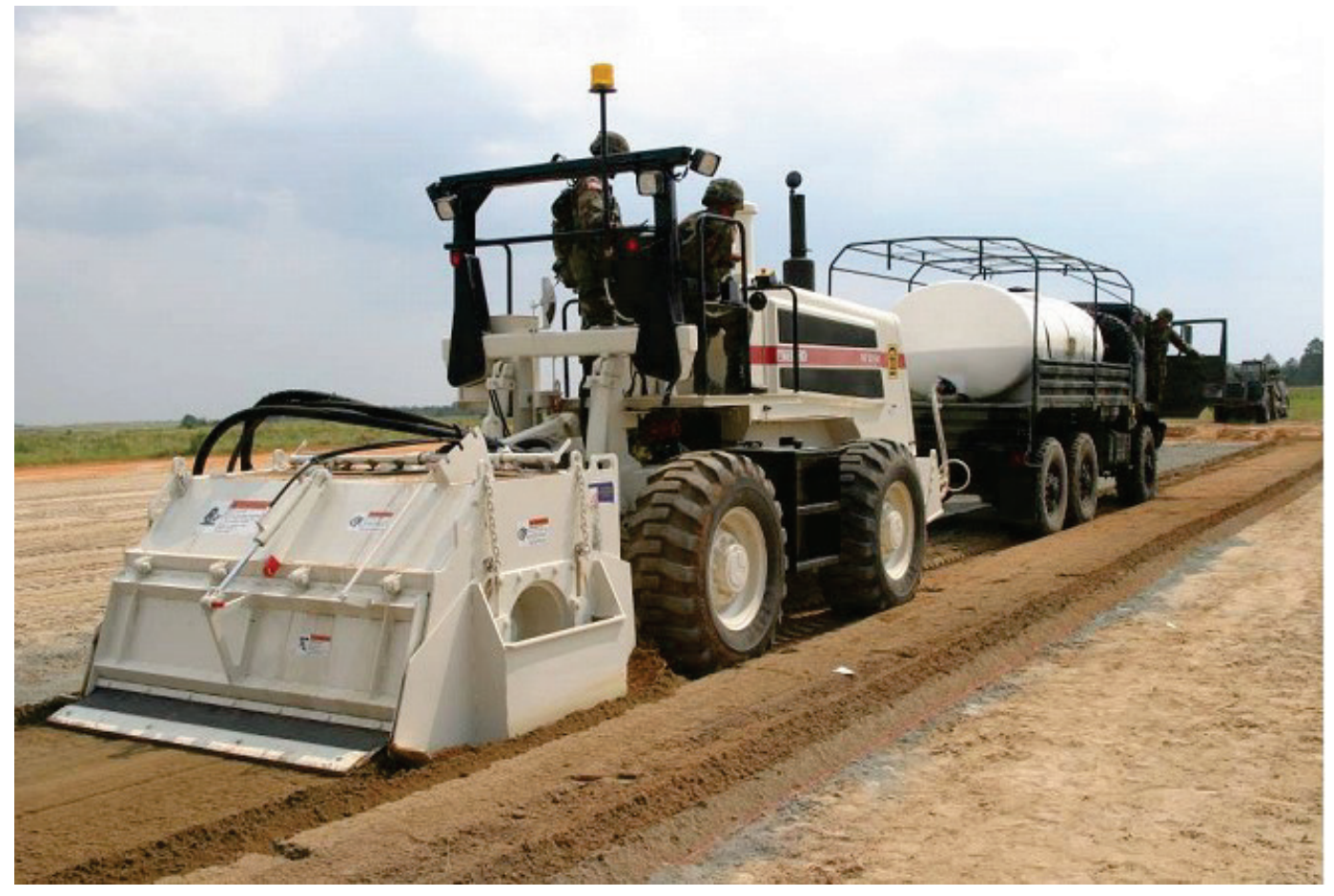


Figure 49. Military Caterpillar 433 compactors closely following the stabilization train.

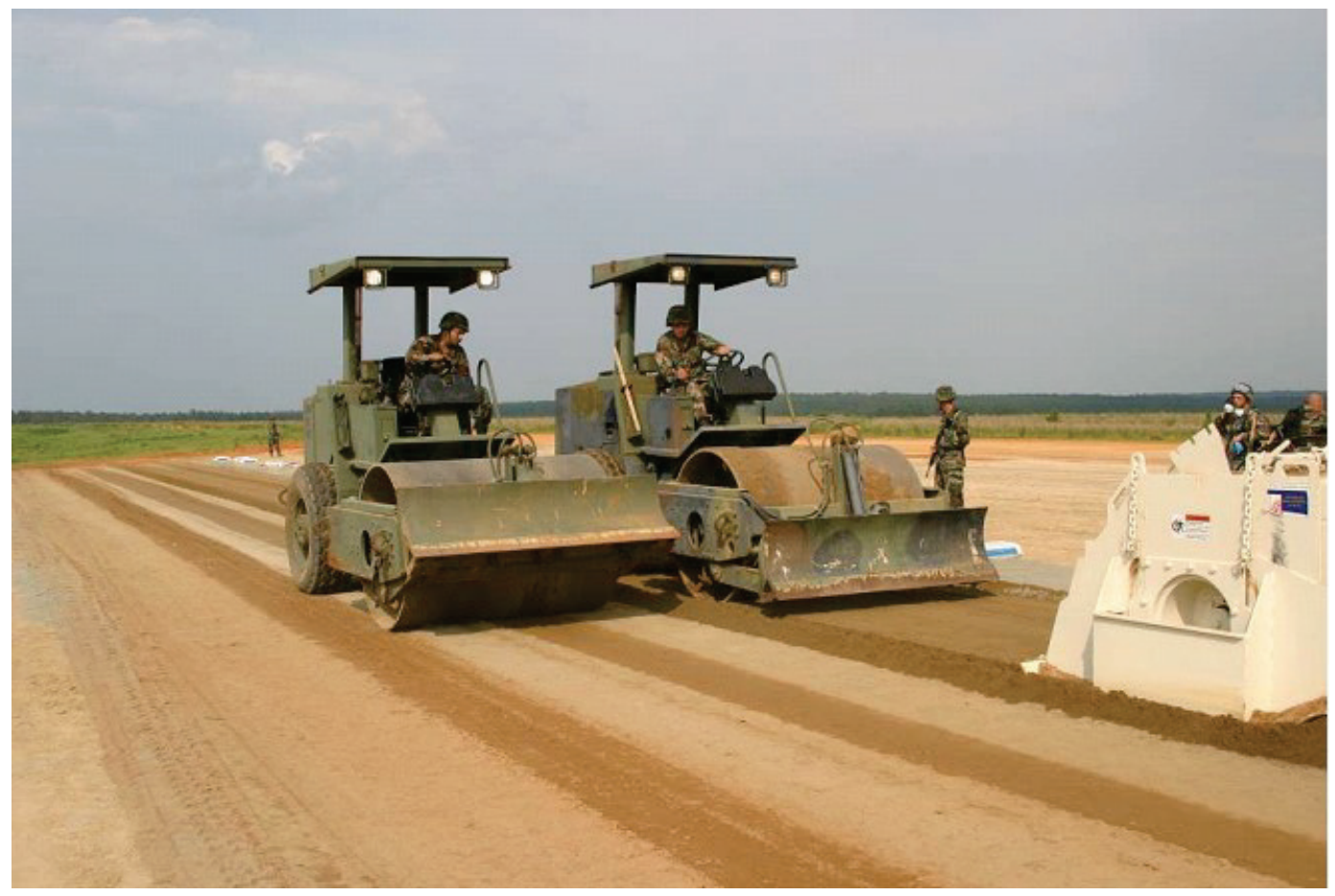

\subsubsection{Emulsion cap}

The final construction step was placement of the polymer emulsion 'cap.' The cap was a spray coating of the same emulsion used for stabilization of the soil. It was intended to provide a temporary wearing surface and serve as a weatherproof/dustproof layer over the stabilized soil. The amount of soil stabilizers used in a JRAC scenario is much lower than what is needed for long-term durability. Thus, to provide adequate durability during precipitation, the polymer cap helps keep water from penetrating the surface and weakening the stabilized soil. The cap was placed using a spray device developed for mounting on the HMMWV truck and at an application rate of $0.5 \mathrm{gal} / \mathrm{sq}$. yd. (Figure 50). The polymer emulsion penetrates approximately $1 / 8$ - to $1 / 4$-in. into the surface. Depending on the level of traffic and use of the apron, the polymer emulsion cap will need to be reapplied as necessary. 
Figure 50. Polymer cap placement using HMMWV sprayer.

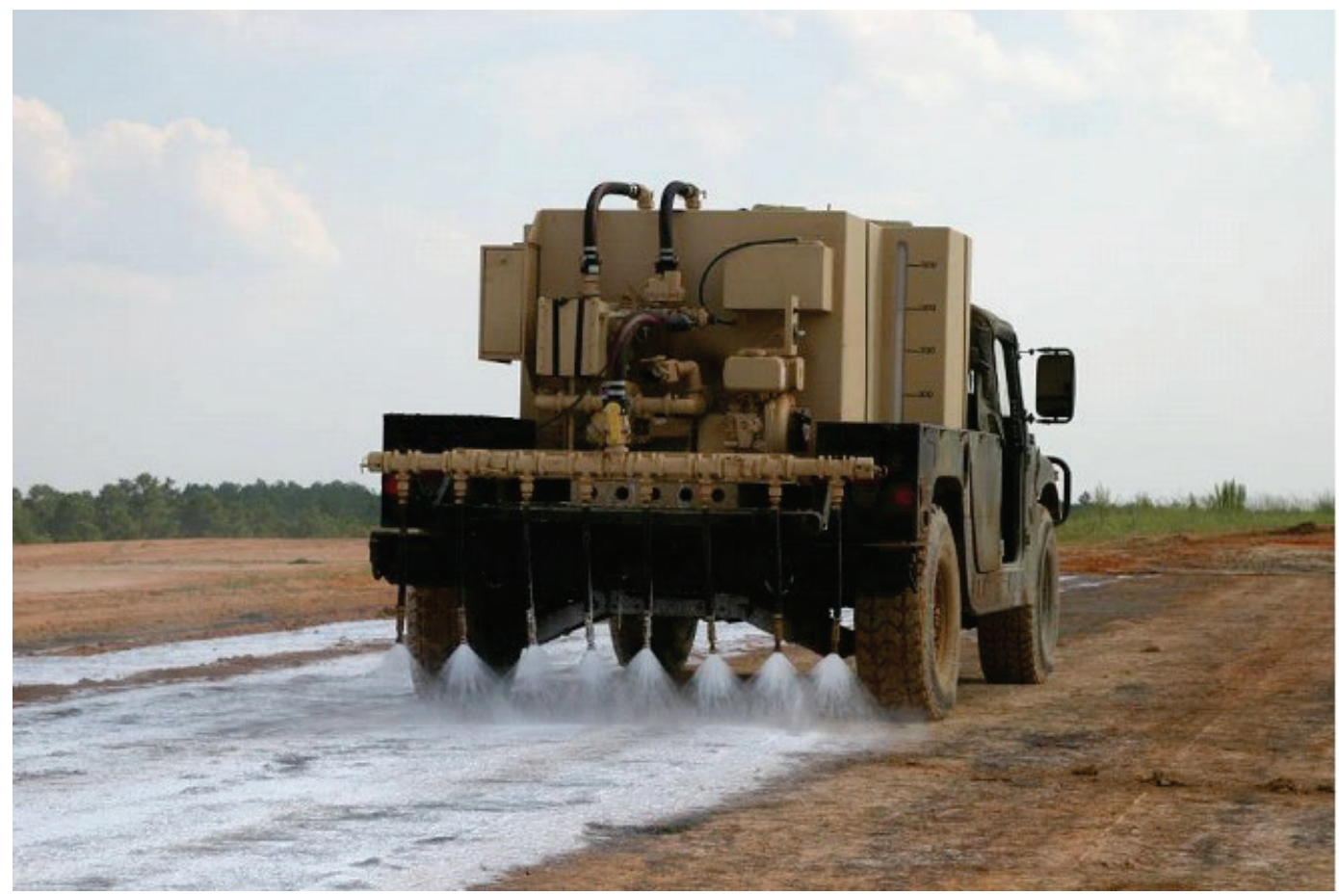

From start to finish, the entire polymer-cement stabilization and capping process of Apron 1 was accomplished in approximately $13 \mathrm{hr}$ (Figure 51).

Figure 51. Completed view of Apron 1.

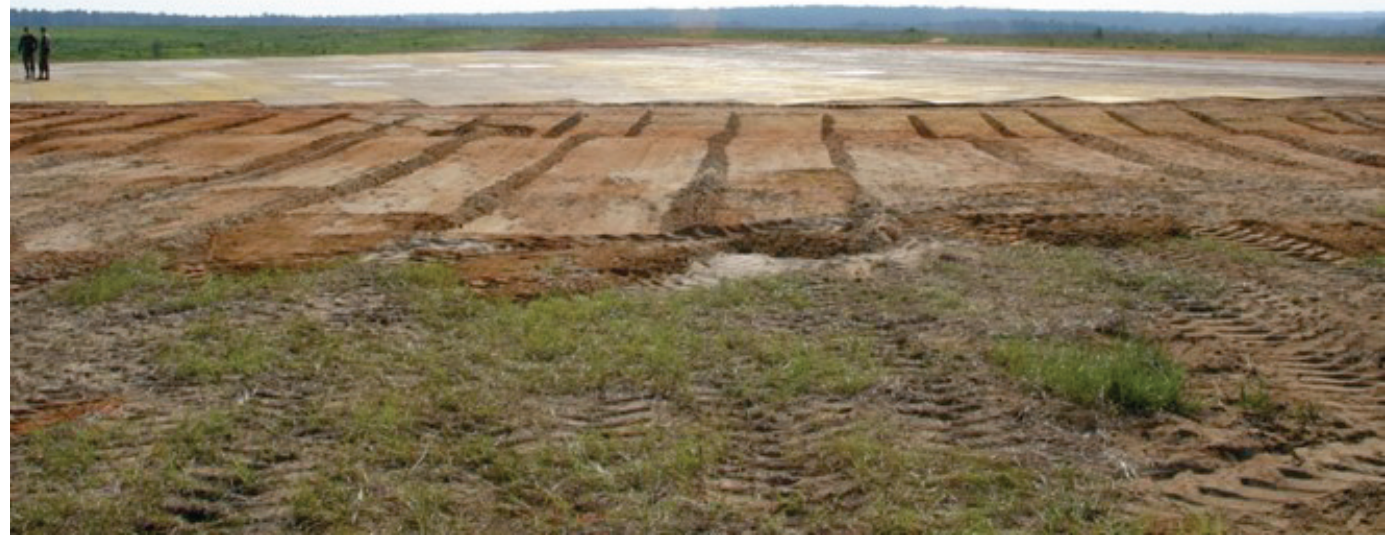




\subsection{Rapid stabilization (Apron 2)}

\subsubsection{Fiber-cement stabilization}

Day 3 and 4: 11:00-03:30

Apron 2 was constructed from a combination of fibers and cement followed by a polymer cap over the surface. The fibers used were 2 in. long, black, polypropylene fibrillated fibers, and the emulsion polymer cap was Soil Sement Engineered Formula ${ }^{\mathrm{TM}}$. The cement was Type III (high-early strength) purchased from local suppliers.

The soil stabilization of Apron 2 began at 12:00 on Wednesday, 14 July and was completed in $15 \mathrm{hr}$. The polymer cap was placed on the surface in about 2 hr on Thursday, 15 July. As with Apron 1, the stabilization required considerable planning. However, after construction of Apron 1, the procedures and timing for construction of Apron 2 was more familiar to the troops. Planning requirements involved:

1. Using the RAVEN portable soils kit to determine soil type, OMC, and soil moisture levels prior to construction.

2. Cement bag spacing to meet a 4 percent dosage rate by weight of dry soil.

3. Measurement of soil moisture content to determine the proper dilution water for the polymer and to meet the OMC of the soil placement.

4. Proper Terex 325 speed and Automated Liquid Proportioning System (ALPS) settings to reach the OMC of the soil.

5. Timing of the cement and fiber bag placement, compaction patterns, water refills, and Terex refueling such that a consistent train of cement placement, Terex operation, and compaction was achieved.

A modified version of the spreadsheet used for polymer-cement stabilization was used for calculations for Apron 2 (Figure 52). For Apron 2 , the average soil moisture levels were much lower (3.2 percent) and the soil had a higher fine content such that the OMC for compaction was 9.7 percent. Studies of similar soils stabilized with fiber and 4 percent cement blends did not show drastic shifts in the OMC from the unstabilized soil.

The total weight of soil to be stabilized in Apron 2 was approximately $2,400,000 \mathrm{lb}$ of soil. Using the spreadsheet in Figure 52 yields a total of 18,600 gal of water needed to reach OMC. Approximately 95,000 lb of 
cement (1,000 94-lb bags) were required to be added to the soil, and 9,500 lb of fiber (475 20-lb bags) and 2,300 gal of emulsion were needed for the surface. The spreadsheet calculates the spacing of the fiber $(15.5 \mathrm{ft})$ and cement $(7.3 \mathrm{ft})$ bags per lane width of the Terex. The cement was placed first and spread with the fiber placed over the spread cement (Figure 53).

Figure 52. Excel spreadsheet used for Apron 2 soil stabilization calculations.

\begin{tabular}{|c|c|c|c|c|c|}
\hline \multicolumn{3}{|c|}{ Calculations for Apron 2 Stabilization } & \multirow{2}{*}{$\begin{array}{l}\text { Inputs } \\
\text { Outputs }\end{array}$} & & \\
\hline & & & & & \\
\hline \multicolumn{6}{|l|}{ Stabilization Info } \\
\hline Longest length of area, $f t$ & \multicolumn{2}{|l|}{$300^{\circ}$} & Shortest length of area $\mathrm{ft}$ & & 100 \\
\hline Depth of stabilization, inches & \multirow{2}{*}{\multicolumn{2}{|c|}{$\begin{array}{r}6 \\
1177^{7}\end{array}$}} & Width of area, $\mathrm{ft}$ & & 203.5 \\
\hline Density of compacted soil, $\mathrm{lbs} / \mathrm{cu} \mathrm{ft}$ & & & \multicolumn{2}{|l|}{$\%$ starting soil moisture content } & $3.20 \%$ \\
\hline \multirow[t]{2}{*}{$\%$ optimum moisture content of soil } & \multirow[t]{2}{*}{$9.70 \%$} & & \multicolumn{2}{|l|}{ Weight of Emulsion, lbs/gallon } & 9.53 \\
\hline & & & \multicolumn{2}{|l|}{ CMI effective lane width, ft } & 5.5 \\
\hline CMI lanes, $5.5 \mathrm{ft}$ wide pass & $37.0^{\circ}$ & & $\%$ mix water to be added & & $6.50 \%$ \\
\hline Area to be stabilized, sq. ft. & 40,700 & & Mix water, gallons & & 18,579 \\
\hline Area to be stabilized, sq yds. & 4,522 & & Mix water, gallons/sq.yd. & & 4.11 \\
\hline Volume to be stabilized, cu. ft & 20,350 & & Final target water content & & $9.70 \%$ \\
\hline Volume to be stabilized, cu. yds. & 754 & & & & \\
\hline Weight of Soil to be stabilized, lbs & $2,380,950$ & & & & \\
\hline & & & & & \\
\hline \multicolumn{2}{|c|}{ Calculations for CMI RS 325} & Pump rate, gallons/min & Minimum time, minutes & Estimated time, hrs & \\
\hline What is the CMI speed in $\mathrm{f} / \mathrm{min}$ ? & \multirow[t]{2}{*}{$30^{\circ}$} & $75.3^{\circ}$ & $251^{\top}$ & $8.40^{\circ}$ & \\
\hline Calculations for Fiber Amounts & & Weight, tbs & $\#$ of $20 \mathrm{lb}$ bags & \# of boxes & Bag Spacing, ft/lane \\
\hline What is the $\%$ fiber? & $0.40 \%$ & 9,524 & 476.19 & 32 & 15.54 \\
\hline \multicolumn{2}{|c|}{ Calculations for Cement Amounts } & Weight, lbs & \# of $94 \mathrm{lb}$ bags & $\#$ of pallets & Bag Spacing, $\mathrm{f} /$ lane \\
\hline What is the $\%$ cement? & $4.00 \%$ & 95,238 & 1013 & 28.9 & 7.30 \\
\hline \multicolumn{2}{|c|}{ Calculations of Polymer Cap } & Volume, gallons & Weight, lbs & $\#$ of totes & \\
\hline How many gallons/sqyd do you wan & 0.50 & 2,261 & $18,835^{\circ}$ & 8 & \\
\hline
\end{tabular}


Figure 53. Fibers being spread over the surface of the cement.

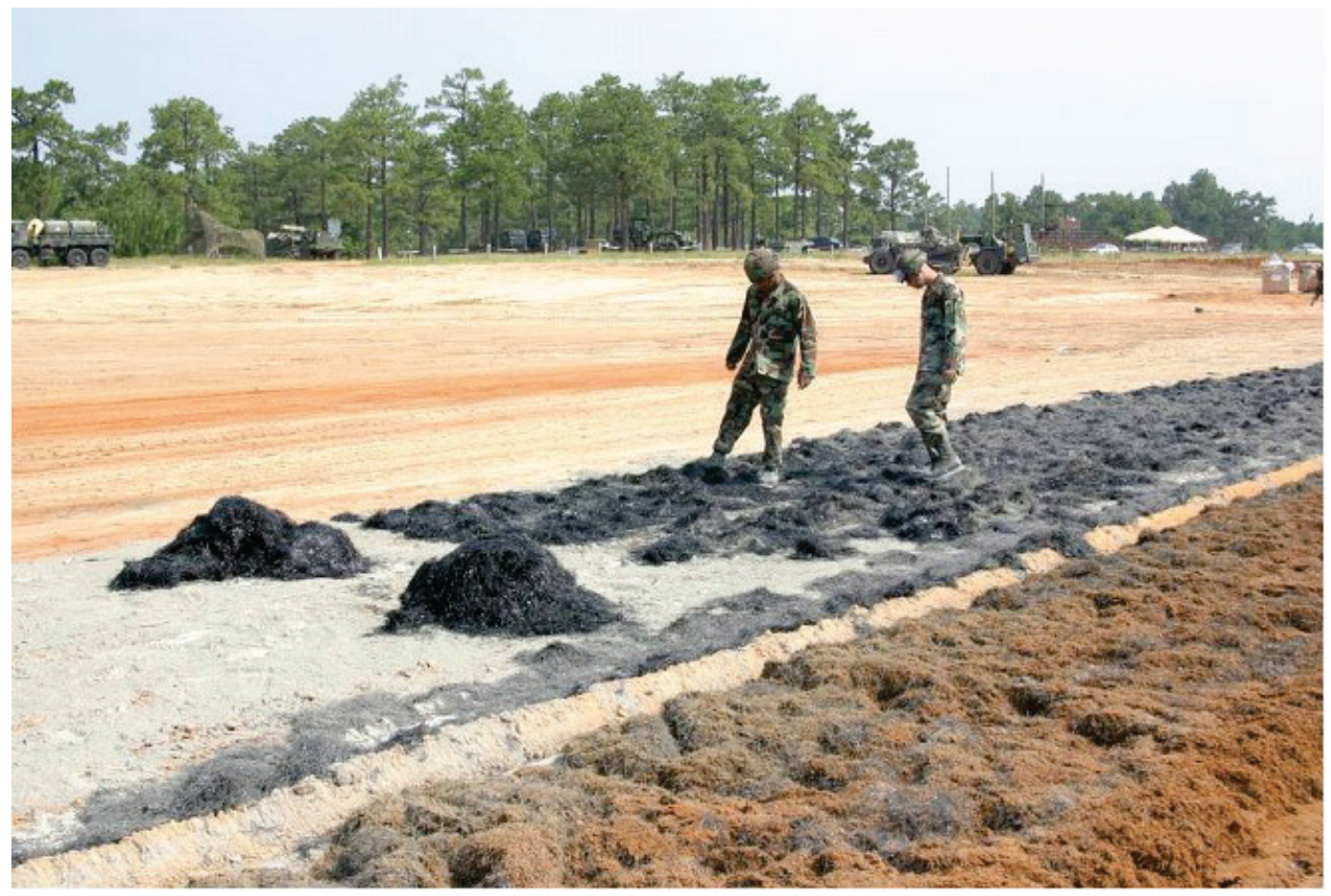

For the water application, the 1,500-gal plastic agricultural tank was used. Thirteen fills of the tank would be needed, or about every three Terex lanes. This required part of the water remaining in the 6,000-gal water truck plus an additional three refills of the water truck. At one point during the stabilization of Apron 2, the entire process was halted for nearly an hour due to the slow turnaround of the water truck.

Similar to Apron 1, a stabilization train was then formed with the MTVR in the lead connected by a boom and nurse hose to the Terex (Figure 54). The Terex was closely followed by two military Caterpillar 433 compactors. The speed of the process was controlled by the Terex. The ALPS unit on the Terex was set to the desired pump rate of $75 \mathrm{gal} / \mathrm{min}$ based on the spreadsheet calculation in Figure 52.

Unlike the polymer cement, the soil-fiber-cement was more difficult to compact, work, and smooth. The material was difficult to hand-work with a shovel and it was best worked with a pitchfork or rake. It was observed that the material can be difficult to smooth by grader or backblading with the Deuce. The fibers tended to 'ball' in front of the blade, making it difficult to obtain a smooth surface. Use of shorter fibers provided relief but was not as efficient at resisting deformation as the longer fibers. In 
short, there was a balance between the length of the fiber needed for soil property improvement and the length needed for efficient construction.

Figure 54. Fiber-cement stabilization train.

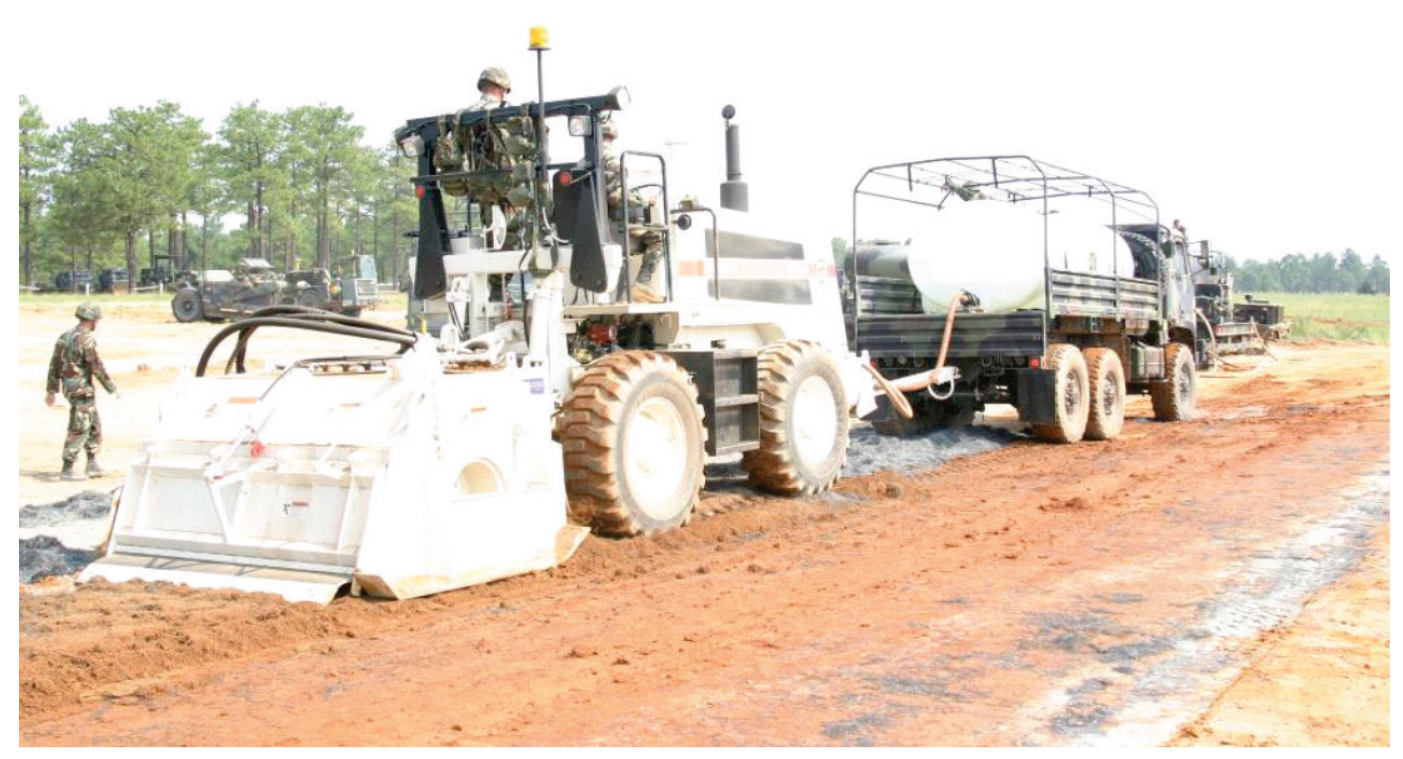

From start to finish, the construction of Apron 2 was accomplished in approximately $17 \mathrm{hr}$ (Figure 55). The surface of the apron was not as smooth as the polymer-cement-stabilized apron, and fibers were visibly protruding from the soil. Most of the protruding fibers were 'locked down' to the soil by the polymer cap. Based on the laboratory testing and field experiments, it was expected that the performance of the soil-fibercement would exceed that of the polymer cement. 
Figure 55. Completed view of Apron 2.

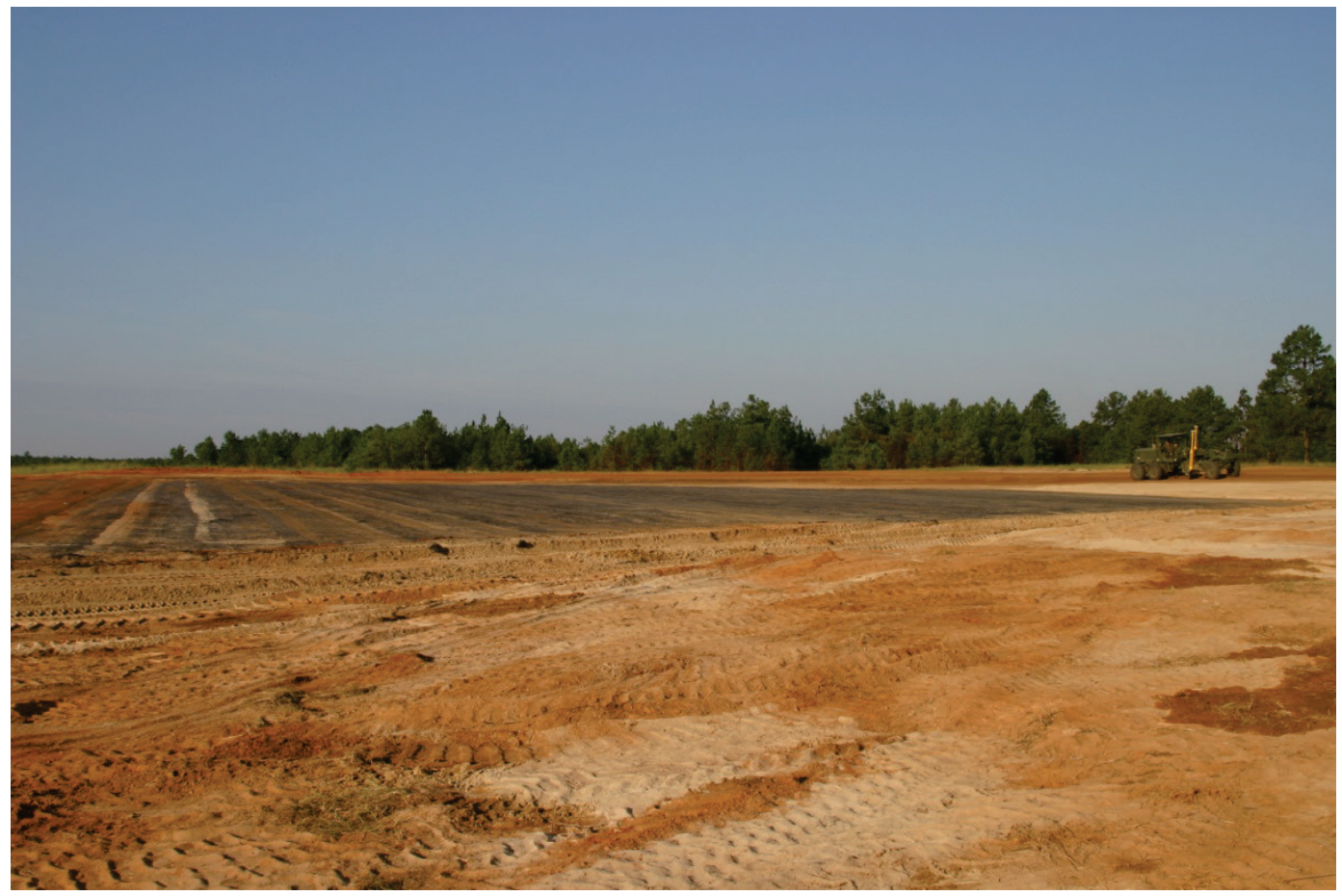

\subsubsection{Dust control}

An area was treated on the taxiway between the two constructed parking aprons to demonstrate dust palliatives on unsurfaced airfields. The whole width of the taxiway was treated, approximately $80 \mathrm{ft}$. The treated section was $150 \mathrm{ft}$ long, and 400 gal of the dust palliative Envirokleen was applied to the section. The HMMWV spray unit applied the product using 5 gal/min spray nozzles. Once the entire section was sprayed, a second pass was made over the section to disperse all the palliative in the spray unit. An additional 400 gal was applied to the shoulders and perimeter of Aprons 1 and 2, approximately $20 \mathrm{ft}$ wide. 


\section{Visitor's Day and Aircraft Landing}

\subsection{Visitor's day}

Prior to completion of the two aprons, a visitor's day was held where participants could observe the various phases of the construction underway. Attendees included representatives from each of the four military services (Army, Air Force, Navy, and Marines) and included a French military contingent as well. Visitors were presented with numerous briefings and demonstrations by the ERDC JRAC team explaining the technology and the intricacies of how the project was completed (Figure 56). The following live field demonstrations were held on the afternoon of Day 3 of the exercise, July 14.

1. Completion of a small section of ACE matting on Apron 1 (Figure 57).

2. Application of polymer dust control agent along the perimeter of Apron 1.

3. Fiber-cement placement, mixing and compaction process occurring on Apron 2.

Following the visitor's day activities, stabilization work continued on Apron 2, and DCP strength testing began on Apron 1.

Figure 56. ERDC JRAC team briefings on Sicily $L Z$ site.

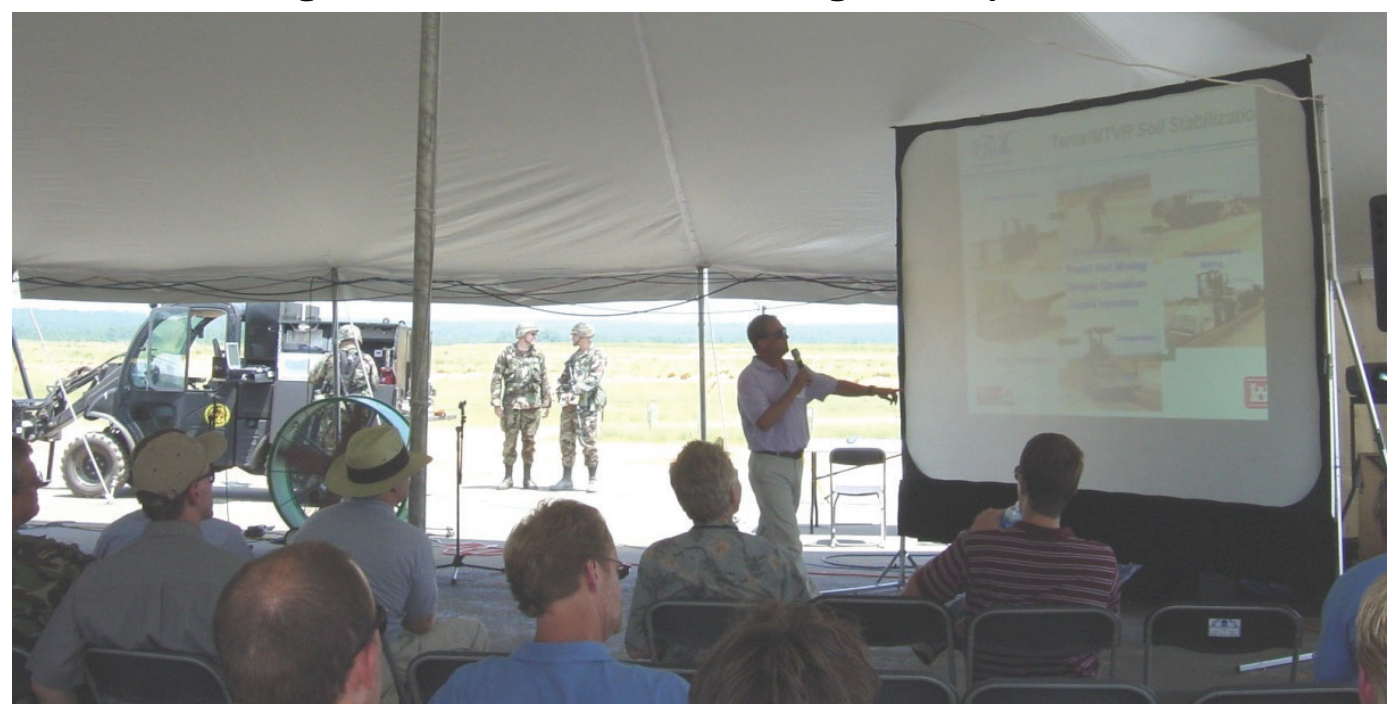


Figure 57. ACE Mat placement during visitor's day.

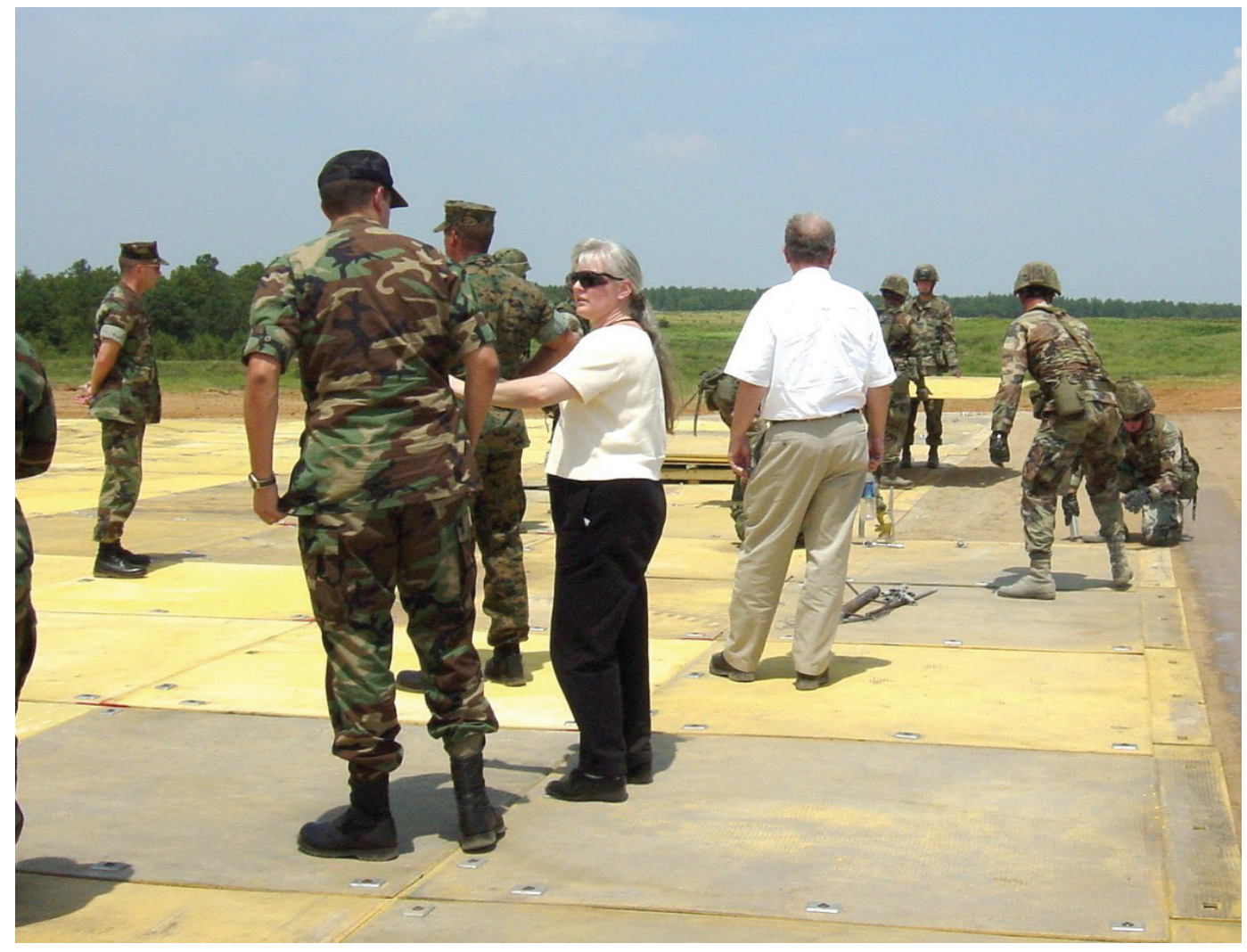

\subsection{Airfield certification}

The certification process for the aprons required identifying a minimum level of CBR prior to authorization of C-130 trafficking. A series of DCP tests were conducted beginning on the afternoon of July 14 and continuing into the night as the cement-polymer-stabilized mixture cured and hardened as described in Chapter 4. The data is shown in Figure 31. A contingent from the U.S. Air Force Special Tactics Squadron (STS) from Pope Air Force Base conducted a careful and thorough inspection of the airstrip and both constructed aprons. Final authorization for $\mathrm{C}-130$ operations from the STS on Apron 1 came the morning of July 15, approximately $1 \mathrm{hr}$ before a landing was scheduled to take place based on final CBR strength values (Figure 58). Apron 2 was in the process of curing at this time and therefore could not be trafficked until the following day. 
Figure 58. Final check of CBR on Apron 1 using a DCP on the morning of C-130 landing.

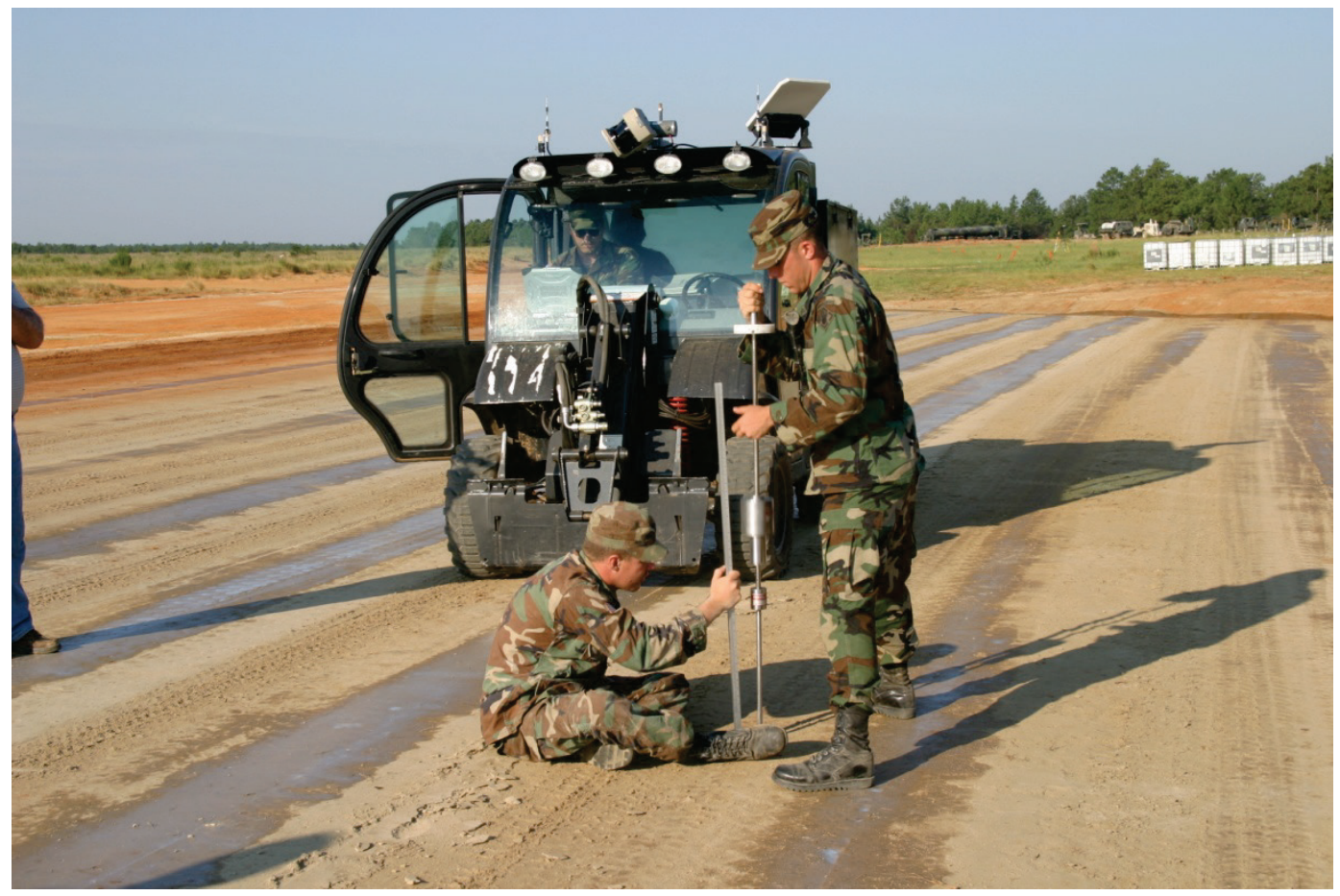

\subsection{C-130 operations}

Upon completion of the construction of the two aprons on July 15, aircraft operations of the C-130 were conducted at Silicy LZ on Apron 1. A single C-130 made a landing on Silicy LZ (Figure 59), taxied onto Apron 1, performed a 180-deg pivot (Figure 60) and parked for attending visitors and ERDC researchers to observe the performance of the stabilized apron (Figure 61). No defects or unusual response was noted, and the pilot commented that this was the smoothest non-surfaced material he had ever trafficked. Trafficking of Apron 2 occurred during the weeks following the demonstration as no scheduled $\mathrm{C}-130$ traffic was available for landing on July 16 when the section was fully cured. 
Figure 59. C-130 making initial touchdown on Sicily LZ with finished Apron 1 in foreground.

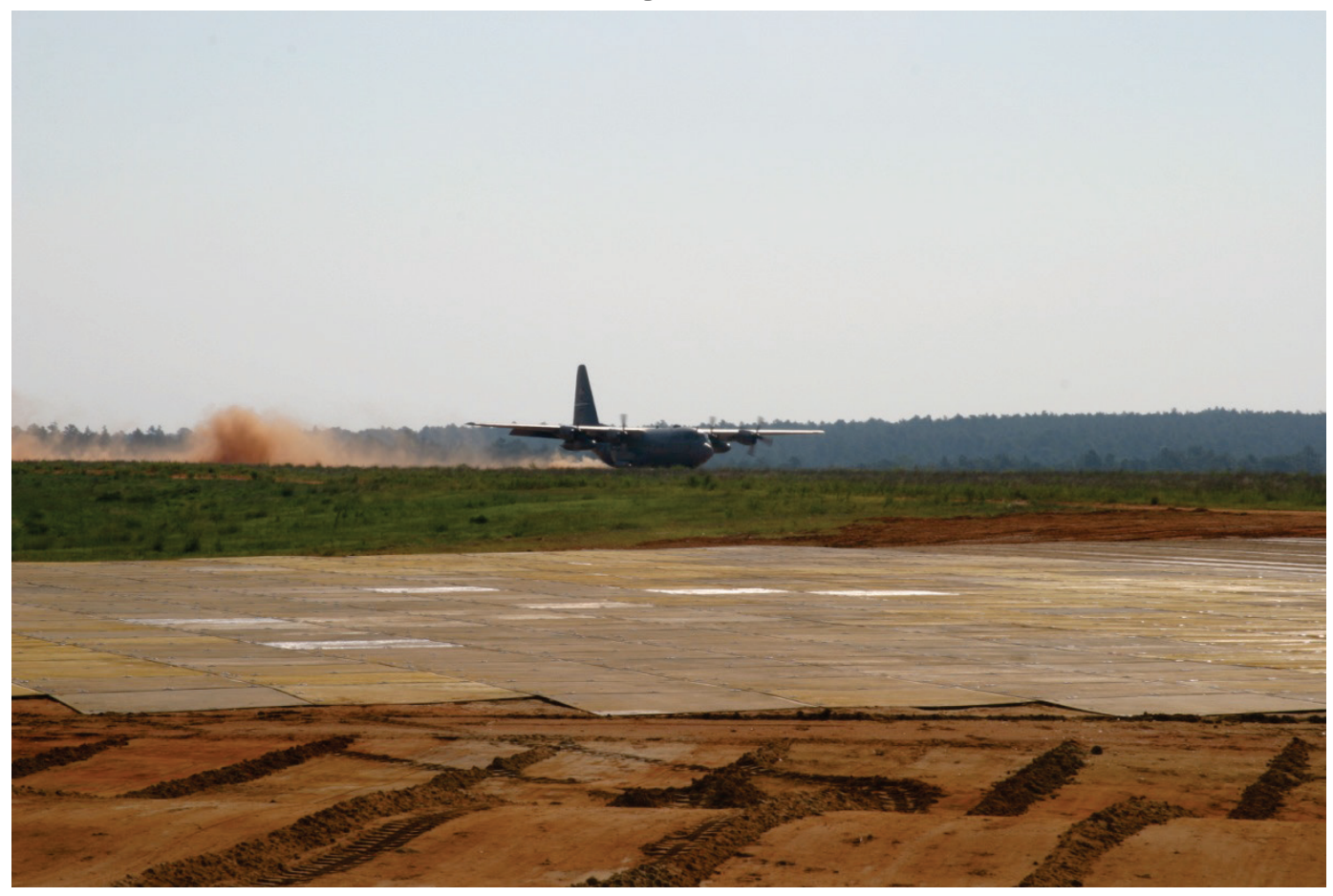

Figure 60. C-130 performing a turn on Apron 1.

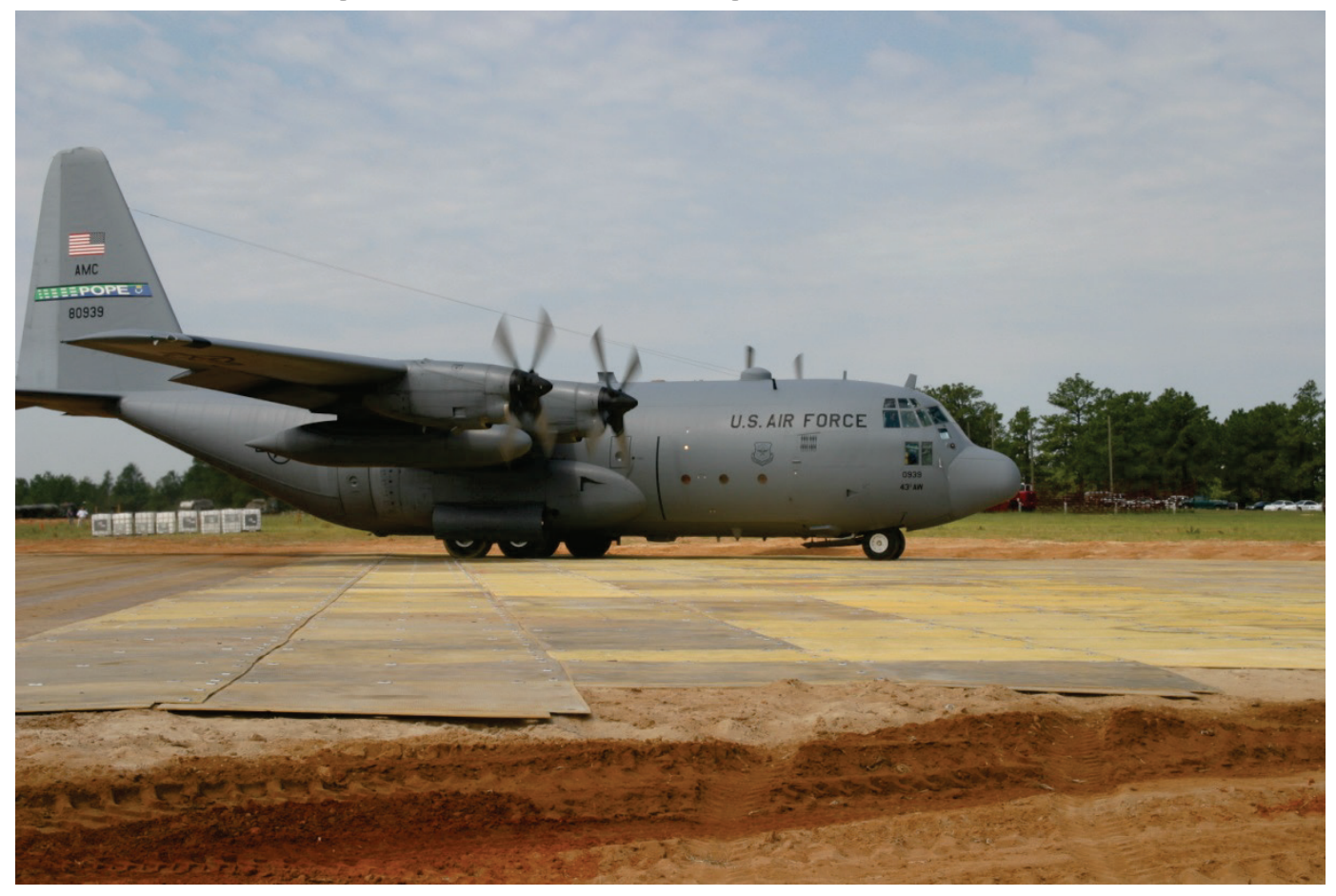


Figure 61. ERDC JRAC team and military leads for the construction effort.

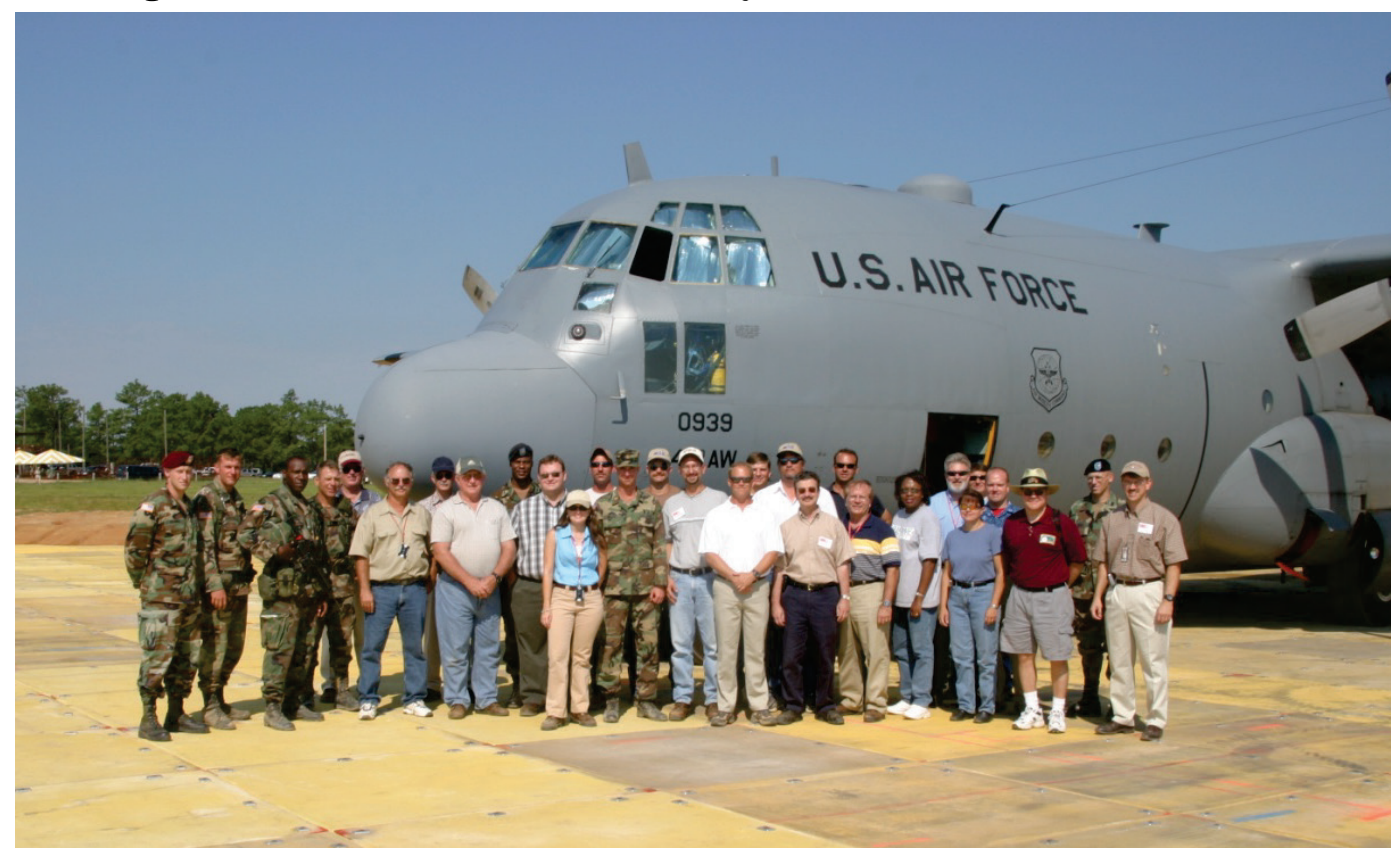




\section{Conclusions and Lessons Learned}

\subsection{Conclusions}

The Joint Rapid Airfield Construction (JRAC) 2004 technology demonstration was, by all accounts, a resounding success. The ability to place the current state of JRAC technology into the hands of the warfighter in a contingency scenario and execute successfully was an excellent benchmark of progress at the 3-yr mark of the overall 6-yr program. A maximum-on-ground (MOG) 1 contingency runway was upgraded to a MOG 3 runway by the construction of two one-acre, trapezoidal, stabilized aprons in $72 \mathrm{hr}$. This met and exceeded the metrics set forth at this 3-yr mark and illustrated the way forward for the future capability of meeting the $\mathrm{C}-17$ criteria in 2007. These metrics were the following.

1. Add MOG 2 ramp space to an existing runway in less than $96 \mathrm{hr}$ (JRAC accomplished this in only $72 \mathrm{hr}$ ).

2. Reduce construction time by at least 50 percent. Conventional construction of the two one-acre aprons was estimated at two weeks' time summarized in Table 2.

3. Increase operational use of MOG 2 ramp space through stabilization. This exercise produced an increase in contingency $\mathrm{C}-130$ operations on Apron 1 from 7 to over 5000.

Table 2. Timeline comparison of conventional to JRAC construction technologies.

\begin{tabular}{|l|c|c|}
\hline \multicolumn{1}{|c|}{ Mission } & Conventional & JRAC \\
\hline Site reconnaissance & 3-4 days & 7 hours \\
\hline Engineering Design & 3-4 days & 5 hours \\
\hline Site Layout and Construction & 7 days & 2.5 days \\
\hline Total time & 13-15 days & 3 days \\
\hline
\end{tabular}

\subsection{Lessons learned}

A number of lessons were learned to apply to the 2007 exercise, as noted here based on selected JRAC technologies that were demonstrated.

\subsubsection{Rapid Assessment Vehicle-Engineer (RAVEN)}

The RAVEN platform demonstrated that housing virtually all the JRAC site assessment and engineering tools on a single mobile platform was a 
viable concept. Further, the ability to conduct a site elevation survey using the RAVEN was critical in reducing the site reconnaissance time from days down to hours.

The automatic dynamic cone penetrometer (DCP) and the autonomous driving features of the RAVEN were demonstrated but not used during the exercise. The DCP, while functional was slower than a manual DCP, and the preferred method for obtaining these data was to use a manual DCP, given the manpower resources available during the exercise. However, in a remote site survey scenario where manpower is limited or where enemies are present, both the automatic DCP and autonomous components are valuable tools to increase soldier safety during the reconnaissance.

It was evident that the horizontal stability of the RAVEN was poor, making it necessary for a vehicle with a lower center of gravity to increase stability, protect the driver, and allow more efficient maneuver in the battle space. This instability makes the current RAVEN platform dangerous to operate under blackout conditions over rough terrain.

\subsubsection{GPS-enabled design/build system}

\subsubsection{Terramodel digital design}

The ability to quickly generate a three-dimensional apron from a template, digitally match that to the existing runway surface, and upload the finished design to the construction equipment was critical in reducing earthmoving construction times. However, development of the Terramodel digital design requires expert users and would be preferably conducted prior to the mission in a pre-planning mode.

\subsubsection{Vehicle GPS design system}

The vehicle GPS design system required a short train-up time for soldiers and a quick turnaround time for operation. Providing the vehicle operators with heads-up displays showing exact cut-fill requirements at every point in the construction area through the GPS design system eliminated the need for time-consuming grade staking. The ability to have the digital display also enabled efficient construction operations during nighttime conditions. 


\subsubsection{Rapid soils analysis}

The use of the RSAK proved to be extremely useful for enabling contingency construction in this compressed timeframe. The ability to estimate modified proctor design properties on-site without extensive testing along with the tools to validate field conditions and test field constructions was a needed capability for this exercise. The soldier requests for immediate access to a portable version of the RSAK suggested its usefulness extends to all facets of the field engineer.

Data storage was inefficient in the first-generation software. Future versions of the software should contain a more robust database for storing field data to expand the capability of the tool to allow quality control/quality assessment to be performed. This should include a more intuitive labeling feature to quickly retrieve information stored from field tests. Error checking to streamline the soil processing is needed beyond those already in place.

\subsubsection{Soil stabilization}

Rapid stabilization of the native soil was very effective at creating the required bearing strength and surface durability to handle the $\mathrm{C}-130$ aircraft. The use of the Terex 325 Reclaimer/Stabilizer provided the necessary equipment technology to enable the rapid stabilization with limited operator training and is certified as C-130 transportable.

The polymer cement stabilization produced a smooth, structurally sound aircraft operating surface with minimal surface preparation that was rapidly constructed. Polymer cement should provide a more durable surface than fiber cement as the polymer binder will improve moisture resistance over the fiber cement technique. However, polymer cement may not be feasible for wet soils as moisture is added during stabilization by the polymer emulsion.

Fiber cement stabilization produced a structurally sound surface with minimal surface preparation and was rapidly constructed. Even though the surface was not as smooth as the polymer cement, it is recommended for most contingency stabilization scenarios. Fiber cement stabilization is more structurally efficient than polymer cement stabilization and may require less equipment needs than polymer cement in some situations. 
The use of lightweight vibratory compactors was effective in compacting stabilized soils by managing the number of passes required to maximize density.

Improvements in the stabilization technique and material application are listed as follows.

- For fiber-cement stabilization, the starting surface must be smooth because the ending surface smoothness mirrors the beginning surface smoothness.

- Shorter fibers are easier to use in construction. The longer fibers chosen for this project tended to accumulate in front of the grader/Deuce blades, making surface finishing difficult.

- For rapid construction, the fibrillated fibers do not 'defibrillate' well with only one pass of the pulvermixer. Monofilament fibers should better serve a rapid construction project and were recommended for the 2007 exercise.

- Polymer emulsion surface capping works well for polymer-cementand fiber-cement-stabilized surfaces, providing excellent dust control and rain protection. However, reapplication to maintain the barrier will be necessary as wear occurs on the surface.

- Synthetic fluids for dust control are best for unstabilized surfaces and performed extremely well for the Fort Bragg silty-sand soil type when placed along parallel taxiways and apron perimeters.

\subsubsection{Matting}

The use of ACE-Mat worked well as a stabilizing agent to the natural subgrade providing a smooth, solid platform for C-130 operations. Maintenance was required to replace pin connectors that may be damaged or pop out during operations. The one concern with the ACE-Mat is that during this demonstration, the trapezoidal apron shape required a stairstep pattern of matting along the apron edges. This jagged boundary proved cumbersome for vehicle maneuvers around the apron perimeter as tear-outs of multiple mat sections were noted during post-demonstration visits. These tear-outs were likely due to snagging of the mat edges or the tie-down wires on vehicle frames. Functionally, the design of the matting 
should be in a square or rectangular shape to minimize tear-out potential from vehicle operations around parked aircraft.

\subsection{Summary}

The 2004 JRAC demonstration project was successful on three important levels.

1. It provided valuable engineering and construction training to many personnel while introducing the technology to the military community as a whole.

2. It provided enduring infrastructure to the Sicily LZ, providing parking aprons and landing surfaces for future combat exercises.

3. It proved the viability of the JRAC process for future missions and the goal of establishing a baseline system of components from which to build on for the more complex $\mathrm{C}-17$ loading criteria.

Based on observations from the 2004 JRAC demonstration, the next phase of development will focus on enhancing the listed capabilities for $\mathrm{C}-17$ capable loadings, finalizing the JRAC decision support tool, and introducing rapid quality control/quality assessment technologies to provide a complete design package for rapid contingency military construction. 


\section{References}

American Society for Testing and Materials (ASTM) International. 200o. Standard test method for determination of water (moisture) content of soil by the microwave oven heating. Designation D4643-00. West Conshohocken, PA: American Society for Testing and Materials International.

Headquarters, Departments of the Army. 1992. Military soils engineering. FM 5-410. Washington, DC: Department of the Army.

Headquarters, Departments of the Army and Air Force. 1994a. Planning and design of roads, airfields and heliports in the theater of operations - Airfield and heliport design. FM 5-430-00-02/AFJPAM 32-8013 Vol. 2. Washington, DC:

Departments of the Army and Air Force.

Headquarters, Departments of the Army and Air Force. 1994b. Planning and design of roads, airfields and heliports in the theater of operations - Road design. FM 5430-00-1/AFJPAM 32-8013, Vol. 1. Washington, DC: Departments of the Army and Air Force.

Headquarters, Air Force Civil Engineering Support Agency. 1997. Criteria and guidance for $C-17$ contingency and training operations on semi-prepared airfields. Engineering Technical Letter (ETL) 97-9. Tyndall AFB, FL: Air Force Civil Engineering Center.

Headquarters, Air Force Civil Engineering Support Agency. 1998. $C$-13o and $C-17$ contigency and training airfield dimensional criteria. Engineering Technical Letter (ETL) 98-5. Tyndall AFB, FL: Air Force Civil Engineering Center.

Headquarters, Air Force Civil Engineering Support Agency. 2004. $C$-130 and $C$-17 landing zone (LZ) dimensional, marking, and lighting criteria. Engineering Technical Letter (ETL) 04-07. Tyndall AFB, FL: Air Force Civil Engineering Center.

Rushing, J. F., V. M. Moore, and J. S. Tingle. 2006. Evaluation of chemical dust pallatives for helipads. ERDC/GSL TR-06-2. Vicksburg, MS: U.S. Army Engineer Research and Development Center.

Tingle, J. S., and T. A. Mann. 2001. Expedient airfield construction using the computeraided earthmoving system. ERDC/GSL TR-01-20. Vicksburg, MS: U.S. Army Engineer Research and Development Center.

Webster, S. L., R. H. Grau, and T. P. Williams. 1992. Description and application of dual mass dynamic cone penetrometer. Instruction Report GL-92-3. Vicksburg, MS: U.S. Army Engineer Waterways Experiment Station. 


\title{
Appendix A: Memorandum of Agreement
}

\author{
MEMORANDUM OF AGREEMENT \\ BETWEEN \\ THE GEOTECHNICAL AND STRUCTURES LABORATORY (GSL) \\ OF THE ENGINEER RESEARCH AND DEVELOPMENT CENTER \\ (ERDC)
}

AND

XVIII AIRBORNE CORPS AND FT. BRAGG

SUBJECT: Joint Rapid Airfield Construction (JRAC) FY 04

Demonstration at Sicily Assault Landing Zone (LZ), Ft. Bragg, NC

1. Purpose. The purpose of this memorandum agreement is to outline the agreement reached between the XVIII Airborne Corps, Ft. Bragg and the Geotechnical and Structures laboratory (GSL) of the Engineer Research and Development Center. The agreement entered into under this memorandum will be effective on or about November 30, 2003, and remain in effect until September 30, 2004, or when the demonstration is complete. It is relevant to all aspects of the planning, organization, and execution of the FYo4 JRAC Demonstration. It serves to outline the roles and responsibilities of each organization during the planning and execution of a Joint Rapid Airfield Construction Technology Demonstration that is scheduled for the summer of 2004 at Ft. Bragg, NC.

2. Background. Beginning in 2001, the U.S. Army Corps of Engineers, Engineer Research and Development Center (ERDC) initiated a new military research effort known as the Joint Rapid Airfield Construction (JRAC) program. The primary objective of this research program is to 
develop methodologies and materials for rapidly upgrading existing or constructing new contingency airfields with the lowest logistical footprint possible. The JRAC program is designed to meet this objective by 1) integrating advanced terrain analysis technologies and performance prediction modeling to optimize contingency airfield site selection, 2) utilizing emerging commercial soil stabilization technologies to rapidly provide contingency airfield surfaces capable of sustaining mission operations, and 3) exploiting new construction technologies to enhance airfield construction productivity.

The program was designed such that two demonstrations would be conducted during the life of the program. A mid-program demonstration is scheduled to take place in 2004 and the final demonstration will take place at the end of the program in 2007. The ERDC has a successful history of working with the XVIII Airborne Corps, and the existence of several un-surfaced airfields makes Ft. Bragg an ideal location for the 2004 Demo.

3. Scope and Proposed Concept of Demonstration. The main focus of the demo is to demonstrate the methods, procedures, and equipment used to expand a chosen contingency airfield in theater from a Maximum-On-Ground (MOG) rating of one to an effective MOG of three. At the Sicily Assault Landing Zone (LZ) site, this goal will be accomplished by the construction of two aircraft parking aprons connected to the existing taxiway (see Demo Schematic). Apron No. 1 (AP1) will employ the use of soil stabilization technology using polymers, cement, or a combination thereof to strengthen the soil for use as a parking apron. The taxiway connecting the new apron to the existing taxiway will be constructed using aircraft matting and soil stabilization or matting alone, depending on the in-situ conditions of the ground materials. The matting system will extend onto the existing taxiway and some short distance in either direction to alleviate any destruction of the taxiway during aircraft turning onto the new apron. A platoon of the $12^{\text {th }}$ (Air Sp) Engineer Brigade, British Armed Forces will construct a second airfield apron (AP2) using sand fiber stabilization technology. This second apron is initially considered an optional construction element, pending confirmed 
acceptance of this task by Ft. Bragg and the British $12^{\text {th }}$ Engineer Brigade. Additional engineer effort will be expanded to the existing taxiway and surrounding areas to alleviate the problems associated with rainfall and erosion.

The FYo4 Demonstration project may involve the upgrade of some portion or portions of the Sicily LZ runway and parallel taxiway using JRAC technologies during the scheduled maintenance and restoration of the LZ. Fort Bragg and ERDC will mutually agree upon the extent of JRAC technologies to be used for this airfield upgrade.

There is planned a limited demonstration of rapid airfield repair technologies at Camp Mackall Army Airfield (AAF). This exercise will be limited in nature and will be conducted on the inactive airstrip at Mackall AAF for a period of not less than five (5) days.

\section{Responsibilities.}

a. Geotechnical and Structures Laboratory of the ERDC.

(1) Dr. Gary Anderton or Mr. Travis Mann will act as the point of contact (POC) for all technical matters during the demonstration.

(2) Provide engineering support for the demonstration including site assessment, design, and evaluation.

(3) Provide all resources associated with the engineering support as well as any manufactured materials that will be required for the demonstration (i.e. mats, and stabilization products). 
(4) Organize a Visitors Day and its associated schedules and be responsible for the rental or lease of any support equipment needed (tents, lights, tables, chairs, etc.). The ERDC will be responsible for sending out all of the invitations to the event.

(5) Assist the 2oth Eng Bde in the development of the required erosion control plans.

(6) Provide information pursuant to completion of an Environmental Assessment (EA) for the demonstration.

(7) Supply all of the manpower, materials, equipment, and coordination to conduct the Camp Mackall AAF exercise.

(8) Provide Fort Bragg Protocol office and the 2oth Eng Bde with a list of VIP's and Distinguished Visitors (DV's) attending the demonstration NLT 3 MAY 2004, updating it as required.

(9) Provide pulverization equipment

b. XVIII Airborne Corps and Ft. Bragg

(1) Act as overall hosts for the demonstration, providing logistical and protocol support for DV's and VIP's beyond the Rank of Colonel or the civilian equivalent.

(2) Provide Public Affairs Office (PAO) support.

(3) The XVIII Airborne Corps and Ft. Bragg coordinates additions to the VIP/DV list with the 20th Eng Bde and ERDC.

(4) Will assist the Public Works Business Center (PWBC).

(5) Will be responsible for the $20^{\text {th }}$ Eng Bde performing the following:

a) Act as the executive agent for coordination and execution of this demonstration in regards to required activities not addressed in the MOA.

b) Provide transportation for visitors from the various sites during the Visitors Day as well as be responsible for any additional logistics.

c) Serve as the liaison between ERDC and PWBC.

d) Develop the required erosion control plan(s). 
e) Submit Environmental Assessment (EA) and Erosion Control Plan (ECP).

f) Execute the ECP plan.

g) Provide one platoon of engineers, ensuring they are available for train-ups and the JRAC demonstration.

h) Coordinate equipment requirements with ERDC.

i) Submit JATT request for airborne operations and air land operations.

j) Submit Range block request and coordinate for access to both Sicily and Camp Mackall AAF for the demonstrations, associated recons and assessments.

k) Provide the number and type of construction equipment required for use in the JRAC demonstration.

1) Serve as the liaison between EDRC and XVIII Airborne Corps.

\section{Dissemination of Information}

Public Information. Prior to releasing information to the public through the Freedom of Information Act, 5 U.S.C. 552, or otherwise, regarding work undertaken pursuant to this MOA, GSL and the XVIII ABC shall coordinate and consult with each other.

Information to Congress. GSL and XVIII ABC share joint responsibility for providing information to Congress, if necessary.

\section{Points of Contact:}

a. This memorandum and ERDC: Mr. Travis A. Mann, Airfields and Pavements Branch, Geotechnical and Structures Laboratory, Engineer Research and Development Center, COM: (601) 634-3531, DSN 446-3531, e-mail Travis.A.Mann@erdc.usace.army.mil

b. $2^{\text {th }}$ Engineer Brigade: Major Daniel Colling, Plans Officer, COM: (910) 396-1098, e-mail collingde@bragg.army.mil. 
KARL HORST

DAVID W. PITTMAN,

$\mathrm{PhD}$

COL(P), GS

Chief of Staff, XVIII ABC

(date signed)
Acting Director,

Geotechnical and Structures Laboratory

Engineer Research and Development Center 


\section{Appendix B: Daily Construction Reports}

Reference sheets are on the following pages. 


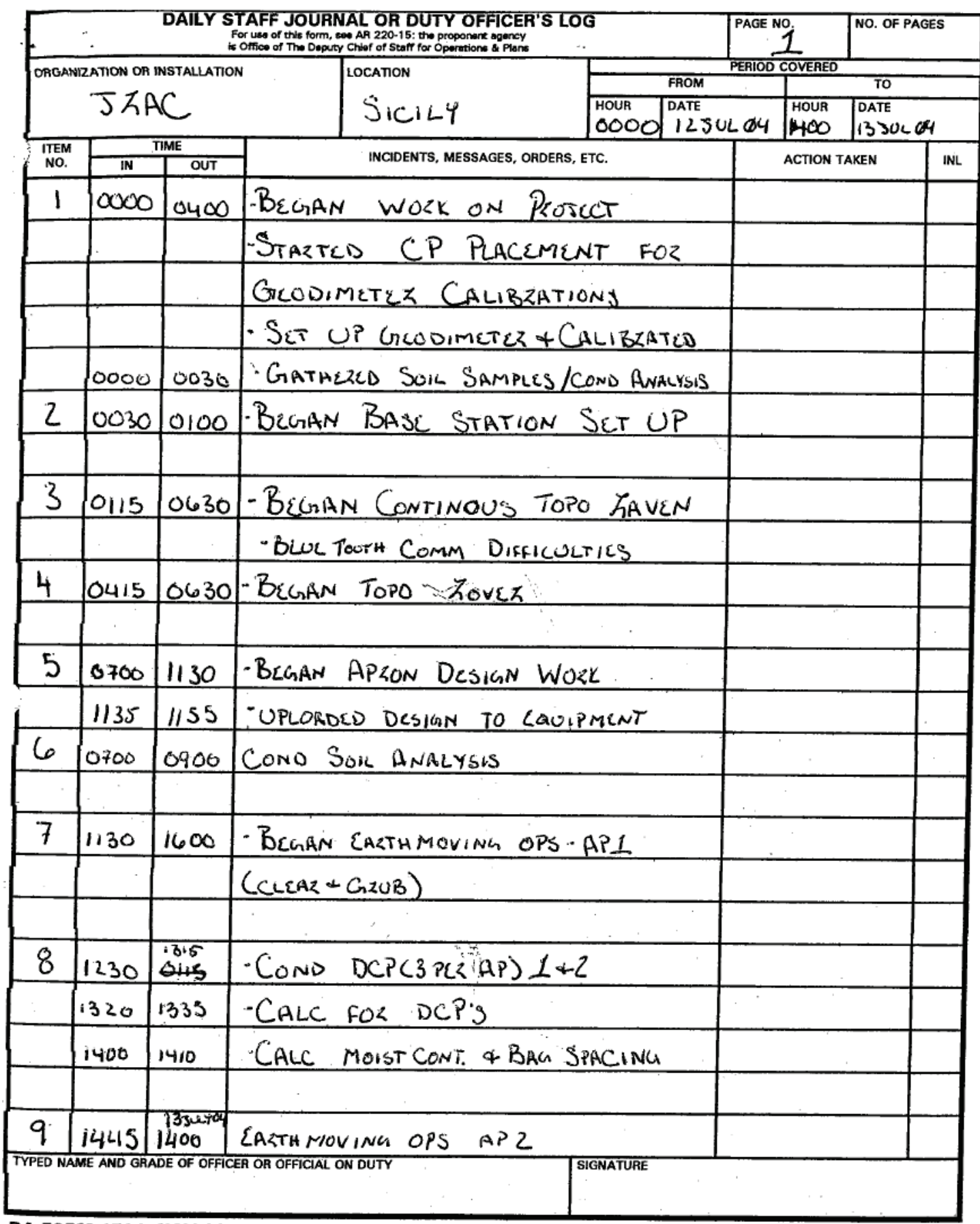




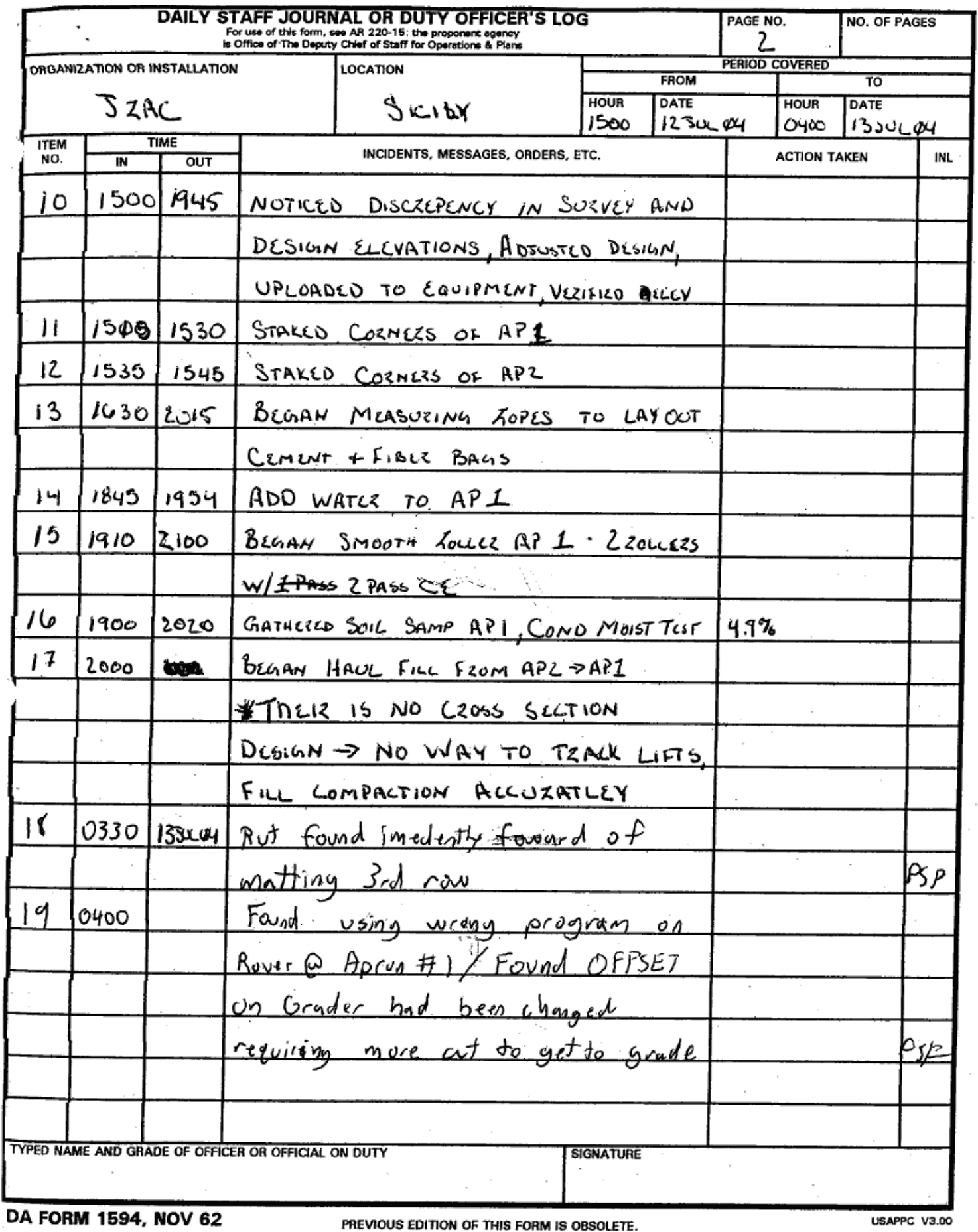




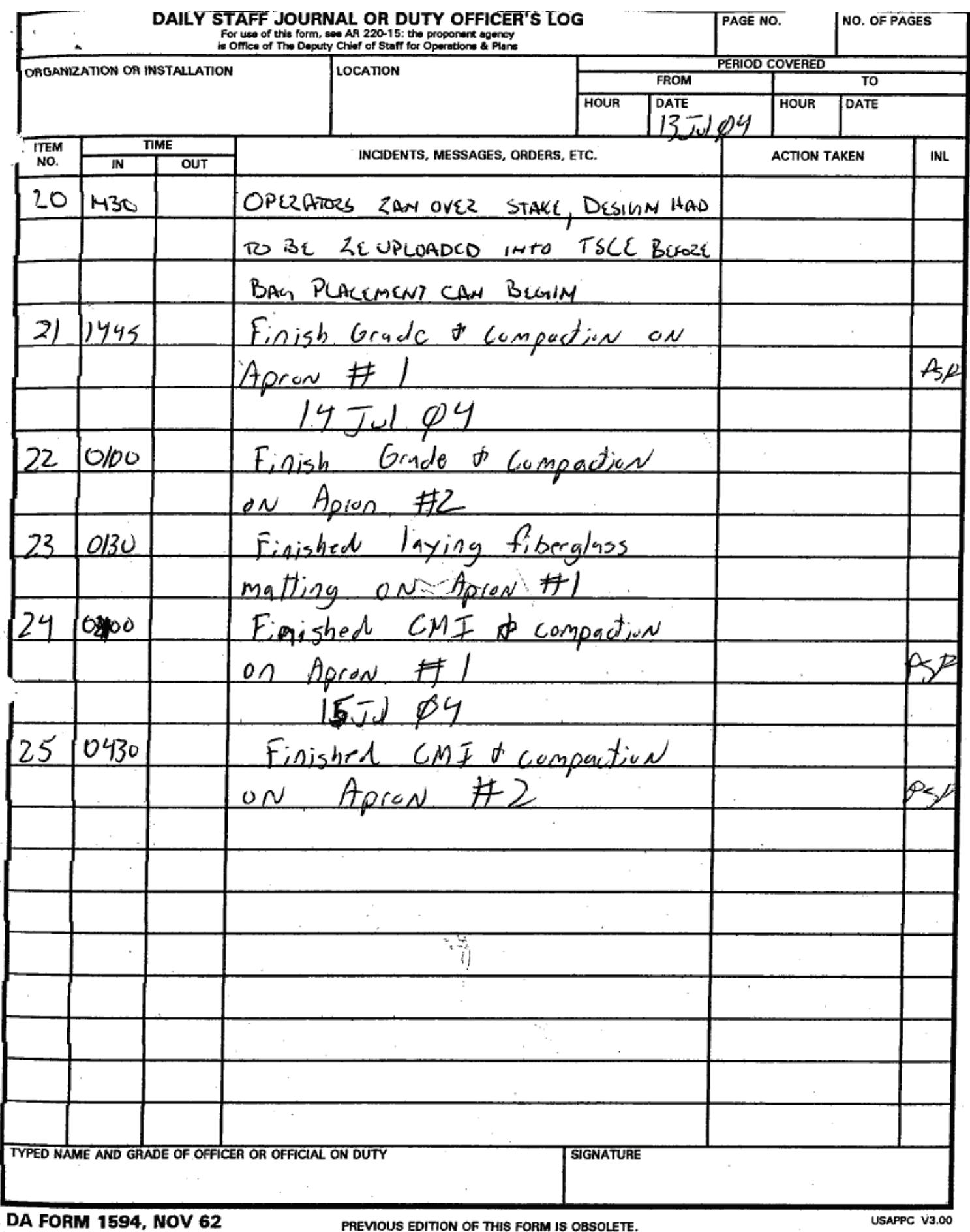




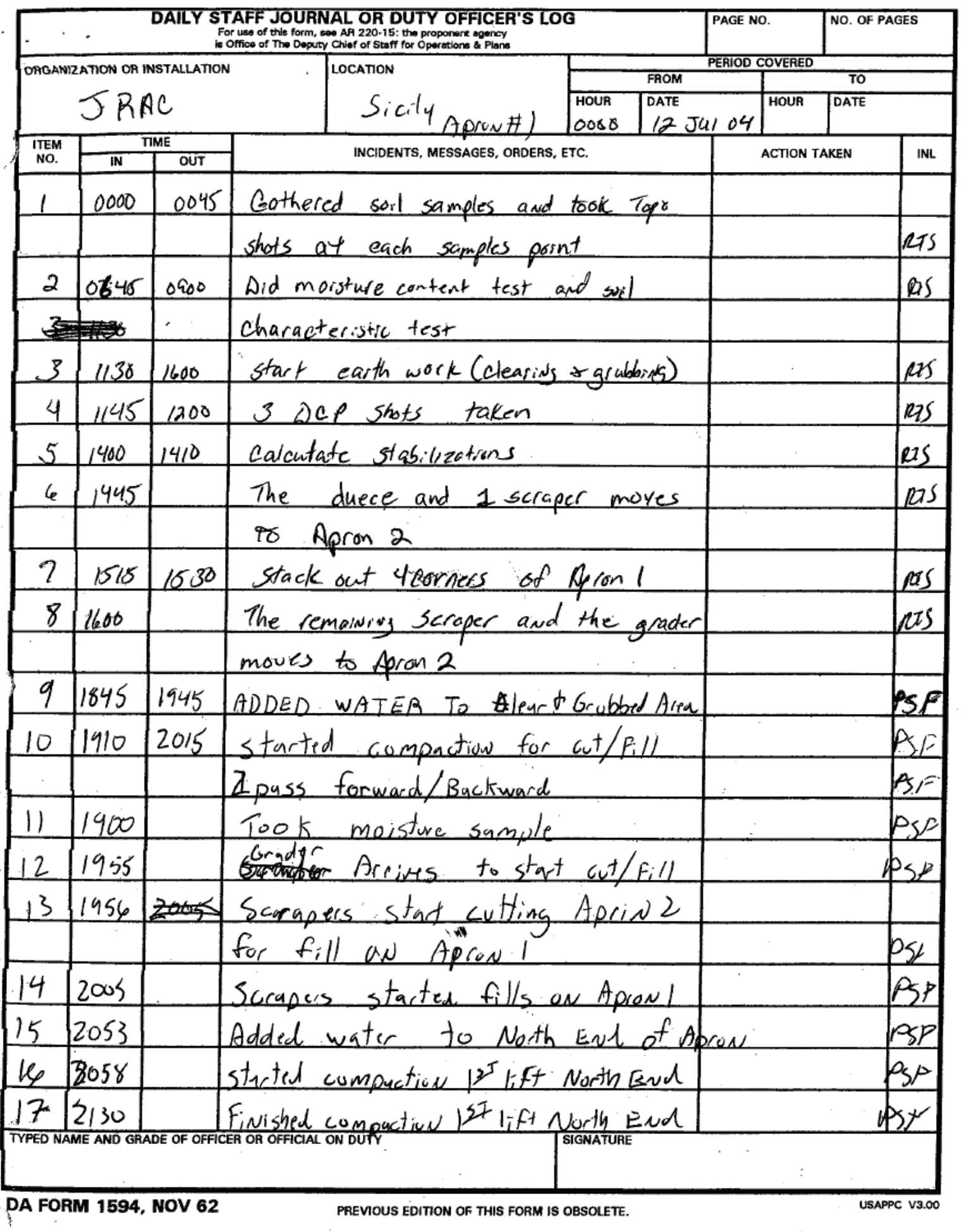




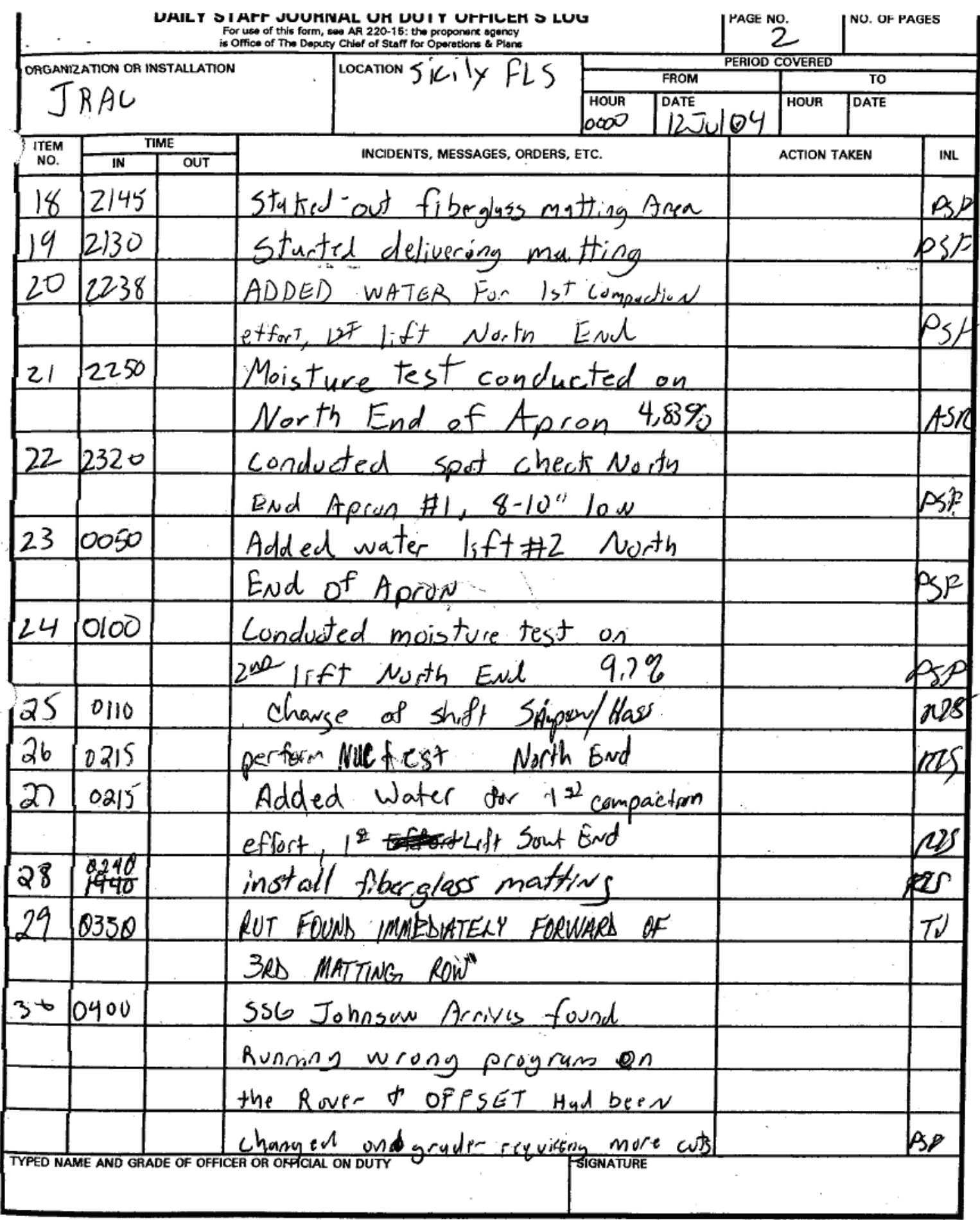




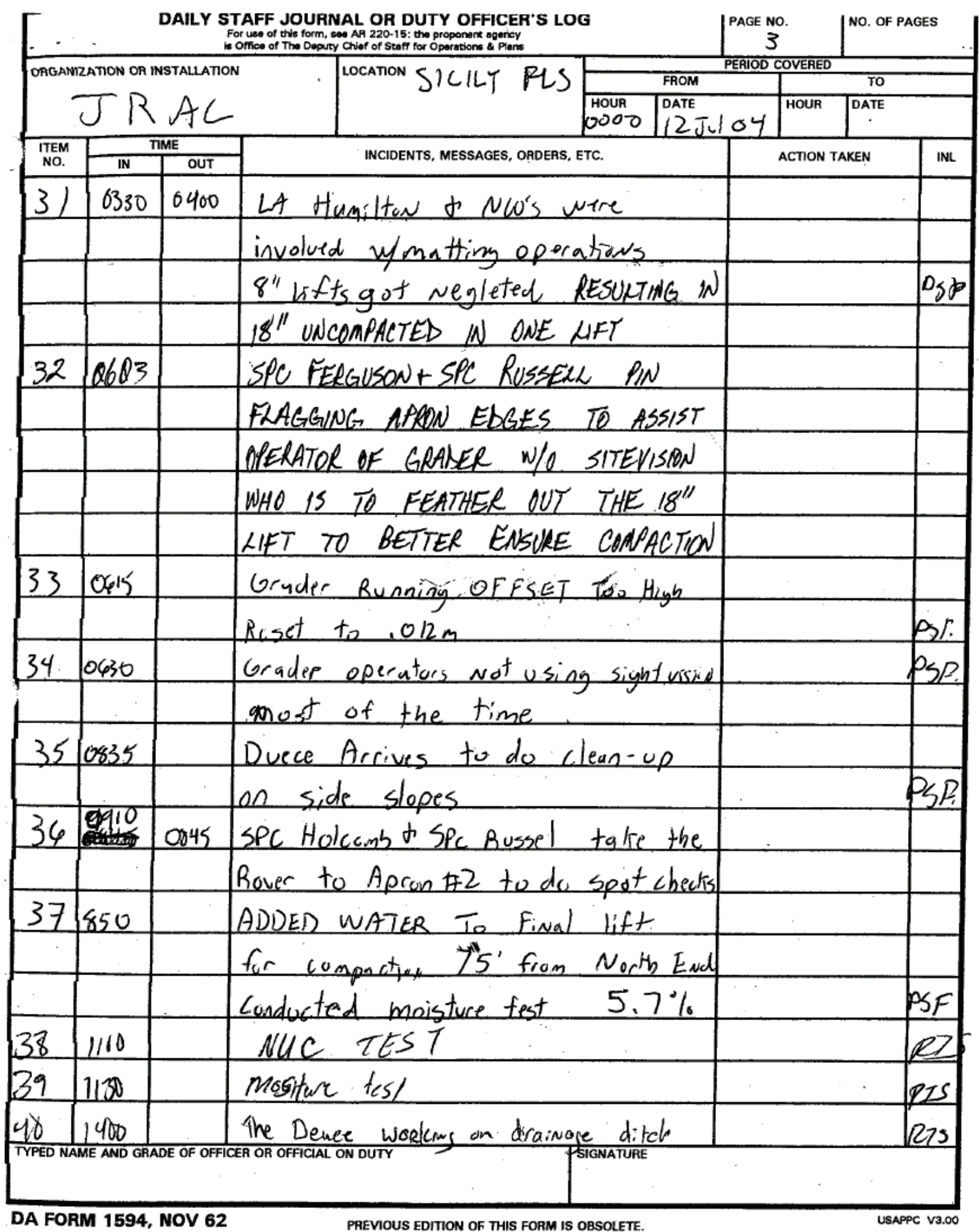




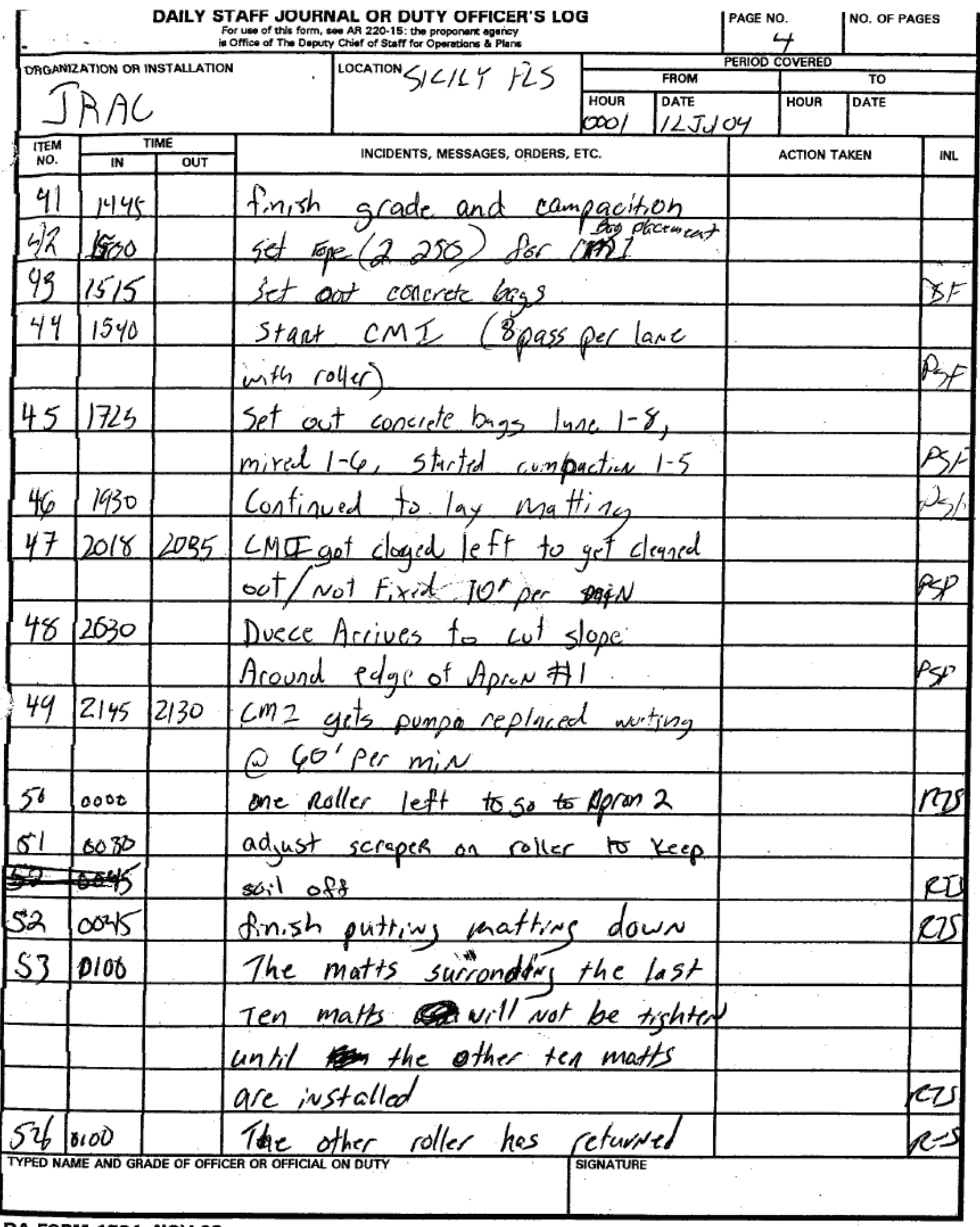




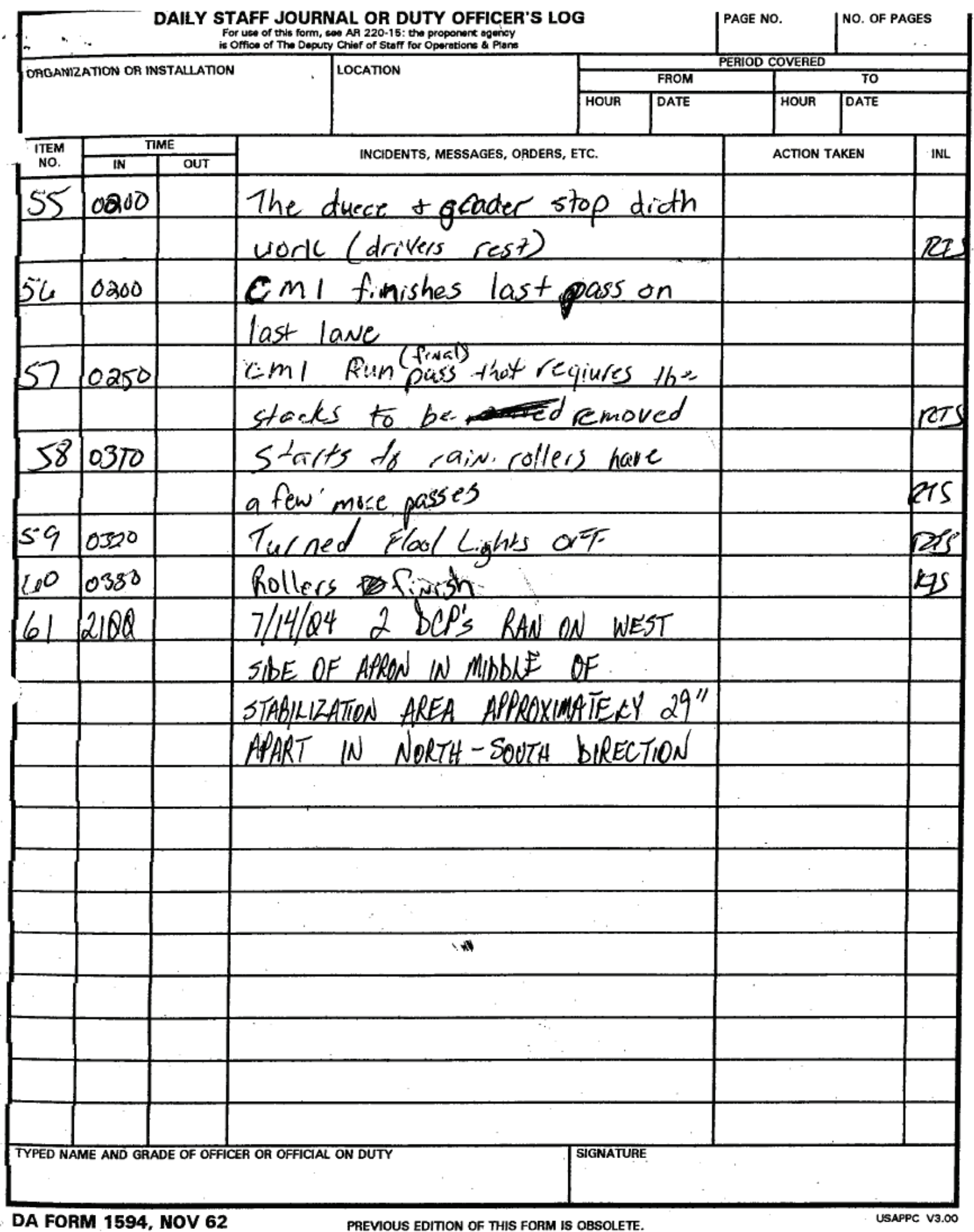




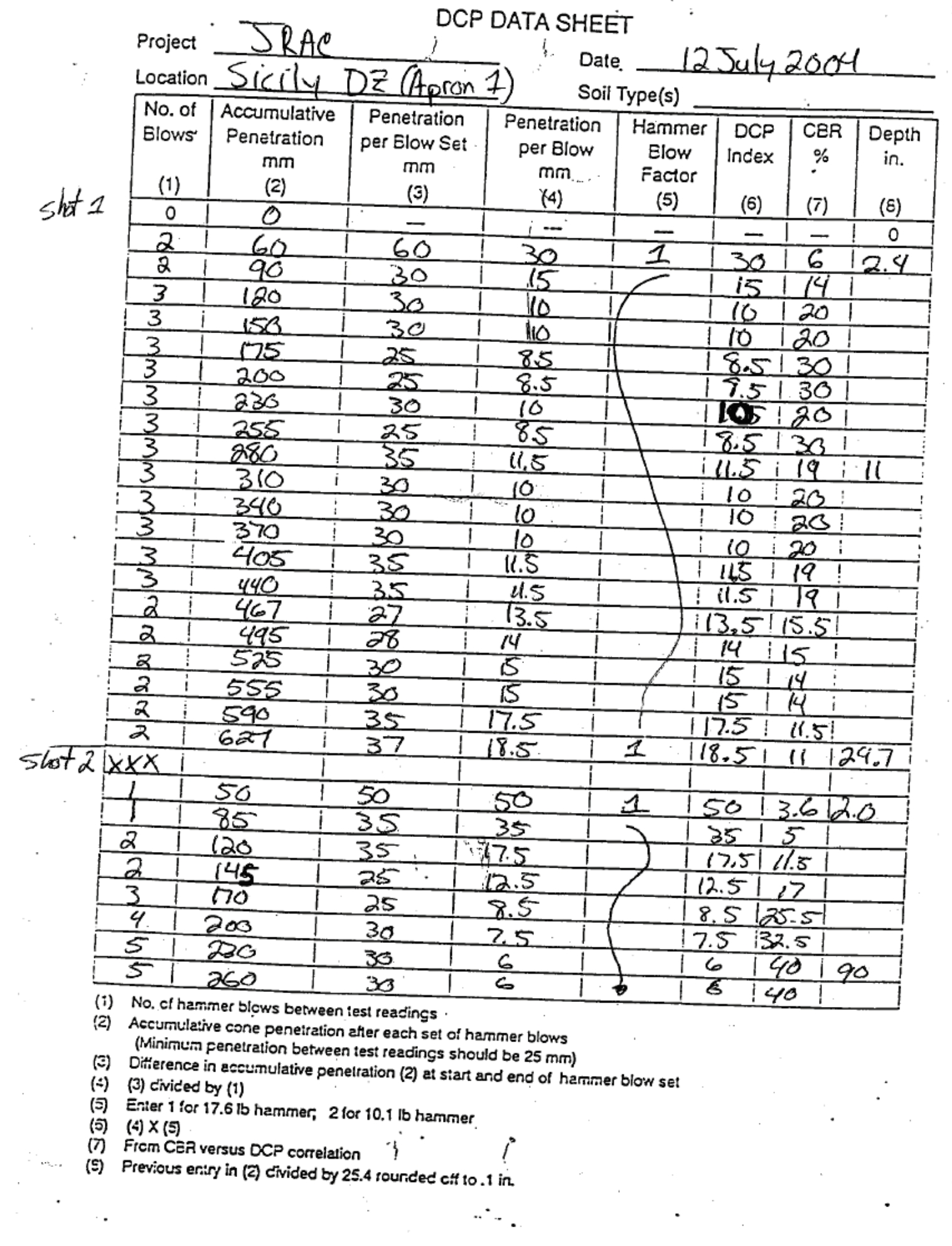




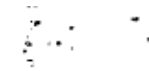

SHOT 3

$$
\text { Project } \frac{\text { IRAC }}{\text { Location SICILY DZ (APRON 1) }} \text { No. of Accumulative (Penetration Type(s) }
$$

\begin{tabular}{|c|c|c|c|c|c|c|c|c|}
\hline & $\begin{array}{l}\text { No. of } \\
\text { Blows } \\
\text { (1) }\end{array}$ & $\begin{array}{c}\text { Accumulative } \\
\text { Penetration } \\
\text { mm ... } \\
(2) \\
\end{array}$ & $\begin{array}{c}\text { Penetration } \\
\text { per Elow Set } \\
\mathrm{mm} \\
\text { (३) } \\
\end{array}$ & $\begin{array}{c}\text { Penetration } \\
\text { per Blow } \\
\text { mm } \\
(4) \\
\end{array}$ & $\begin{array}{c}\text { Hammer } \\
\text { Elow } \\
\text { Factor } \\
(5)\end{array}$ & \begin{tabular}{|c|} 
DCP \\
Index \\
$(6)$ \\
\end{tabular} & $\begin{array}{c}\text { CER } \\
\% \\
(\overline{7}) \\
\end{array}$ & $\begin{array}{l}\text { Depth } \\
\text { in. } \\
\text { (घ) } \\
\end{array}$ \\
\hline & 0 & 0 & - & $i \ldots$ & -1 & $1-$ & - & 0 \\
\hline & 5 & 290 & 30 & 6 & 1 & 6 & 401 & \\
\hline & 4 & 315 & 25 & 6,5 & 1 & 5,51 & 35,5 & \\
\hline & 4 & 345 & 30 & 17.5 & 1 & 7,51 & 32.5 & \\
\hline & 3 & 380 & 35 & 112 & 1 & 121 & 18 & \\
\hline & 3 & 415 & 35 & 12 & 1 & 121 & 18 & \\
\hline & 2 & 450 & 35 & 17.5 & 1 & 17.51 & 1.1 .5 & 18 \\
\hline & 2 & 496 & 45 & 27,5 & 1 & 127.5 & 71 & \\
\hline & 2 & 540 & 50 & 25 & 1 & 1251 & 8 & \\
\hline & 1 & 565 & 25 & 12,5 & 1 & $i 12,5 i$ & 117 & \\
\hline & 1 & 595 & 30 & 15 & $T$ & 15 & 14 & 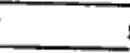 \\
\hline & -1 & 620 & 25 & 12.5 & 1 & 12.5 & 17 & 24 \\
\hline & $x \times x$ & & $\vdots$ & & & $i$ & 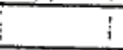 & 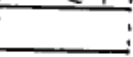 \\
\hline SHOT $3 !$ & $i$ & 50 & 50 & 50 & 1 & 50 & $3,7 !$ & 2 \\
\hline & 1 & 80 & 30 & 30 & 1 & 30 & 61 & \\
\hline & 1 & 110 & 30 & 30 & 1 & 30 & 6 & \\
\hline : & 1 & 135 & 25 & 25 & 1 & 25 & 8 & \\
\hline & 2 & 175 & 40 & 20 & 1 & 1201 & 16 & \\
\hline & 2 & 205 & 30 & 15 & 1 & 1151 & 14 & \\
\hline & 3 & 235 & 30 & 10 & 1 & 10 & 20 & \\
\hline & 3 & 265 & 30 & 10 & 1 & 101 & 201 & \\
\hline & 3 & 290 & 25 & 8.5 & 1 & 8.51 & 25.51 & \\
\hline & 3 & 320 & 30 & 10 & 1 & 101 & 201 & \\
\hline & 3 & 345 & 25 & 8.5 & 1 & 8,51 & 25,51 & 14 \\
\hline & 3 & 375 & 30 & 10 & 1 & 101 & 201 & \\
\hline & 3 & 400 & 25 & 8.5 & 1 & 8.512 & 25.51 & \\
\hline & 3 & 430 & 30 & 10 & 1 & 101 & 201 & \\
\hline & 3 & 460 & 30 & 10 & 1 & 10 & 201 & \\
\hline & 3 & 500 & 40 & 13,1 & 1 & 13.11 & 161 & \\
\hline & 2 & 535 & 35 & 17.5 & & 17.5 & 11.51 & \\
\hline $\begin{array}{l}\text { (i) } \\
\text { (2) } \\
\text { (3) } \\
\text { (i) } \\
\text { (घ) } \\
\text { (5) } \\
\text { (7) } \\
\text { (9) }\end{array}$ & $\begin{array}{l}\text { No. of h } \\
\text { Accumb } \\
\text { (Minimi } \\
\text { Ditteren } \\
\text { (3) c'ivict } \\
\text { Enter 1f } \\
\text { (4) X (9) } \\
\text { Frcm CE } \\
\text { Frevious }\end{array}$ & 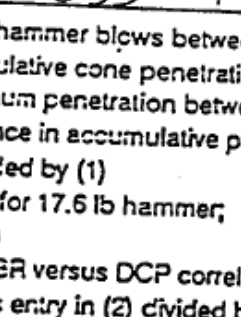 & $\begin{array}{l}\text { ween test reacings } \\
\text { ration after each set } \\
\text { tween test readings } \\
\text { penetration (2) at st } \\
\text { r. } 2 \text { for } 10.1 \mathrm{lb} \text { hamn } \\
\text { relation ij }\end{array}$ & $\begin{array}{l}\text { of hammer blows } \\
\text { should be } 25 \mathrm{~mm} \text { ) } \\
\text { tart and end of ham }\end{array}$ & iner blow se: & $17.5 !$ & 11.51 & . \\
\hline
\end{tabular}




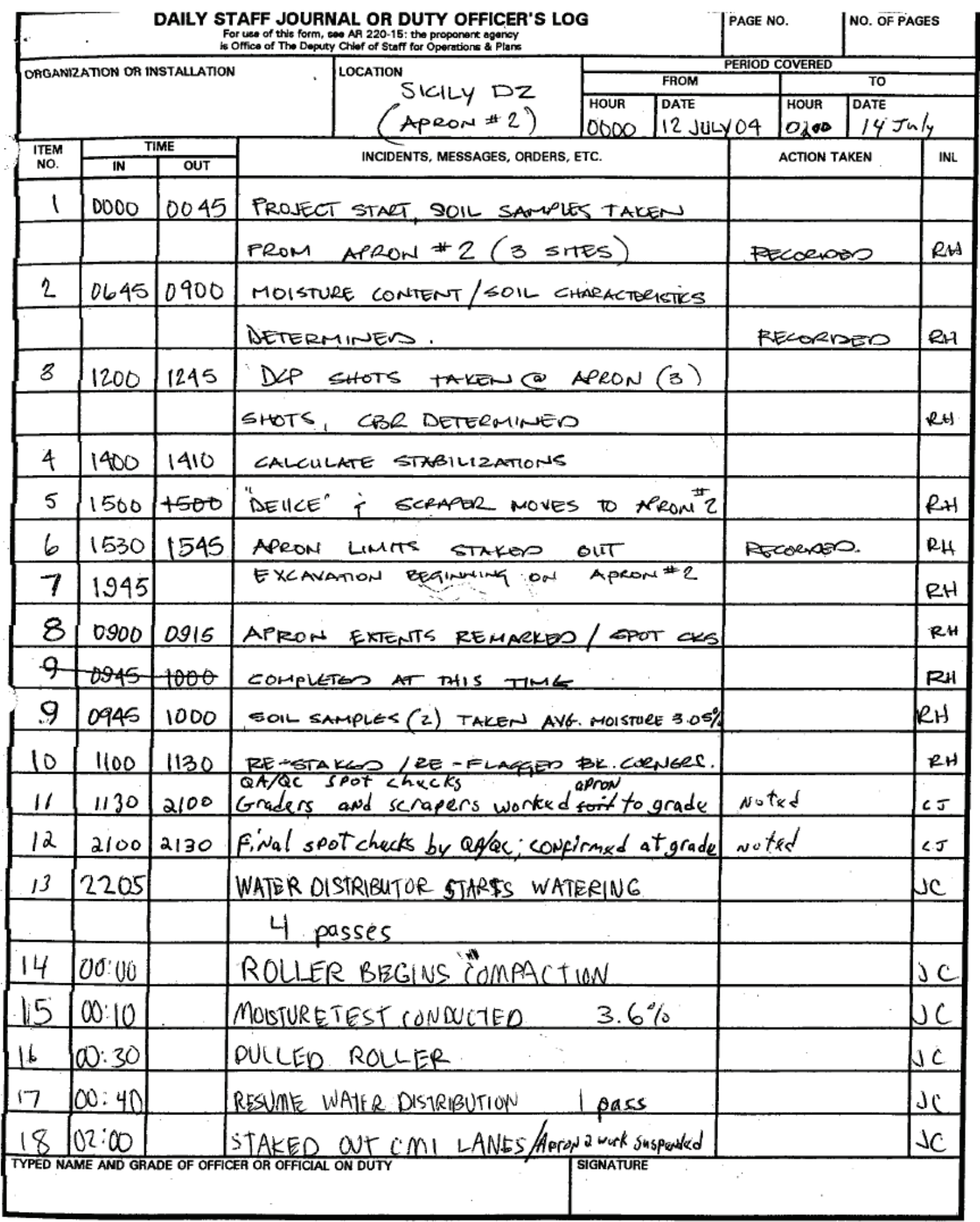




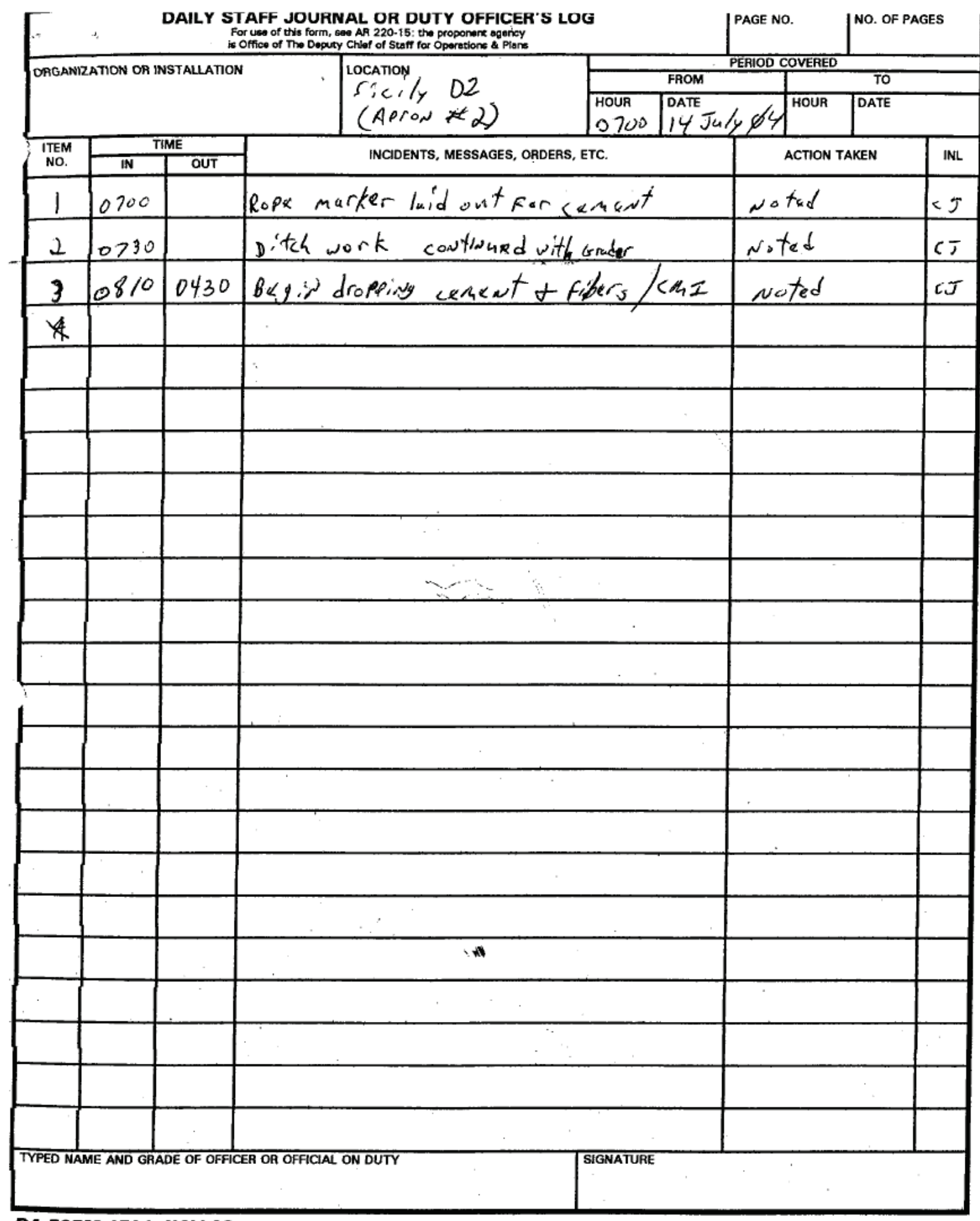




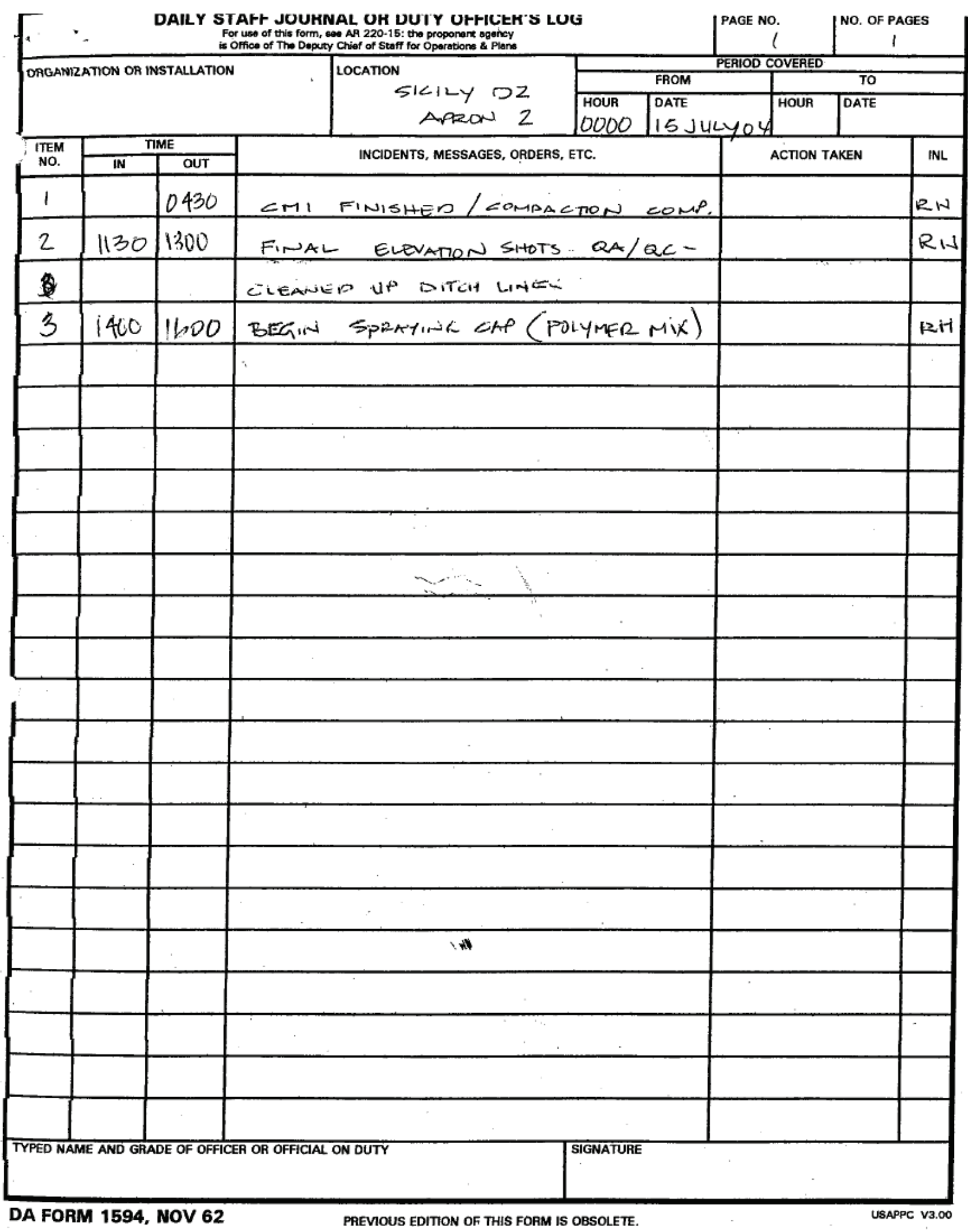




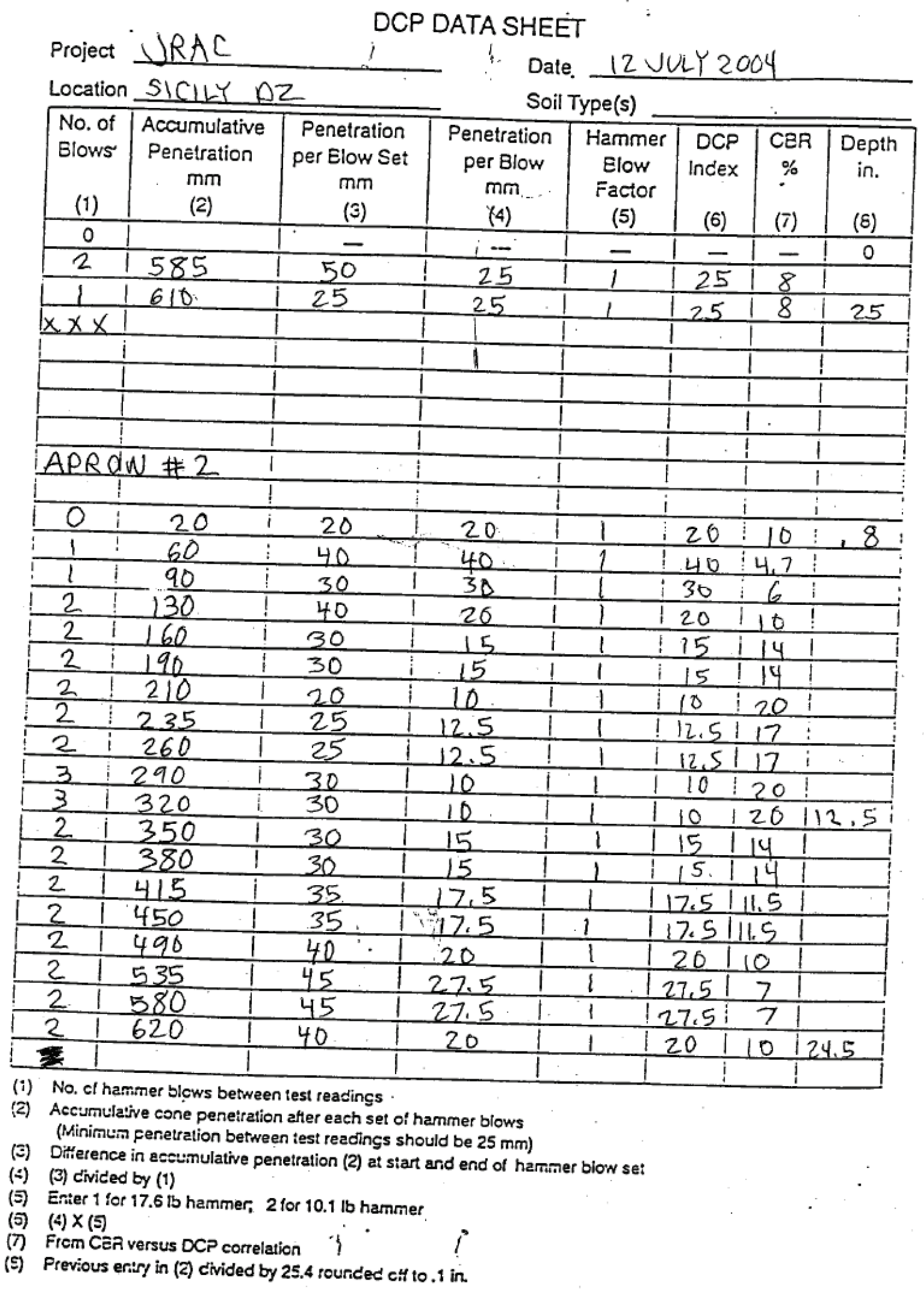




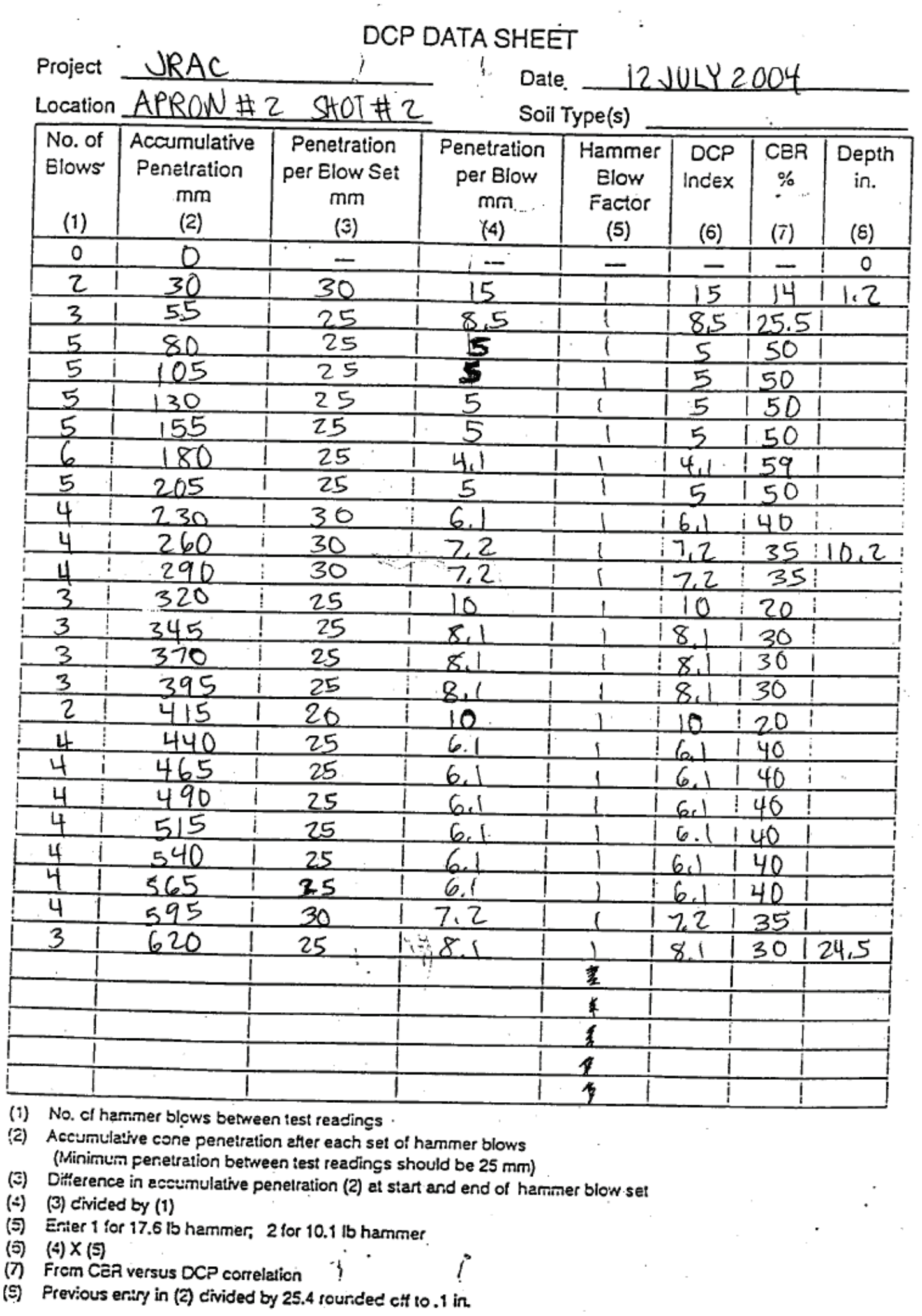




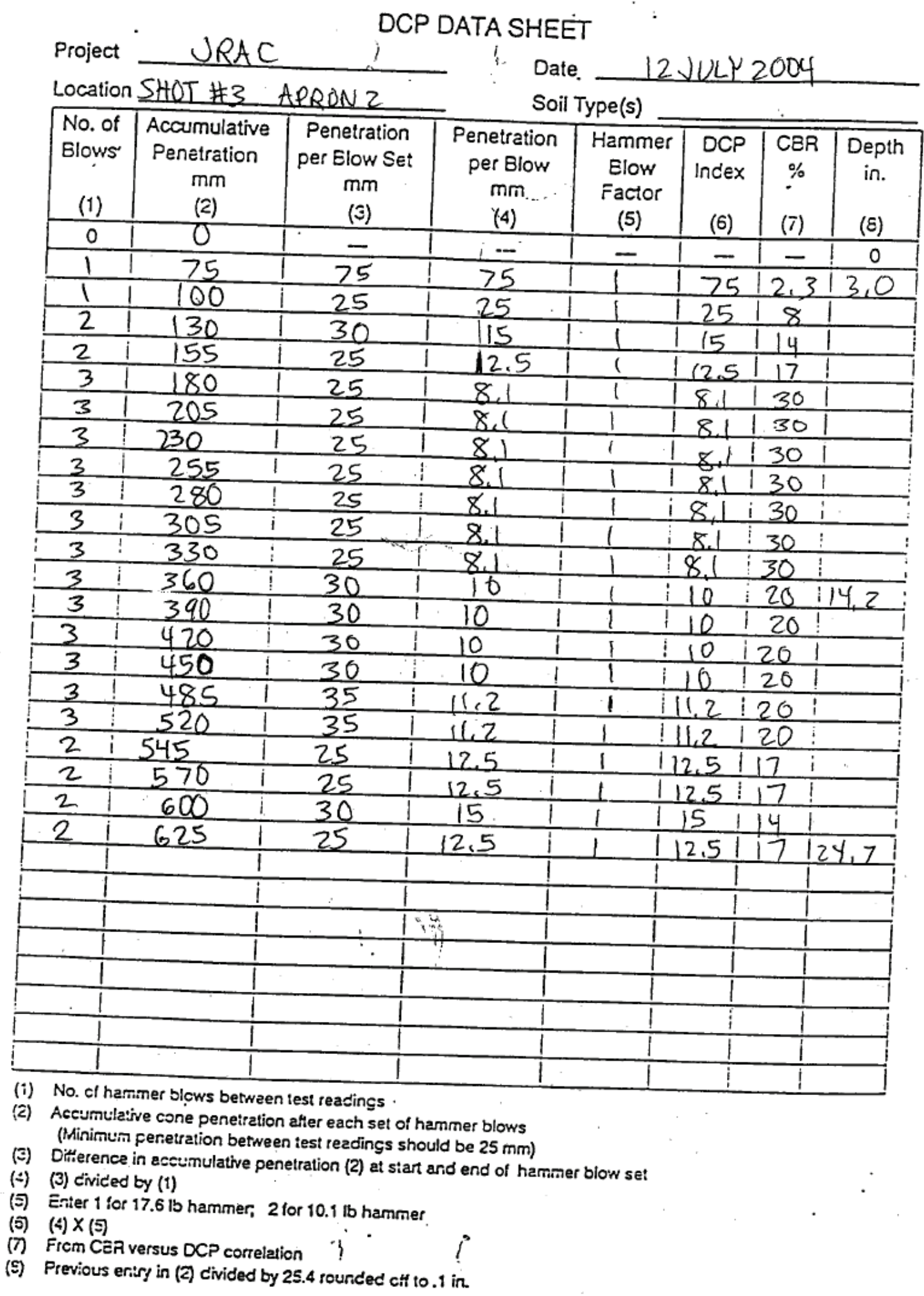




\section{Appendix C: Procedure for Performing a Soils Analysis}

1. Select a desirable area for field sample and record location (enter value in program)

2. Obtain a moist field sample of between 200 and 300 grams (enter value in program)

3. Dry field sample in microwave

4. Weigh dried field sample (enter value in program)

5. Crush dried sample with mortar and pestle

6. Pour field sample over splitter dividing it into two equal portions

7. Weigh amount of material retained on splitter (enter value in program)

8. Ensure that the split sample weighs no more than 150 grams dry

9. Weigh each sieve in stack empty (8 entries) (clean sieves with brushes if dirty)

(enter values in program)

10. Take one pan from the splitter and weight out approximately half the soil

(enter value in program) 
11. Pour sample into sieve stack and sieve for 4 minutes

12. Remove sieves from stack

13. Weigh each sieve with soil (8 entries)

(enter value in program)

14. Place all material on the \#100, \#200 and Pan sieves into a container for use in Plastic Limit Test

15. Clean sieves with brushes

16. Weight out remaining soil left in splitter pan from Step 10 (enter value in program)

17. Pour sample into sieve stack and sieve for 4 minutes

18. Remove sieves from stack

18. Weigh each sieve with soil (8 entries)

(enter values in program)

19. Place all material on the \#100, \#200 and pan sieves into container used in Step 14.

20. Conduct Plastic Limit Test on soil saved from Steps 14 \& 18

(enter value in program)

21. Note the soil classification 


\section{Appendix D: Equipment Lists}

In order to make a demonstration of this size occur, there were numerous pieces of equipment needed to both perform and support the exercise. Table D1 gives a summary of all the major equipment used, where used, and who supplied each piece. "Application" refers to where the item was used, "vendor" indicates who actually supplied the item, and "origin location" indicates where the item came from and to where it was eventually returned.

Table D1. Training/demonstration equipment list.

\begin{tabular}{|c|c|c|c|c|c|}
\hline ITEM & \begin{tabular}{|c|} 
NO. \\
REQ'D
\end{tabular} & APPLICATION & VENDOR & $\begin{array}{c}\text { ORIGIN } \\
\text { LOCATION }\end{array}$ & $\begin{array}{l}\text { TOTAL } \\
\text { COST }\end{array}$ \\
\hline DEUCE & 1 & Demo Exercise & Ft. Bragg & Ft. Bragg & $\mathrm{n} / \mathrm{a}$ \\
\hline Scraper & 2 & Demo Exercise & Ft. Bragg & Ft. Bragg & $\mathrm{n} / \mathrm{a}$ \\
\hline Grader & 1 & Demo Exercise & Ft. Bragg & Ft. Bragg & $\mathrm{n} / \mathrm{a}$ \\
\hline Vibratory Compactor & 2 & Demo Exercise & Ft. Bragg & Ft. Bragg & $\mathrm{n} / \mathrm{a}$ \\
\hline Loader w/Forks & 1 & Demo Exercise & Ft. Bragg & Ft. Bragg & $\mathrm{n} / \mathrm{a}$ \\
\hline Bobcat w/Forks & 1 & Demo Exercise & Ft. Bragg & Ft. Bragg & $\mathrm{n} / \mathrm{a}$ \\
\hline Fuel Truck & 1 & Demo Exercise & Ft. Bragg & Ft. Bragg & $\mathrm{n} / \mathrm{a}$ \\
\hline Water Tanker (6000 Gal) & 1 & Demo Exercise & Ft. Bragg & Ft. Bragg & $\mathrm{n} / \mathrm{a}$ \\
\hline Potable Water Tank & 1 & Demo Exercise & Ft. Bragg & Ft. Bragg & $\mathrm{n} / \mathrm{a}$ \\
\hline RYDER 28' Rental Truck & 1 & Training Week & Ryder Commercial & Fayetteville, NC & $\$ 900$ \\
\hline RAVEN Vehicle & 1 & Training and Demo & ERDC & Vicksburg, MS & $\$ 50,000$ \\
\hline RAVEN Transport/Support Con-Ex & 1 & Training and Demo & ERDC & Vicksburg, MS & $\$ 5,000$ \\
\hline HMMWV w/dust control sprayer & 1 & Demo Exercise & ERDC & Vicksburg, MS & $\mathrm{n} / \mathrm{a}$ \\
\hline CMI Terex 325A & 1 & Training and Demo & ERDC & Vicksburg, MS & $\$ 270,000$ \\
\hline Asphalt Emulsion Distributor & 1 & Training and Demo & ERDC & Vicksburg, MS & $\mathrm{n} / \mathrm{a}$ \\
\hline Chevrolet Tahoe 4-DR SUV & 1 & Demo Exercise & ERDC & Vicksburg, MS & $\mathrm{n} / \mathrm{a}$ \\
\hline Diesel Generator (56KW) & 1 & Demo Exercise & Sunbelt Rentals & Fayetteville, NC & $\$ 500$ \\
\hline Portable A/C (2-Ton) & 1 & ERDC Command Tent & Sunbelt Rentals & Fayetteville, NC & $\$ 100$ \\
\hline Diesel Light Plant (4000W) & 3 & ERDC Comm/Visitor Tents & Sunbelt Rentals & Fayetteville, NC & $\$ 300$ \\
\hline High Volume Fans & 6 & Visitor/Display Tents & Sunbelt Rentals & Fayetteville, NC & $\$ 300$ \\
\hline Parking Lot Blower (Gas) & 1 & Demo Exercise & Sunbelt Rentals & Fayetteville, NC & $\$ 50$ \\
\hline Pump Hoses (2-inch) & 4 & Demo Exercise & Sunbelt Rentals & Fayetteville, NC & $\$ 30$ \\
\hline Operations Tent (10'x10') & 2 & ERDC Command Tent & Ft. Bragg & Ft. Bragg & $\mathrm{n} / \mathrm{a}$ \\
\hline Folding Tables & 2 & ERDC Command Tent & Office Max Store & (Local Purchase) & $\$ 30$ \\
\hline Chairs & 8 & ERDC Command Tent & Office Max Store & (Local Purchase) & $\$ 64$ \\
\hline Cots & 2 & ERDC Command Tent & Ft. Bragg & Ft. Bragg & $\mathrm{n} / \mathrm{a}$ \\
\hline Drop Lights & 4 & ERDC Command Tent & Lowe's Home Improv. & (Local Purchase) & $\$ 60$ \\
\hline Tent Rental (1 LG, 2 SM) & 3 & Visitor/Display Tents & & Fayetteville, NC & $\$ 1,820$ \\
\hline Chairs & 200 & Visitor Tent & & Fayetteville, NC & $\$ 200$ \\
\hline Folding Tables & 10 & Display Tent & & Fayetteville, NC & $\$ 80$ \\
\hline A/V Equipment Rental/Ops. & 1 & Visitor Tent & & Fayetteville, NC & $\$ 7,500$ \\
\hline
\end{tabular}

The main materials used in the training and demo are listed in Table D2. The numbers shown reflect mainly the materials expended during the demo exercise. The materials used during the training week were limited in 
quantity and, in the case of Multi-Purpose Mats, these were disassembled and taken from the training site and used in the demo exercise.

Table D2. Training/demonstration materials list.

\begin{tabular}{|c|c|c|c|c|c|c|c|c|}
\hline \multirow[b]{2}{*}{ ITEM } & \multirow[b]{2}{*}{ UNIT } & \multirow[b]{2}{*}{ NO. } & \multicolumn{2}{|c|}{ WT/UNIT TOTAL WT. } & \multicolumn{3}{|c|}{ DIMENSIONS/UNIT } & \multirow{2}{*}{$\begin{array}{l}\text { Total } \\
\text { Cost }\end{array}$} \\
\hline & & & (LBS) & (LBS) & $\mathrm{L}$ & W & $\mathrm{H}$ & \\
\hline Multi-Purpose (MP) Matting & 10 mats/pallet & 61 pallets & 1250 & 76250 & 6'-8" & 6'-8" & $16 "$ & $\mathrm{n} / \mathrm{a}$ \\
\hline MP Mat Pins & 50 pins/bucket & 65 buckets & 25 & 1625 & $18 "$ & $10 "$ & --- & $\mathrm{n} / \mathrm{a}$ \\
\hline MP Duckbill Anchors & Tote Box & 1 & 80 & 80 & $24 "$ & $14 "$ & $8 "$ & $\mathrm{n} / \mathrm{a}$ \\
\hline Sand Fibers & Box/Pallet & 50 & 350 & 17500 & $3^{\prime}$ & $4^{\prime}$ & $4^{\prime}$ & n/a \\
\hline Soil Sement Polymer & 250 Gal. Tote & 16 & 2295 & 36720 & $3^{\prime}$ & $3^{\prime}$ & 3'-6" & $\$ 40,000$ \\
\hline Type III Portland Cement & 40 bags/pallet & 18 pallets & 3760 & 67680 & $30 "$ & $12 "$ & $5 "$ & $\$ 10,220$ \\
\hline Construction Water & Gallons & 30,000 & - & --- & -- & -- & - & ** \\
\hline JP-8 Fuel & Gallons & 300 (estimate) & & & & & & ** \\
\hline \multicolumn{9}{|c|}{ Notes: "n/a" indicates no cost associated with this item - supplied out of ERDC inventories at little or no cost. } \\
\hline${ }^{* *}$ indicates a cos & ansulate & ENBL & & & & & & \\
\hline
\end{tabular}

In addition to the materials listed, there were numerous other items that were used or expended during the training and demonstration exercise. These miscellaneous items range from pens, pencils, and markers to paper clips, pad paper, tape, and string, to cups, plates, coffee, bottled water, paper towels, and tissue. It is estimated that between the week of training and the demo exercise week, more than 1,00o bottles of water were consumed by ERDC team members, soldiers, visitors, and vendors/contractors.

As with the equipment, there were some items that were shipped directly from the ERDC facility in Vicksburg to Fort Bragg. These material items included the following: the MP Mat, pins, and duckbill anchors and the sand fibers. 


\section{Unit Conversion Factors}

\begin{tabular}{|l|c|l|}
\hline Multiply & By & To Obtain \\
\hline cubic feet & 0.02831685 & cubic meters \\
\hline cubic inches & $1.6387064 \mathrm{E}-05$ & cubic meters \\
\hline degrees (angle) & 0.01745329 & radians \\
\hline feet & 0.3048 & meters \\
\hline inches & 0.0254 & meters \\
\hline miles (U.S. statute) & $1,609.347$ & meters \\
\hline miles per hour & 0.44704 & meters per second \\
\hline square feet & 0.09290304 & square meters \\
\hline square inches & $6.4516 \mathrm{E}-04$ & square meters \\
\hline yards & 0.9144 & meters \\
\hline
\end{tabular}




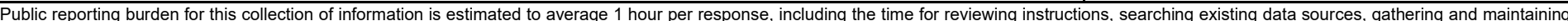

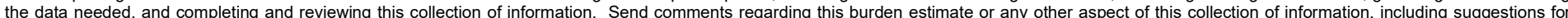

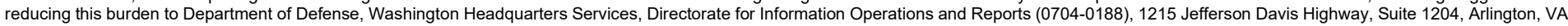

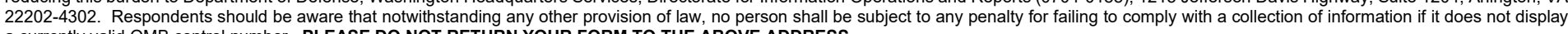
a currently valid OMB control number. PLEASE DO NOT RETURN YOUR FORM TO THE ABOVE ADDRESS.

1. REPORT DATE (DD-MM-YYYY) 1 2. REPORT TYPE

March 2021 Final

3. DATES COVERED (From - To)

\section{TITLE AND SUBTITLE}

5a. CONTRACT NUMBER

Joint Rapid Airfield Construction (JRAC) Program 2004 Demonstration Project--Fort Bragg, North Carolina

\section{5b. GRANT NUMBER}

5c. PROGRAM ELEMENT NUMBER 487724

\section{AUTHOR(S)}

Gary L. Anderton, Ernest S. Berney IV, John K. Newman, Travis A. Mann, Chad Gartrell, and Daniel K. Miller

5d. PROJECT NUMBER

117101

5e. TASK NUMBER

5f. WORK UNIT NUMBER

\section{PERFORMING ORGANIZATION NAME(S) AND ADDRESS(ES)}

8. PERFORMING ORGANIZATION REPORT NUMBER

Geotechnical and Structures Laboratory

U.S. Army Engineer Research and Development Center

ERDC/GSL TR-21-8

3909 Halls Ferry Road

Vicksburg, MS 39180

\section{SPONSORING / MONITORING AGENCY NAME(S) AND ADDRESS(ES)}

10. SPONSOR/MONITOR'S ACRONYM(S)

U.S. Army Corps of Engineers

Washington, DC 20314-1000

11. SPONSOR/MONITOR'S REPORT NUMBER(S)

\section{DISTRIBUTION / AVAILABILITY STATEMENT}

Approved for public release; distribution is unlimited.

\section{SUPPLEMENTARY NOTES}

Conducted for the Office of the Assistant Secretary of the Army for Acquisition, Logistics and Technology under "Joint Rapid Airfield Construction"

\section{ABSTRACT}

This report describes the demonstration of technologies and procedures developed during April 2002 and May 2004 under the Joint Rapid Airfield Construction (JRAC) Program. The demonstration took place at Sicily Landing Zone (LZ) at Fort Bragg, NC, in July of 2004. The objective of the exercise was to demonstrate the procedures and technologies developed under the JRAC Program by rapidly building two parking aprons capable of supporting C-130 transport aircraft taxiing and parking operations. The exercise was conducted under continuous 24-hr operations to simulate a real-world rapid construction environment. Apron 1 (north apron) was constructed using two technologies, one-half being ACE ${ }^{\mathrm{TM}}$ Matting and the other half being a cement-polymer stabilized soil surface. Apron 2 (south apron) was constructed solely of a fiber-cement-stabilized soil system. Both aprons were treated with a polymer emulsion surface application to form a sealed surface against abrasion and water infiltration. The entire construction of both aprons required 76 hr, with Apron 1 finished in $48 \mathrm{hr}$. The construction of Apron 1 was validated by operation of a C-130 aircraft approximately 31 hr after completion with success and high praises from the aircraft flight crew on the stability and surface of the apron, as well as its dustabating characteristics.

\begin{tabular}{|c|c|c|c|c|c|}
\hline \multicolumn{2}{|c|}{ 15. SUBJECT TERMS } & \multicolumn{2}{|l|}{ Contingency } & \multicolumn{2}{|l|}{ Soil Analysis } \\
\hline \multicolumn{2}{|c|}{ Airfield } & \multicolumn{2}{|l|}{ Stabilization } & \multicolumn{2}{|c|}{ Runways (Aeronautics)--Design and construction } \\
\hline \multicolumn{2}{|l|}{ Construction } & \multicolumn{2}{|l|}{ Matting } & \multicolumn{2}{|c|}{ Runways (Aeronautics)_Evaluation } \\
\hline \multicolumn{2}{|l|}{ Military bases } & \multicolumn{2}{|l|}{ Air bases } & \multicolumn{2}{|c|}{ Soil stabilization } \\
\hline \multicolumn{3}{|c|}{ 16. SECURITY CLASSIFICATION OF: } & $\begin{array}{l}\text { 17. LIMITATION } \\
\text { OF ABSTRACT }\end{array}$ & $\begin{array}{l}\text { 18. NUMBER } \\
\text { OF PAGES }\end{array}$ & $\begin{array}{l}\text { 19a. NAME OF RESPONSIBLE } \\
\text { PERSON }\end{array}$ \\
\hline $\begin{array}{l}\text { a. REPORT } \\
\text { Unclassified }\end{array}$ & $\begin{array}{l}\text { b. ABSTRACT } \\
\text { Unclassified }\end{array}$ & $\begin{array}{l}\text { c. THIS PAGE } \\
\text { Unclassified }\end{array}$ & SAR & 134 & $\begin{array}{l}\text { 19b. TELEPHONE NUMBER (include } \\
\text { area code) }\end{array}$ \\
\hline
\end{tabular}


